Ediguer E. Franco

\title{
ANALISE DO MÉTODO DE MEDIÇÃO DE VISCOSIDADE DE LÍQUIDOS POR ULTRA-SOM USANDO A REFLEXÃO DE ONDAS DE CISALHAMENTO
}

Dissertação apresentada à Escola Politécnica da Universidade de São Paulo para obtenção do título de Mestre em Engenharia. 
Ediguer E. Franco

\section{ANALISE DO MÉTODO DE MEDIÇÃO DE VISCOSIDADE DE LÍQUIDOS POR ULTRA-SOM USANDO A REFLEXÃO DE ONDAS DE CISALHAMENTO}

Dissertação apresentada à Escola Politécnica da Universidade de São Paulo para obtenção do título de Mestre em Engenharia.

Área de concentração:

Engenharia Mecânica

Orientador:

Prof. Dr. Flávio Buiochi 
À minha esposa Adriana, aos meus pais Tulia e Ediguer e às minhas irmãs Maria del Rosario e Diana Liliana. 
que toda la vida es sueño, y los sueños, sueños son.

Pedro Calderón de la Barca, "La vida es sueño"

Freedom is the freedom to say that two plus two make four.

George Orwell, "1984" 


\section{AGRADECIMENTOS}

Ao meu orientador Prof. Dr. Flávio Buiochi pela sua constante orientação e permanente apoio no desenvolvimento do trabalho

Ao Prof. Dr. Julio Cezar Adamowski pela sua ajuda e inúmeras sugestões.

A Marco Aurelio Brizzotti, Wilfredo Montealegre, João Batista da Silva, Daniel Verga Boeri, Maro Jinbo, Juan Carlos Guglielmo e todos os colegas do PMR.

Aos todos meus amigo colombianos em Brasil. 


\section{SUMÁRIO}

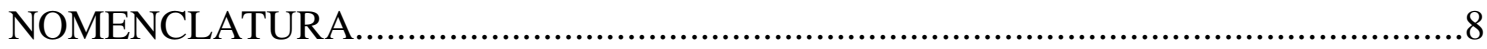

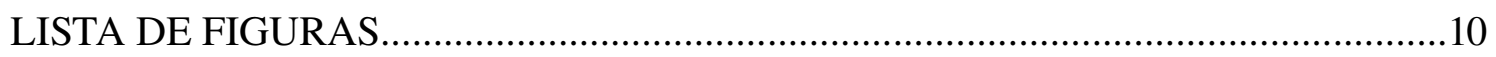

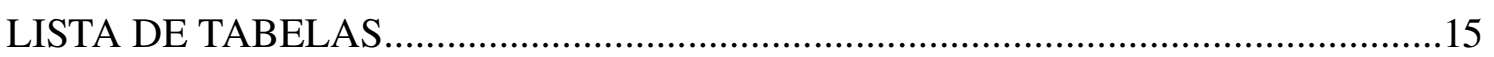

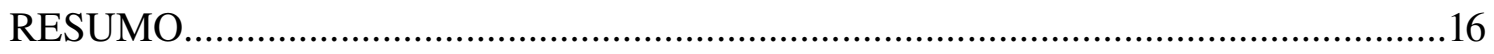

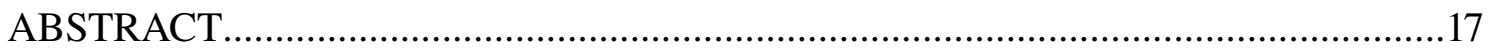

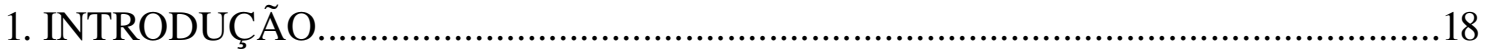

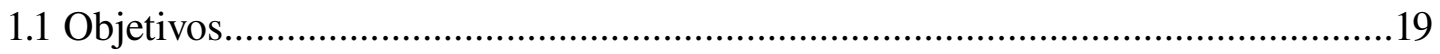

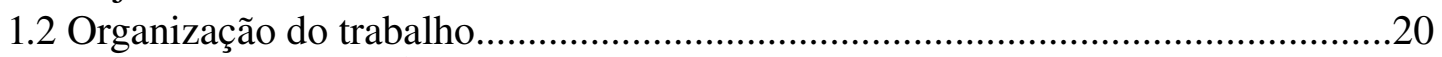

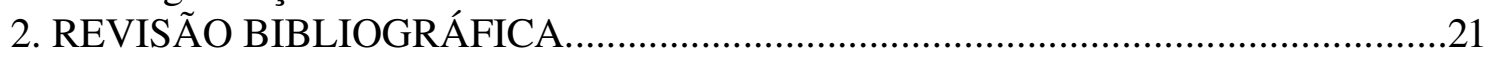

3. PROPAGAÇÃO DE ONDAS ACÚSTICAS EM MEIOS ISOTRÓPICOS................29

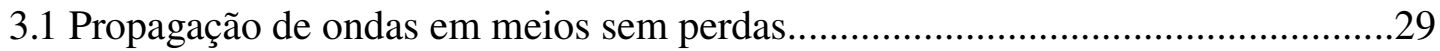

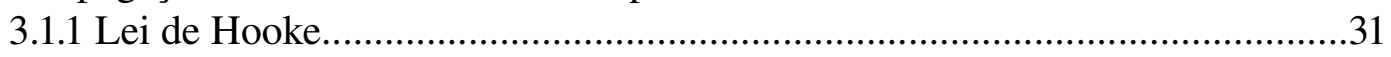

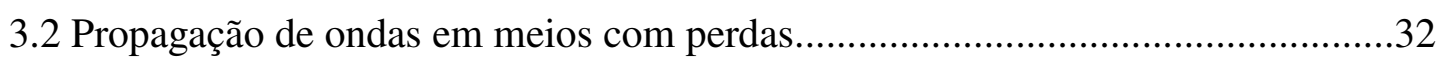

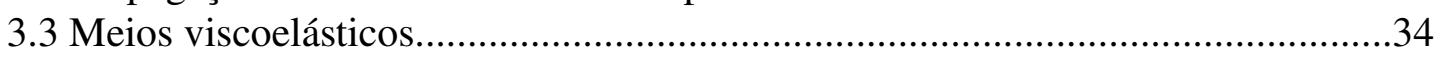

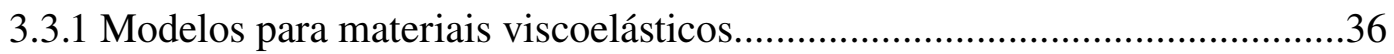

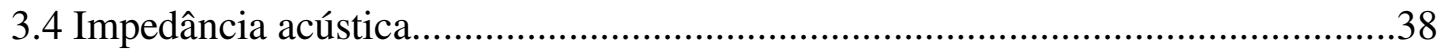

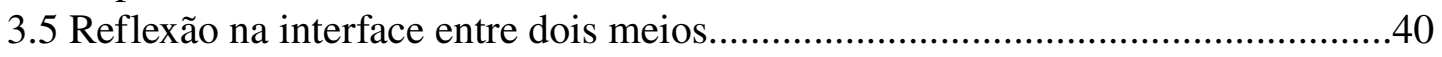

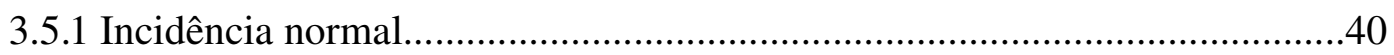

3.5.1 Incidência oblíqua...................................................................................42

4. MEDIÇÃO DE VISCOSIDADE PELO MÉTODO DA REFLEXÃO DE ONDAS DE

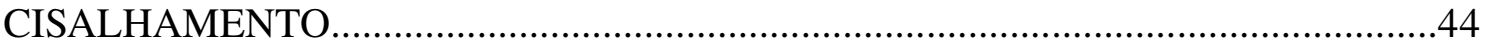

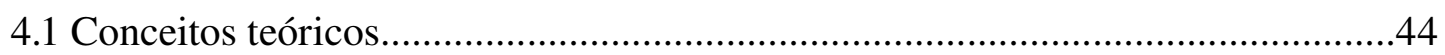

4.2 Simplificação no caso de líquido Newtoniano....................................................46

4.3 Determinação experimental do coeficiente de reflexão.......................................46

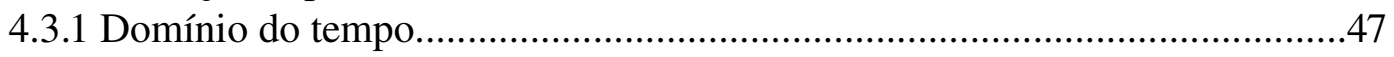

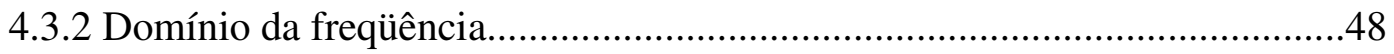

4.3.3 Considerações sobre a medição do coeficiente de reflexão..........................48

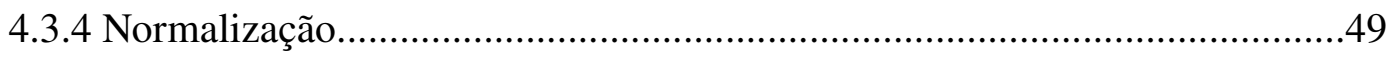

4.4 Parâmetros que afetam a medição.....................................................................50

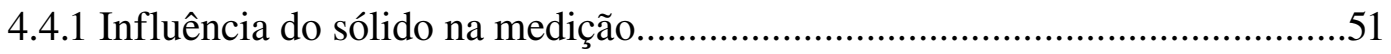

4.4.2 Influência da densidade do líquido na medição..........................................52

4.4.3 Influência da freqüência na medição........................................................53

4.5 Comparação entre o modelo Newtoniano e o modelo de Maxwell na predição do

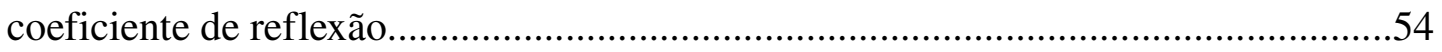

5. MODELAGEM MATRICIAL DE TRANSDUTORES ULTRA-SÔNICOS...............57

5.1 Características básicas de um transdutor de ultra-som.........................................57

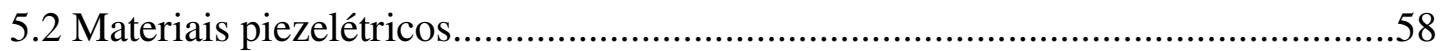

5.3 Modelo matricial para transdutores de múltiplos elementos..............................60

5.3.1 Solução 1: cerâmica vibrando sem troca de energia com o meio externo.....62 
5.3.2 Solução 2: cerâmica vibrando com troca de energia com o meio externo....62

5.3.3 Representação matricial dos elementos ativos. .63

4.3.4 Representação matricial dos elementos passivos.......................................65

5.3.5 Modelagem do transdutor multielemento...................................................66

5.4 Aplicação na simulação do comportamento das células de medição...................68

5.4.1 Uso do modelo matricial no estudo do efeito da variação da temperatura

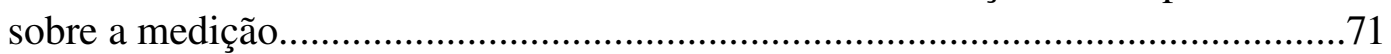

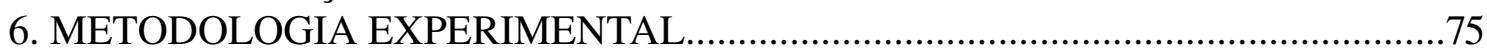

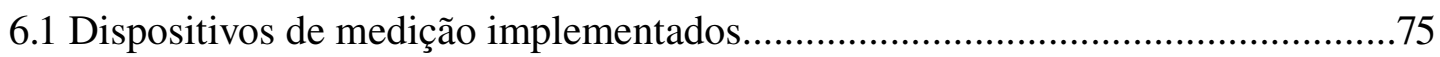

6.1.1 Dispositivo 1: Célula de incidência normal sem conversão de modo............75

6.1.2 Dispositivo 2: Célula de incidência normal com conversão de modo............77

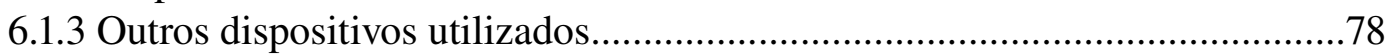

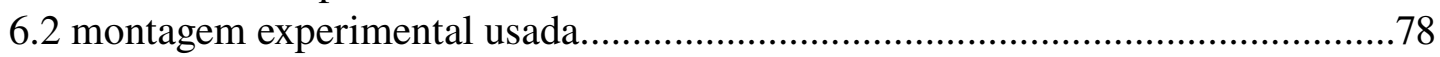

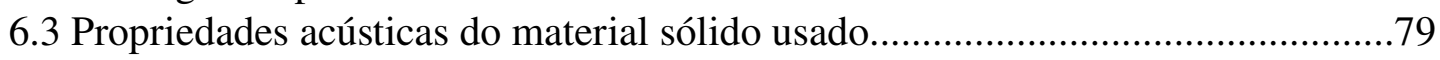

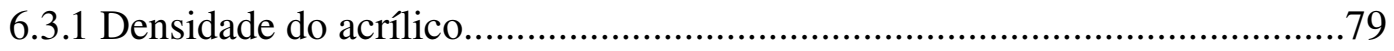

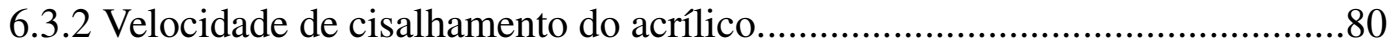

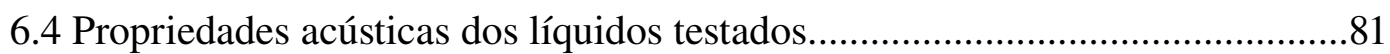

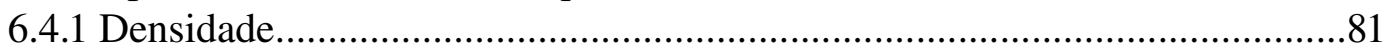

6.4.2 Viscosidade a baixa freqüência............................................................82

6.5 analise dos fatores externos que afetam a medição.......................................83

6.5.1 Efeito da normalização na medição do coeficiente de reflexão.....................85

6.5.2 Estudo experimental do comportamento da fase no tempo............................86

6.5.3 Estabilidade térmica do sistema de medição............................................87

6.6 InfluÊncia dA largura de banda do transdutor na medição do coeficiente de

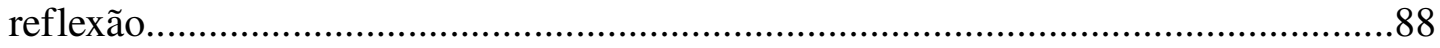

6.7 análise da propagação do erro na medição..................................................90

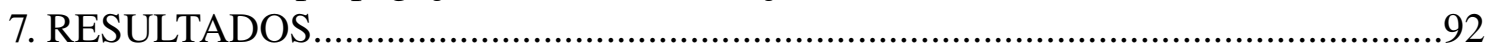

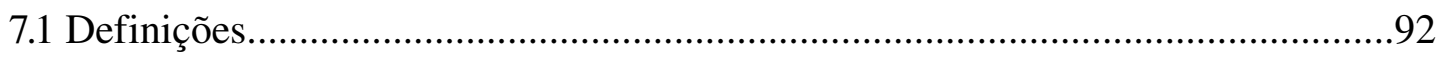

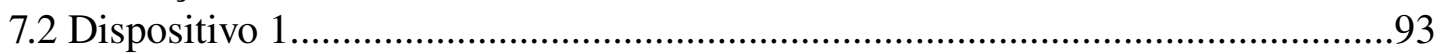

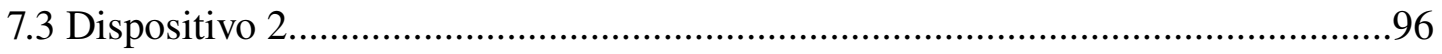

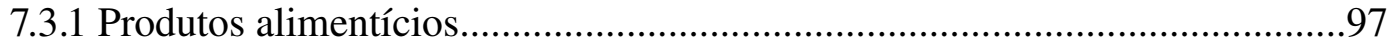

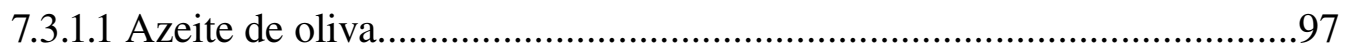

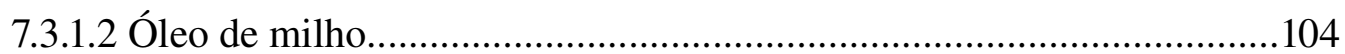

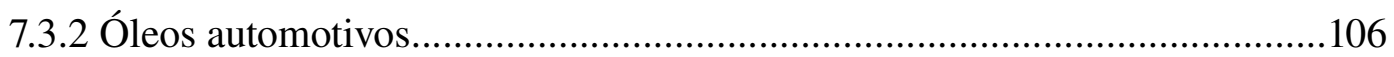

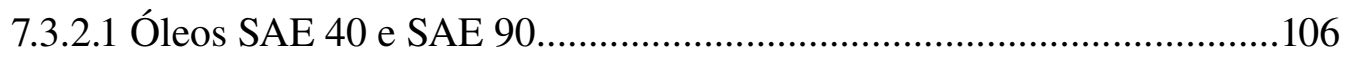

7.3.2.2 Óleos SAE 140 e SAE 250.................................................................110

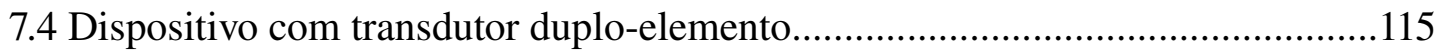

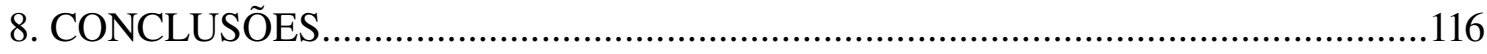

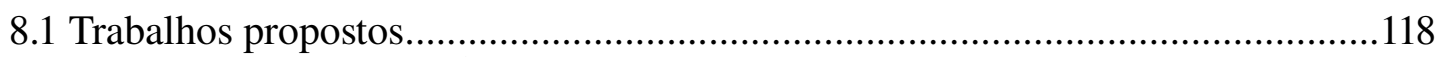

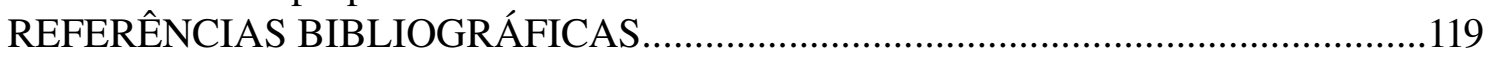




\section{NOMENCLATURA}

\section{Símbolos gregos}

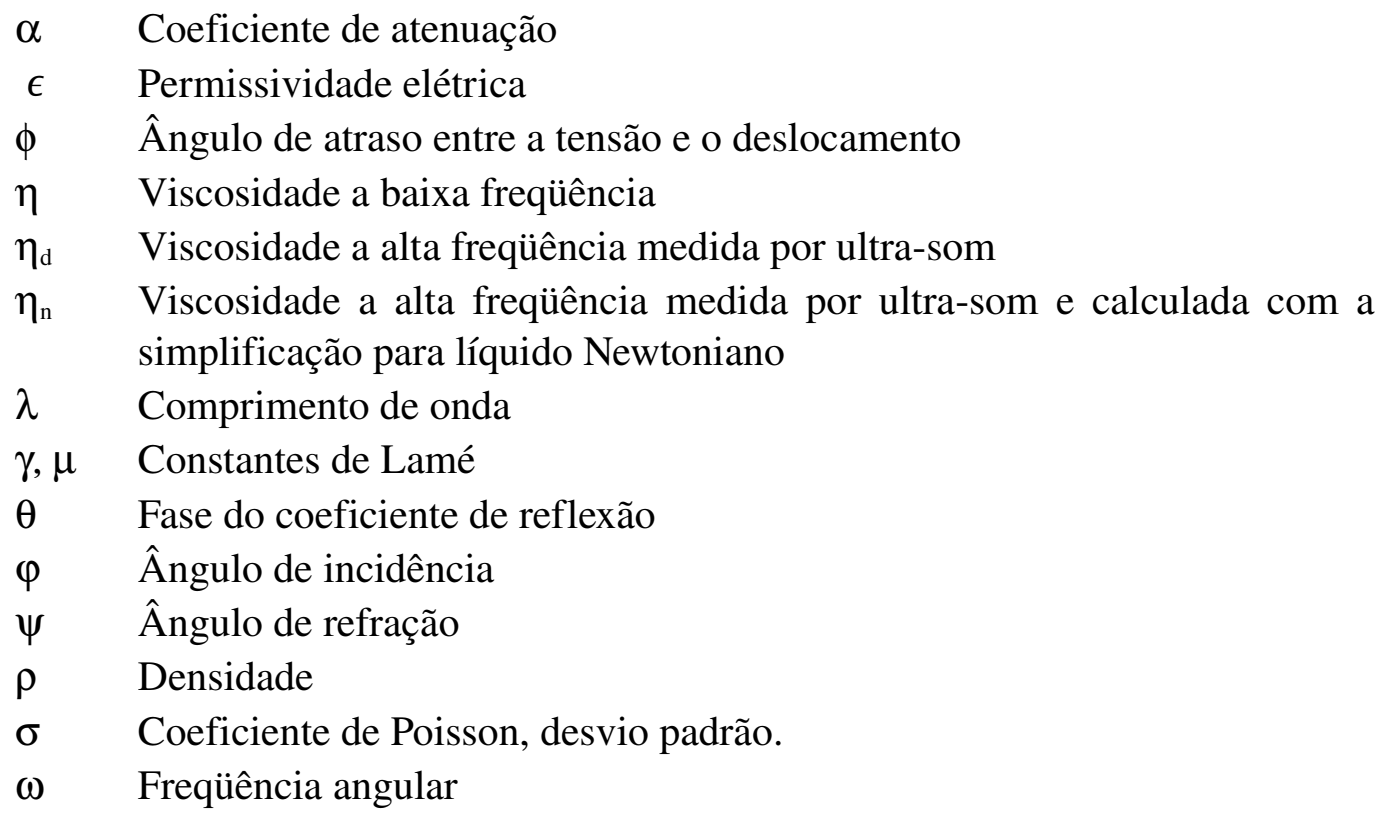

\section{Símbolos latinos}

$\begin{array}{ll}c & \text { Constante elástica do meio } \\ c_{I J} & \text { Tensor reduzido das constantes elásticas } \\ j & \text { Número imaginário } \\ t & \text { Tempo } \\ u & \text { Deslocamento da partícula } \\ \dot{u} & \text { Velocidade da partícula } \\ v & \text { Velocidade do som } \\ z_{0} & \text { Profundidade de penetração } \\ C & \text { Capacitância } \\ D & \text { Deslocamento elétrico } \\ E & \text { Campo elétrico } \\ F & \text { Força } \\ G^{*} & \text { Módulo de cisalhamento complexo } \\ G^{\prime} & \text { Módulo elástico } \\ G^{\prime \prime} & \text { Módulo de perda } \\ Q & \text { Fator de qualidade }\end{array}$


$p \quad$ Pressão

$r \quad$ Magnitude do coeficiente de reflexão

$R \quad$ Resistência elétrica

$R^{*} \quad$ Coeficiente de reflexão

$S \quad$ Deformação

$T$ Tensão, coeficiente de transmissão.

$V \quad$ Voltagem (tensão elétrica)

$X \quad$ Reatância

$Z \quad$ Impedância acústica

$\mathfrak{I}$ Componente imaginária de um número complexo

$\mathfrak{R}$ Componente real de um número complexo

\section{Subscritos}

$1,2, \ldots$ Meio 1 , meio $2, \ldots$

$p \quad$ Onda longitudinal ou de pressão

$c \quad$ Onda de cisalhamento (shear wave)

$x, y, z$ Eixos do sistema de coordenadas retangulares

$B \quad$ Onda propagando-se para trás

$F \quad$ Onda propagando-se pela frente

$J, K \quad$ Notação tensorial reduzida

\section{Superescritos}

E Propriedade medida a campo elétrico constante

Pot Grandeza expressa em termos de potência

$S \quad$ Propriedade medida a deformação constante

$S P \quad$ Referência a um meio sem perdas 


\section{LISTA DE FIGURAS}

Figura 2.1 Arranjos usados por Mason et al. (1949) para a medição da elasticidade e a viscosidade de cisalhamento de polímeros líquidos: (a) incidência normal, (b) incidência oblíqua.

Figura 2.2 Montagem usada por Cohen-Tenoudji et al. (1987).

Figura 2.3 Montagem usada por Sheen, Chien e Raptis (1996).Figura 1.4 Esquema da montagem usada por Buiochi, Adamowski e Furukawa (1998).

Figura 2.4 Esquema da montagem usada por Buiochi, Adamowski e Furukawa (1998).

Figura 3.1 Geometria usada na dedução da equação da onda longitudinal (a) e de cisalhamento (b), ambas propagando-se ao longo do eixo z.......... 29

Figura 3.2 Modelos de (a) Kelvin-Voigt e (b) Maxwell.................................... 35

Figura 3.3 Variação do modulo de cisalhamento e a viscosidade normalizados em função da frequiência normalizada para o modelo de Maxwell.....

Figura 3.4 Incidência normal de uma onda na interface entre dois meios de impedância acústica diferente localizada em $z=0$.

Figura 3.5 Incidência oblíqua de uma onda $S H$ na interface entre dois meios de impedância acústica diferente localizada em $z=0$.

Figura 4.1 Principio de normalização

Figura 4.2 Efeito dos materiais sólidos acrílico e alumínio sobre o coeficiente de reflexão (modelo de líquido Newtoniano): a) magnitude e b) fase em graus.

Figura 4.3 Efeito do material sólido sobre o coeficiente de reflexão (modelo de líquido Newtoniano): a) magnitude e b) fase em graus.......................

Figura 4.4 Efeito da densidade do líquido sobre o coeficiente de reflexão (modelo de líquido Newtoniano): a) magnitude e b) fase em graus...

Figura 4.5 Efeito da freqüência de operação sobre o coeficiente de reflexão (modelo de líquido Newtoniano): a) magnitude e b) fase em graus... 
Figura 4.6 Simulação do coeficiente de reflexão, na faixa de viscosidade entre 0 e 200Pa.s, usando o modelo de líquido Newtoniano (linha sólida) e o modelo de Maxwell (linha tracejada) para vários valores de $G_{\infty}$ : a) magnitude e b) fase em graus

Figura 4.7 Simulação do coeficiente de reflexão, em função da freqüência, para um liquido com viscosidade de 1Pa.s, usando o modelo de líquido Newtoniano (linha sólida) e o modelo de Maxwell (linha tracejada) para vários valores de $G$ : a) magnitude e b) fase em graus

Figura 4.8 Simulação do coeficiente de reflexão, na faixa de viscosidade entre 0 e 5Pa.s, usando o modelo de líquido Newtoniano (linha sólida) e o modelo de Maxwell (linha tracejada) para vários valores de $G$ : a) magnitude e b) fase em graus

Figura 4.9 Simulação do coeficiente de reflexão, em função da freqüência, para um liquido com viscosidade de 10Pa.s, usando o modelo de líquido Newtoniano (linha sólida) e o modelo de Maxwell (linha tracejada) para vários valores de $G$ : a) magnitude e b) fase em graus.

Figura 5.1 Esquema básico de um transdutor de ultra-som

Figura 5.2 Geometria usada no desenvolvimento do modelo.

Figura 5.3 Cerâmica piezelétrica vibrando num meio diferente do vácuo............

Figura 5.4 Modelo do elemento ativo.

Modelo do elemento passivo.

Transdutor multielemento.

Figura 5.7 Modelo do transdutor em modo (a) emissor e (b) receptor.

Figura 5.8 Modelo da célula de medição sem conversão.

Figura 5.9 Resposta temporal do dispositivo da figura 5.8: a) e b) resposta temporal e forma de onda simulados, c) e d) resposta temporal e forma de onda experimentais.

Figura 5.10 Modelo da célula de medição com conversão de modo.......................

Figura 5.11 Simulação dos sinais nos casos com ar e com óleo SAE 250 a $20^{\circ} \mathrm{C}$ e $1 M H z:$ a) sinais refletidos pelas interfaces de referência $(n(t))$ e de medição $(a(t))$ e b) sinais refletidos pela interface de medição.

Figura 5.12 Variação do coeficiente de reflexão e da viscosidade em função de um gradiente linear de temperatura no meio sólido.

Figura 5.13 Variação do coeficiente de reflexão e da viscosidade em função da variação de temperatura na linha de retardo, nos casos com (linha sólida) e sem (linha tracejada) normalização.

Figura 6.1 Esquema do dispositivo 1: Célula de incidência normal sem conversão de modo. 
Figura 6.2 Esquema do dispositivo 2: Célula de incidência normal com conversão de modo

Figura 6.3 Montagem experimental usada para excitação em banda larga...........

Figura 6.4 Velocidade de cisalhamento em função da temperatura para acrílico

Figura 6.5 Viscosidade versus temperatura medida com o viscosímetro rotacional, para azeite de oliva: os círculo representam as medições feitas e a linha sólida o polinômio ajustado (ver tabela 6.2)

Figura 6.6 Magnitude e fase do coeficiente de reflexão versus tempo, para azeite de oliva a $15^{\circ} \mathrm{C}$ e freqüência de operação de $1,0 \mathrm{MHz}$...............

Figura 6.7 Efeito da normalização sobre a medição do coeficiente de reflexão do óleo SAE90 a $20^{\circ} \mathrm{C}$ e freqüência de operação de $0,5 \mathrm{MHz}: \mathrm{CN}$ com normalização e SN sem normalização.

Figura 6.8 Mudança da fase com o tempo para SAE 40 a 1,0MHz (dispositivo 2)

Figura 6.9 Mudança da fase com o tempo para SAE 40 a 1,0MHz (dispositivo 2).

Figura 6.10 Mudança da fase com o tempo para SAE 40 a 1,0MHz (dispositivo 2).

Figura 6.11 Mudança da fase com o tempo para SAE 40 a 1,0MHz (dispositivo 2)

Figura 7.1 Gráficos do coeficiente de reflexão em função do tempo para a) óleo de milho a $30^{\circ} \mathrm{C}$ no domínio do tempo e b) SAE 90 a $22,4^{\circ} \mathrm{C}$ no domínio da freqüência.

Figura 7.2 Sinal obtido com o dispositivo 2 a $1 \mathrm{MHz}$

Figura 7.3 Coeficiente de reflexão em função da freqüência do azeite de oliva a $15^{\circ} \mathrm{C}$, calculado no domínio da frequiência (círculos) e no domínio do tempo (estrelas).

Figura 7.4 Viscosidade em função da freqüência do azeite de oliva a $15^{\circ} \mathrm{C}$, valores calculados no domínio da frequiência (círculos) e domínio do tempo (estrelas)

Figura 7.5 Viscosidade em função da frequiência do azeite de oliva a $15^{\circ} \mathrm{C}$. Valores obtidos usando a magnitude e a fase do coeficiente de reflexão (círculos) e simplificação para líquido Newtoniano (estrelas).

Figura 7.6 Módulo elástico em função da frequiência do azeite de oliva a $15^{\circ} \mathrm{C}$.

Figura 7.7 Viscosidade em função da temperatura do azeite de oliva, na freqüência de operação de $3,5 \mathrm{MHz}$. Valores obtidos usando a magnitude e a fase do coeficiente de reflexão (círculos) e simplificação para líquido Newtoniano (estrelas). 
Figura 7.8 Coeficiente de reflexão em função da temperatura para óleo de milho nas freqüências de $1 \mathrm{MHz}$ (círculos) e $2,25 \mathrm{MHz}$ (estrelas). Linha sólida: modelo Newtoniano a $1 \mathrm{MHz}$ e linha tracajada: modelo Newtoniano a 2,25 $\mathrm{MHz}$.

Figura 7.9 Viscosidade dinâmica em função da temperatura para óleo de milho, na frequiência de operação de $1 M H$. Valores obtidos usando a magnitude e a fase do coeficiente de reflexão (círculos) e simplificação para líquido Newtoniano (estrelas).

Figura 7.10 Viscosidade dinâmica em função da temperatura para óleo de milho, na frequiência de operação de $2,25 \mathrm{MHz}$. Valores obtidos usando a magnitude e a fase do coeficiente de reflexão (círculos) e simplificação para líquido Newtoniano (estrelas).

Figura 7.11 Módulo elástico em função da temperatura para óleo de milho a $1 \mathrm{MHz}$ (círculos) e $2,25 \mathrm{MHz}$ (estrelas)

Figura 7.12 Coeficiente de reflexão em função da freqüência para SAE 40 (círculos) e SAE 90 (estrelas) a $22,5 \pm 0,5^{\circ} \mathrm{C}$. Linha sólida: modelo Newtoniano e linha tracejada: modelo de Maxwell $\left(G_{\infty}=1.10^{8} e\right.$ $\left.1.10^{9} \mathrm{~Pa}\right)$

Figura 7.13 Viscosidade em função da freqüência para SAE 40 a temperatura ambiente $\left(22,5 \pm 0,5^{\circ} \mathrm{C}\right)$ : Valores obtidos usando a magnitude e a fase do coeficiente de reflexão (círculos) e simplificação para líquido Newtoniano (estrelas).....

Figura 7.14 Viscosidade em função da freqüência para SAE 40 a temperatura ambiente $\left(22,5 \pm 0,5^{\circ} \mathrm{C}\right)$. Comparação entre os valores medidos por ultra-som e os calculados usando os modelos teóricos.

Figura 7.15 Viscosidade em função da freqüência para SAE 90 a temperatura ambiente $\left(22,5 \pm 0,5^{\circ} \mathrm{C}\right)$. Valores obtidos usando a magnitude e a fase do coeficiente de reflexão (círculos) e simplificação para líquido Newtoniano (estrelas)..

Figura 7.16 Viscosidade em função da freqüência para SAE 90 a temperatura ambiente $\left(22,5 \pm 0,5^{\circ} \mathrm{C}\right)$. Comparação entre os valores medidos por ultra-som e os calculados usando os modelos teóricos.

Figura 7.17 Módulo elástico em função da freqüência para SAE 40 (círculos) e SAE 90 (estrelas) a temperatura ambiente $\left(22,5 \pm 0,5^{\circ} \mathrm{C}\right)$

Figura 7.18 Coeficiente de reflexão em função da freqüência para SAE 140 (círculos) e SAE 250 (estrelas) a temperatura ambiente $\left(22,5 \pm 0,5^{\circ} \mathrm{C}\right)$

Figura 7.19 Viscosidade em função da frequiência para SAE 140 a temperatura ambiente $\left(22,5 \pm 0,5^{\circ} \mathrm{C}\right)$. Valores obtidos usando a magnitude e a fase do coeficiente de reflexão (círculos) e simplificação para líquido Newtoniano (estrelas). 
Figura 7.20 Viscosidade em função da freqüência para SAE 140 a temperatura ambiente $\left(22,5 \pm 0,5^{\circ} \mathrm{C}\right)$. Comparação entre os valores medidos por ultra-som e os calculados usando os modelos teóricos..

Figura 7.21 Viscosidade em função da frequiência para SAE 250 a temperatura ambiente $\left(22,5 \pm 0,5^{\circ} \mathrm{C}\right)$. Valores obtidos usando a magnitude e a fase do coeficiente de reflexão (círculos) e simplificação para líquido Newtoniano (estrelas)

Figura 7.22 Viscosidade em função da frequiência para SAE 250 a temperatura ambiente $\left(22,5 \pm 0,5^{\circ} \mathrm{C}\right)$. Comparação entre os valores medidos por ultra-som e os calculados usando os modelos teóricos.

Figura 7.23 Módulo elástico em função da frequiência para SAE 140 (círculos) e SAE 250 (estrelas) a temperatura ambiente $\left(22,5 \pm 0,5^{\circ} \mathrm{C}\right) \ldots$ 


\section{LISTA DE TABELAS}

Tabela 6.1 Densidade do acrílico

Tabela 6.2 Velocidade de cisalhamento do acrílico: polinômios ajustados.......... 81

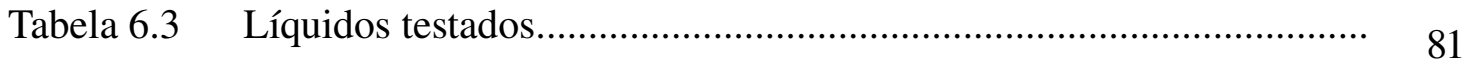

Tabela 6.4 Densidade dos líquidos testados................................................. 82

Tabela 6.5 Viscosidade estática dos líquidos testados..................................... 83

Tabela 6.6 Comparação dos coeficientes de reflexão calculados nos domínios do tempo e da freqüência, para $\mathrm{SAE} 40$ a $20^{\circ} \mathrm{C}$ nas freqüências de 2,25 e $3,5 \mathrm{MHz}$

Tabela 7.1 Nomenclatura e unidades usadas nas tabelas e gráficos de resultados

Tabela 7.2 Medições feitas com o dispositivo 1 para diferentes líquidos: cálculo do coeficiente de reflexão feito no domínio da frequiência....

Tabela 7.3 Medições feitas com o dispositivo 1 para diferentes líquidos: cálculo do coeficiente de reflexão feito no domínio do tempo

Tabela 7.4 Impedância acústica de cisalhamento em função da freqüência para azeite de oliva a $15^{\circ} \mathrm{C}$

Tabela 7.5 Teste de repetibilidade da medição com azeite de oliva a $15^{\circ} \mathrm{C}$ e freqüência de operação de $3,5 \mathrm{MHz}$

Tabela 7.6 Impedância acústica de cisalhamento para azeite de oliva a $15^{\circ} \mathrm{C}$ a $1 M H z$.

Tabela 7.7 Resultados do teste feito com o transdutor duplo-elemento com conversão de modo, para os óleos automotivos SAE 40, 90 e 140 a $20,3 \pm 0,17^{\circ} \mathrm{C}$ e frequiência de operação de $0,5 \mathrm{MHz}$. 


\section{RESUMO}

Neste trabalho é analisada a medição de viscosidade de líquidos por ultra-som pelo método da reflexão de ondas de cisalhamento. O método baseia-se na medição da magnitude e fase do coeficiente de reflexão quando as ondas de cisalhamento incidem na interface entre um sólido e o líquido testado. Foram analisados os conceitos teóricos do método da medição de viscosidade e desenvolvida a metodologia experimental a fim de evitar a influência indesejada de fatores externos, como a temperatura e a instabilidade da eletrônica, sobre a medição. Foram obtidos resultados com dois óleos alimentícios (azeite de oliva e óleo de milho) e quatro óleos automotivos do tipo SAE (40, 90, 140 e 250). Foi mostrado que para uma frequiência de operação baixa o suficiente para garantir comportamento Newtoniano do líquido, os valores de viscosidade têm excelente concordância numérica com os valores obtidos usando o viscosímetro rotacional, no caso dos óleos menos viscosos. Já no caso dos óleos mais viscosos, foram obtidos valores de viscosidade menores que os obtidos com viscosímetro rotacional, e o aumento no módulo elástico sugere um comportamento mais viscoelástico. Foi mostrado que o método de cálculo simplificado usado por alguns autores, que permite calcular a viscosidade a partir somente da magnitude do coeficiente de reflexão, não fornece os valores esperados de viscosidade. 


\begin{abstract}
This work deals with the ultrasonic measurement of liquids viscosity by means of the shear reflectance method. The method is based on the measurement of the magnitude and phase of the complex reflection coefficient of shear waves at a solidliquid sample interface. Basic concepts of the viscosity measurement method were analyzed and the experimental methodology was developed to avoid the undesired influence of external factors, such as temperature and electronic instability. Experimental results were obtained with two kinds of eatable oils (olive and corn oils) and four different automotive oils (SAE 40, 90, 140 e 250). For an operating frequency low enough to obtain Newtonian liquid behavior, as for less viscous liquids, it was shown that the viscosity results have good agreement with rotational viscometer measurements. In the case of more viscous liquids, the measured viscosity values were smaller than those obtained by the rotational viscometer, and the elastic modulus is increased, suggesting viscoelastic behavior. It is shown that a simplified model used by other authors, which obtains the viscosity without measuring the phase of the complex reflection coefficient, results in greater errors associated with the values obtained by the rotational viscometer.
\end{abstract}




\section{INTRODUÇÃO}

As propriedades físicas de um meio podem ser obtidas através da medição dos parâmetros acústicos desse meio, assim, a partir da medição de parâmetros como velocidade de propagação, impedância característica, atenuação e espalhamento, podese calcular a densidade, a viscosidade, o grau de homogeneização de uma mistura, a concentração de partículas sólidas num líquido, etc. (Buiochi, 2000). Atualmente nas indústrias químicas, petroquímicas, alimentícias e farmacêuticas, entre outras, existe uma demanda considerável de instrumentos de medição que realizam a caracterização ou discriminação de líquidos com elevada sensibilidade e acurácia. Além disso, devido à automação dos processos, muitas vezes, precisa-se de medições na linha de processo (in-line). Para esse propósito, o uso de técnicas por ultra-som é interessante por se tratar de métodos relativamente robustos, precisos, não destrutivos e que podem ser aplicados na linha de processo (Higuti, 2001; Saggin and Coupland, 2003).

Em muitos produtos industriais, a viscosidade é um parâmetro importante. Por exemplo, nos motores de combustão, as variações na viscosidade do óleo lubrificante podem-se relacionar com a sua degradação ou contaminação. Outro exemplo é a monitoração em processos de cura de polímeros de alto desempenho, usados como substitutos dos metais. Uma vez que a viscosidade muda rapidamente com o tempo de cura e dela depende o escoamento do polímero, a sua monitoração é de grande importância para garantir o preenchimento adequado do molde (Buiochi et al., 1998). Já na indústria de alimentos, precisa-se da monitoração da viscosidade para controlar a qualidade das matérias-primas, avaliar o efeito das variações na formulação e garantir uma melhor consistência do produto final (Race,1991).

Existem vários tipos de dispositivos para a medição da viscosidade de líquidos, os 
quais são catalogados segundo Dealy and Broadhead (1993) em dispositivos off-line quando as medições são feitas no laboratório com amostras retiradas manualmente da linha de processo, on-line, quando são feitas num escoamento secundário à linha de processo (operação by pass) e in-line, quando as medições são feitas na linha de processo. Entre os viscosímetros do tipo off-line tem-se o viscosímetro rotacional que está constituído de dois cilindros concêntricos com o fluido em teste entre eles. Um dos cilindros gira escoando o fluido e, dependendo da velocidade e da força requerida, podese calcular a viscosidade. Outro viscosímetro do tipo off-line tem uma haste vibrando que ao ser imerso no líquido muda sua frequiência de ressonância em função da viscosidade. No caso do tipo on-line, tem-se o viscosímetro capilar, que tem dois transdutores de pressão, colocados em lugares diferentes de um tubo, que medem a queda de pressão que é proporcional à viscosidade. Os viscosímetros off-line, acima descritos, são pouco apropriados para medições na linha de processo porque precisam de partes móveis e imersas no líquido que obstruem o escoamento e causam perdas de carga. Já o método do viscosímetro capilar, tem a desvantagem de ser restrito a líquidos Newtonianos.

A medição do coeficiente de reflexão complexo de uma onda ultra-sônica de cisalhamento incidindo na interface entre um sólido e o líquido testado é o método mais atraente para o desenvolvimento de um viscosímetro in-line (Harrison e Barlow, 1981; Cohen-Tenoudji et al., 1987; Buiochi, 2000). O método tem as vantagens de não usar peças móveis ou que obstruam o escoamento, podendo ser usado em fluido confinado, por exemplo, injeção de polímeros, e em fluido estático ou em movimento. Além disso, como é suficiente uma quantidade muito pequena de fluido para fazer a medição, pode ser usado com filmes poliméricos e polpa de papel.

\subsection{OBJETIVOS}

- Desenvolver um modelo analítico para a simulação do funcionamento das células de medição.

- Analisar os principais fatores que afetam a precisão das medidas, fazendo uma avaliação da contribuição de cada parâmetro no erro total e detectando os fatores que podem ser melhorados para aumentar a precisão da medição nas células existentes. 
- Desenvolver uma nova célula de medição, baseada no modelo analítico e na análise das células anteriores, melhorando o controle da temperatura nas medições (precisão de $0,1^{\circ} \mathrm{C}$ ).

- Realizar medições experimentais e comparar os resultados com os modelos teóricos e a viscosidade obtida a baixa freqüência utilizando o viscosímetro rotacional.

\subsection{ORGANIZAÇÃO DO TRABALHO}

No capítulo 2 (revisão bibliográfica) é feita uma descrição cronológica dos trabalhos mais relevantes e são discutidas as características principais desses trabalhos, além dos resultados mais importantes.

Os capítulos 3, 4 e 5 contêm as bases teóricas necessárias para a abordagem da medição de viscosidade de líquidos pelo método da reflexão de ondas de cisalhamento. O capítulo 3 contém uma discussão da teoria da propagação de ondas acústicas em meios isotrópicos considerados como perfeitamente elásticos, perfeitamente viscosos e viscoelástico. O capítulo 4 apresenta a base teórica envolvida no método de medição de viscosidade de líquidos por ultra-som. O capítulo 5 trata sobre a teoria dos transdutores ultra-sônicos piezelétricos, sendo apresentado um modelo matricial unidimensional que simula o funcionamento dos dispositivos de medição implementados neste trabalho.

No capítulo 6 são apresentados os dispositivos de medição desenvolvidos neste trabalho e os métodos experimentais usados. No capítulo 7 são apresentados e discutidos os resultados obtidos. O trabalho finaliza no capítulo $8 \mathrm{com}$ as conclusões gerais e as propostas para trabalhos futuros. 


\section{CAPÍTULO 2}

\section{REVISÃO BIBLIOGRÁFICA}

Mason (1947) apud Mason (1949) verificou experimentalmente que um líquido submetido a altas taxas de cisalhamento apresenta comportamento elástico, além do bem conhecido comportamento viscoso, ou seja, comporta-se como um fluido viscoelástico. Esse comportamento foi descrito teoricamente tempos atrás por vários autores, entre eles Maxwell, no seu clássico trabalho sobre a teoria dinâmica dos gases. Foram usados cristais que geram ondas torcionais para medir a elasticidade e a viscosidade de cisalhamento de líquidos em alta freqüência, que está relacionada com a carga mecânica e o incremento na frequiência de ressonância do cristal.

No trabalho de O'Neil (1948), foram analisados os fenômenos de reflexão e refração de ondas planas de cisalhamento ao atingir a interface entre dois meios com impedâncias acústicas diferentes, onde um dos meios é essencialmente um sólido elástico e o outro é um líquido. Foram desenvolvidas as relações teóricas que permitem derivar as propriedades do líquido em termos das propriedades conhecidas dos meios.

A medição da viscosidade de líquidos pelo método da reflexão de ondas de cisalhamento foi inicialmente proposta por Mason et al. (1949), para medir as propriedades dos líquidos a freqüências maiores, que não podem ser alcançadas com os cristais torcionais. Isso ocorre devido às pequenas dimensões requeridas que limitam esse tipo de cristais a freqüências menores que $500 \mathrm{kHz}$. Nesse trabalho foram apresentadas as equações fundamentais para incidência normal e oblíqua, baseadas em modelos mecânicos com dois tempos de relaxação. Foram feitas medições da elasticidade e da viscosidade de polímeros líquidos (Polyisobutylene) a freqüências de até $60 \mathrm{MHz}$. A figura 2.1 mostra as montagens experimentais usadas nas medições, as 
setas indicam a direção de propagação das ondas. Na figura 2.1(a), pode-se ver o dispositivo usado para incidência normal, onde a emissão e a recepção das ondas foram feitas com o mesmo cristal (modo pulso-eco). A figura 2.1(b) apresenta o dispositivo usado para incidência oblíqua, onde a onda incide na interface com ângulo $\phi$, dois cristais, o emissor e o receptor, foram colados em uma linha de retardo para trabalhar no modo transmissão-recepção. A incidência oblíqua tem a vantagem de aumentar a sensibilidade da medição. Nos dois casos a linha de retardo foi feita de quartzo (fused quartz), devido a sua baixa atenuação.

(a)

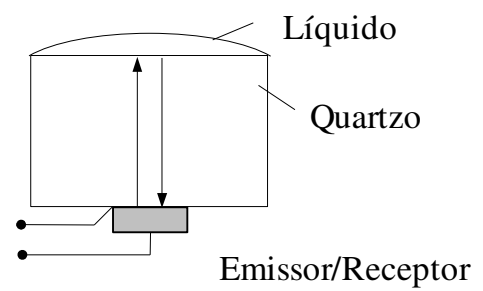

(b)

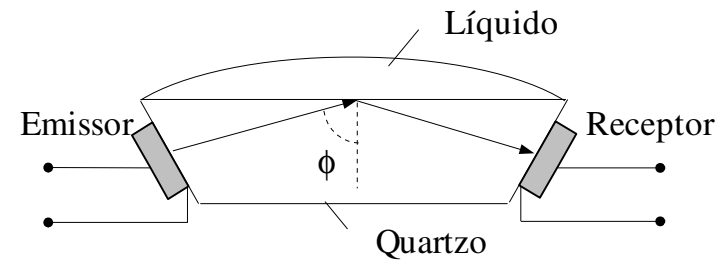

Figura 2.1. Montagens experimentais usadas por Mason et al. (1949) para a medição da elasticidade e a viscosidade de cisalhamento de polímeros líquidos: (a) incidência normal, (b) incidência oblíqua.

Barlow e Lamb (1959) usaram o método da reflexão de ondas de cisalhamento para o estudo do comportamento viscoelástico de óleos lubrificantes. Nesse trabalho é apresentada a teoria envolvida na medição, além de uma discussão sobre a variação da viscosidade e do módulo de elasticidade com a temperatura e a pressão. Foram feitas medições a diferentes temperaturas e pressões, da impedância de cisalhamento para três óleos lubrificantes com diferentes viscosidades de baixa freqüência. Foi usado um dispositivo do tipo mostrado na figura 2.1(b) para as medições a baixa pressão e um dispositivo do tipo da figura 2.1(a) para alta pressão. Os dados obtidos de impedância de cisalhamento e viscosidade dinâmica mostraram boa concordância com os resultados teóricos. Finalmente, a partir de dados experimentais, foi concluído que na realidade tem-se um espectro contínuo de tempos de relaxação, em lugar de somente um valor.

McSkimin e Andreatch (1967) aplicaram um método similar ao mostrado na figura 2.1(a) à medição da viscosidade de líquidos pouco viscosos, da ordem de 0,001Pa.s, com frequiência de trabalho de $40 \mathrm{MHz}$. Nesse trabalho, a linha de retardo, de quartzo do tipo AT-cut, foi projetada com superfícies biseladas para espalhar a energia 
ultra-sônica difratada nas sucessivas reflexões das ondas. O dispositivo todo foi colocado num cilindro de bronze mantido a temperatura constante com precisão de $0,01^{\circ} \mathrm{C}$, mediante circulação de um fluido. Foi medida a impedância de cisalhamento na interface sólido-líquido e calculada a viscosidade dinâmica. A comparação entre a viscosidade de alta freqüência medida e a viscosidade de baixa freqüência obtida da literatura (Handbook of Chemistry and Physics) foi satisfatória. Nesse trabalho, a diferença de fase foi medida por um método que usa a freqüência de repetição dos pulsos refletidos pela interface, para o caso com e sem líquido. O método é preciso e apropriado para o processamento analógico dos sinais usado na época.

No trabalho de Moore et al. (1967) foi usado o dispositivo desenvolvido por McSkimin e Andreatch (1967) para medir as propriedades viscoelásticas de soluções de polystyrene com dois diferentes solventes, para várias frações de volume. Os resultados do módulo elástico dinâmico e a viscosidade de alta freqüência foram comparados com dois modelos teóricos para materiais viscoelásticos apresentando uma boa concordância, principalmente a baixas frações de volume de polystyrene.

Nos trabalhos de Kirk e Martinoty (1976) e Martinoty (1983) foi usado um dispositivo similar ao mostrado na figura 2.1(b), mas, somente com um cristal no modo transmissão-reflexão, para medir a viscosidade anisotrópica em cristais líquidos nemáticos (Kirk e Martinoty, 1976), e a viscosidade de polímeros flexíveis em um meio nemático (Martinoty, 1983). Foram usadas múltiplas reflexões para aumentar o efeito da redução de amplitude, não sendo medida a fase da onda. A viscosidade foi obtida a partir da parte real da impedância acústica, que pode ser expressa somente em termos da amplitude do coeficiente de reflexão. Isso é possível supondo que a variação de fase é pequena, visto que o período da onda de cisalhamento é muito maior que o tempo de relaxação do líquido medido. Nessas condições tem-se comportamento basicamente Newtoniano e as partes real e imaginária da impedância acústica são iguais. A freqüência de trabalho foi $5 \mathrm{MHz}$.

Cohen-Tenoudji et al. (1987) usaram a montagem da figura 2.2 para pesquisar o comportamento da viscosidade dinâmica de resinas poliméricas no processo de cura. As medições foram feitas diretamente no molde colocado dentro do autoclave à temperatura de cura $\left(121^{\circ} \mathrm{C}\right)$. O transdutor de ondas de cisalhamento, com freqüência central de $1 \mathrm{MHz}$, é colado a uma linha de retardo de cobre. A face oposta da linha de retardo de 
cobre é colada a uma outra linha de retardo de alumínio que, ao fazer parte da parede do molde, está em contato com a resina. Têm-se duas reflexões no transdutor: uma proveniente da interface cobre-alumínio e outra da interface alumínio-resina (ou alumínio-ar). A primeira reflexão é usada para realizar uma normalização dos sinais obtidos, isso ajuda a eliminar os erros induzidos, principalmente na fase das ondas, pelas flutuações na temperatura (autocalibração). Foi medida a viscosidade de alta freqüência da resina em função do tempo de cura e os resultados foram comparados com medições feitas nas mesmas condições com um viscosímetro rotacional a baixa taxa de cisalhamento $(10 \mathrm{~Hz})$. Os gráficos dos resultados mostraram boa correlação, contudo os valores das viscosidades dinâmica e de baixa frequiência diferem numericamente.

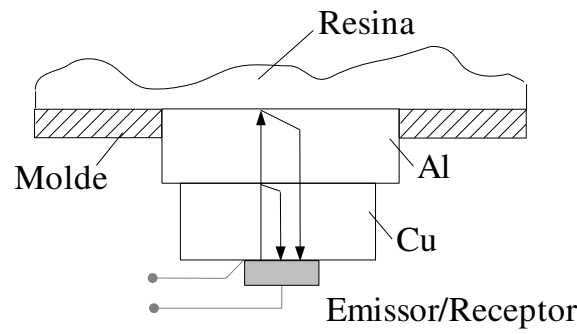

Figura 2.2. Montagem usada por Cohen-Tenoudji et al. (1987).

No trabalho de Sheen, Chien e Raptis (1995) foi apresentado um dispositivo (inline) que mede simultaneamente a densidade e a viscosidade de líquidos Newtonianos. Foi usado um transdutor de ondas longitudinais de $1 \mathrm{MHz}$ de freqüência central para medir a densidade, usando a velocidade de propagação e a impedância acústica da onda no líquido. A raiz quadrada do produto entre a densidade e a viscosidade ( $\sqrt{\rho \eta})$ foi medido usando o método da reflexão de ondas de cisalhamento com freqüência de trabalho de $5 \mathrm{MHz}$. Os dispositivos de medição que faziam parte da parede de uma tubulação onde escoava o líquido foram montados conforme mostra a figura 2.3. A linha de retardo tem um degrau que gera uma reflexão usada para a normalização dos sinais, ou seja, autocalibração. Os resultados obtidos para vários fluidos derivados do petróleo mostraram boa concordância com os dados teóricos. Além disso, foi mostrado que o método é apropriado para a monitoração do processo de cura de resinas. 


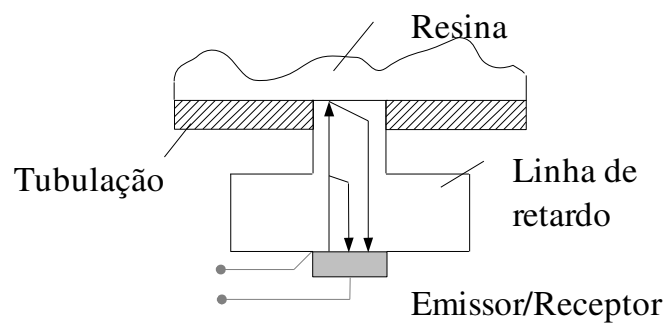

Figura 2.3. Montagem usada por Sheen, Chien e Raptis (1996).

Sheen, Chien e Raptis (1996) apresentaram uma discussão dos modelos de Maxwell, Voigt e lei da potência que descrevem o comportamento dos líquidos não Newtonianos a altas taxas de cisalhamento. Usando tais modelos, foi estudado o desempenho de alguns materiais, metais e polímeros, para serem usados como meio sólido na interface sólido-amostra. Finalmente, foram feitas medições com fluidos de viscosidade padrão e os resultados comparados com os modelos teóricos. Foi concluído que o modelo de Maxwell descreve adequadamente o comportamento de líquidos de alta viscosidade(>200Pa.s), e o modelo da lei da potência é mais adequado para líquidos na faixa entre 10 e 100Pa.s.

No trabalho de Shah e Balasubramaniam (1996) foi analisado o efeito das excitações em banda larga no método. Foram feitas simulações da resposta da interface sólido-líquido às ondas de cisalhamento incidentes, variando parâmetros como a freqüência da onda, o tipo de material sólido e a densidade e viscosidade do líquido. As simulações foram validadas com medições experimentais. Foi mostrado que um bom casamento de impedâncias na interface aumenta a sensibilidade da medição.

Alig et al. (1996) aplicaram o método ao estudo do comportamento viscoelástico de filmes poliméricos e sua dependência do tempo e da temperatura. Foi usada incidência oblíqua no modo transmissão-recepção. O transmissor foi excitado na faixa 3-40MHz mediante um burst senoidal.

Longin, Verdier and Piau (1997) estudaram as propriedades viscoelásticas do polímero PDMS (polydimethylsiloxanes) usando técnicas reológicas convencionais, assim como o ultra-som. Foi usada incidência normal e oblíqua com frequiências entre 1,5-5MHz, os melhores resultados foram obtidos com incidência normal. 
Mukai et al. (1997) estudaram as propriedades reológicas de um cristal líquido (Smetic-A liquid crystal) usando incidência oblíqua com frequiência de $3 \mathrm{MHz}$. Foram usados cristais de quartzo para gerar e receber as ondas de cisalhamento e um prisma, também de quartzo, como meio sólido.

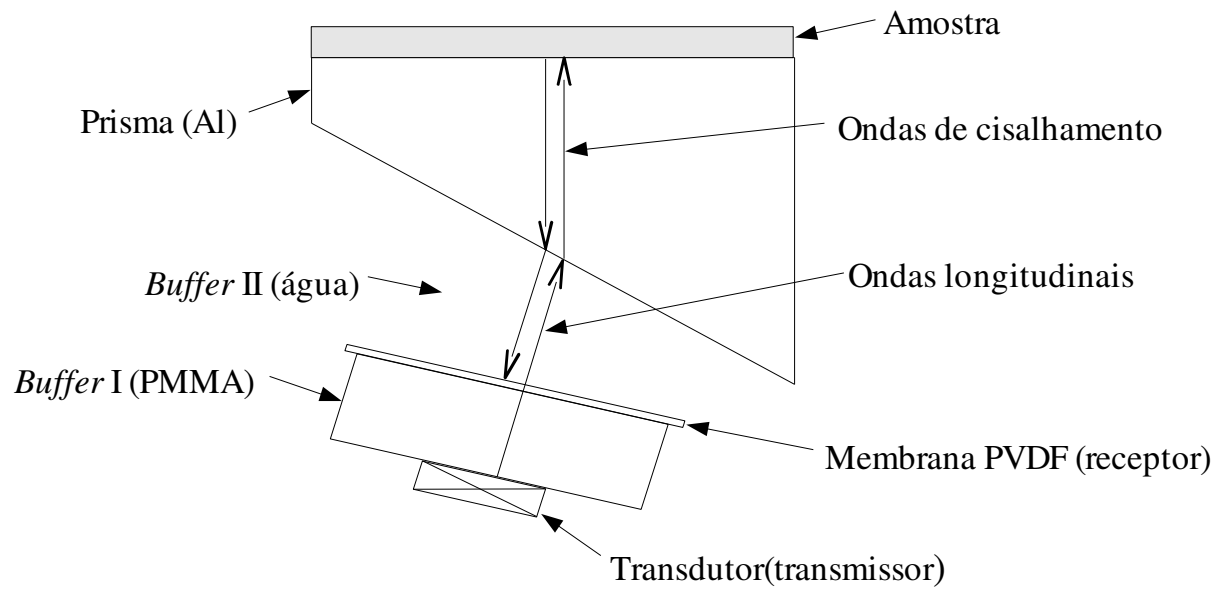

Figura 2.4. Esquema da montagem usada por Buiochi, Adamowski e Furukawa (1998).

No trabalho de Buiochi, Adamowski e Furukawa (1998) foi apresentada uma célula de medição que usa a técnica da conversão de modo para gerar as ondas de cisalhamento a partir de ondas longitudinais. Essa técnica permite eliminar as ondas longitudinais indesejadas, geradas pelos transdutores de cisalhamento. Além disso, foi usado como receptor uma membrana de PVDF (Poly-Vinyldene Fluoride), que devido à sua grande abertura reduz os erros por difração. A figura 2.4 apresenta um esquema da montagem. Foram feitas medições com glicerina e mel.

Kulmyrzaev e McClements (1999) estudaram as propriedades dinâmicas do mel. Foi usada incidência normal na faixa de 5 a $15 \mathrm{MHz}$. As amostras foram misturas de água-mel com frações de volume de mel entre 30 e 100\%. Foi concluído que o método é apropriado para a caracterização desse líquido. Não foi possível obter resultados coerentes para concentrações de mel inferiores a 70\%, tendo sido concluído que o método se restringe a fluidos de alta viscosidade ( $\eta>0,3$ Pa.s $)$. Os dados medidos foram comparados com medições feitas com um viscosímetro rotacional mostrando alta correlação. Contudo, os valores medidos por ultra-som foram aproximadamente a metade dos medidos com o viscosímetro rotacional.

Balasubramaniam (1999) usou o método da reflexão de ondas de cisalhamento na 
monitoração simultânea da temperatura e da viscosidade em fornos com banhos de vidro líquido. Foi usado um dispositivo do tipo mostrado na figura 2.3, mas com uma linha de retardo longa e parecida com uma guia de onda. Um extremo da linha de retardo foi colocado dentro do forno em contato com o banho e no outro extremo foi colado o transdutor de cisalhamento. A linha de retardo foi resfriada usando circulação de água para manter o transdutor à temperatura ambiente. Foi usado um método de calibração da temperatura e da viscosidade para realizar a medição. Esse processo de calibração deve ser feito para cada linha de retardo usada e para cada material testado. Foi mostrada uma excelente repetibilidade das medições com vidro líquido.

Na tese de Buiochi (2000) é feita uma detalhada revisão dos conceitos teóricos e experimentais envolvidos na medição de líquidos por ultra-som. Nesse trabalho foram desenvolvidas duas células de medição, do tipo mostrado na figura 2.4 , que usam a conversão de modo para gerar as ondas de cisalhamento, entre 1 e $10 \mathrm{MHz}$, e membranas de PVDF na recepção. Além disso, foram usadas duas estratégias de medição: o método da reflexão relativa e o método das múltiplas reflexões relativas. O comportamento da viscosidade com a freqüência foi amplamente estudado usando os modelos de Maxwell, com um e dois tempos de relaxação, e de Voigt. Foram feitas medições com óleos automotivos e glucose de milho e os resultados comparados com os resultados teóricos.

Shah e Balasubramaniam (2000) usaram incidência normal e o princípio de autocalibração para medir a viscosidade de fluidos padrão. Foram usados dois modelos aproximados para líquidos Newtonianos. O primeiro usa somente a magnitude do coeficiente de reflexão medido, supondo que a mudança de fase é muito pequena, e o segundo usa a fase medida para calcular a magnitude. Foi analisado o efeito na medição do tipo de material sólido usado na interface.

No trabalho de Saggin e Coupland (2001) foi analisada a viabilidade de aplicar o método na monitoração da viscosidade dos fluidos usados na indústria de alimentos. Foram feitas medições com óleos vegetais (milho, oliva e sementes de algodão) e fluidos padrão, derivados do petróleo, usados na calibração de instrumentos reológicos. Foi verificada a viabilidade do método e concluído que é sensível somente à viscosidade do fluido, não sendo afetado por sua composição.

Greenwood e Bamberger (2002) usaram o método para medir a viscosidade e a velocidade de cisalhamento em líquidos de baixa viscosidade (mistura agua-açúcar) e de 
alta viscosidade (óleos de silicone). Concluíram que para líquidos pouco viscosos, o método da reflexão de ondas de cisalhamento mede a viscosidade do líquido. Entretanto, para líquidos de alta viscosidade, é medido o módulo de cisalhamento.

Buiochi et al. (2003) aplicaram a célula de medição desenvolvida por Buiochi (2000) e o método das múltiplas reflexões no estudo da viscosidade dinâmica dos óleos automotivos SAE 90 e SAE 140 e da glucose de milho (Karo). O estudo foi feito na faixa de freqüência entre 1 e $5 \mathrm{MHz}$. Os resultados experimentais foram comparados com o modelo de Maxwell, mostrando boa concordância.

Saggin e Coupland (2003) estudaram misturas água-açúcar e água-açúcarxanthan. O xanthan gum é um biopolímero usado na indústria de alimentos para aumentar a viscosidade de misturas. Foi usada reflexão de ondas de cisalhamento a $10 \mathrm{MHz}$ e os dados obtidos foram comparados com medições feitas com métodos convencionais (viscometria oscilatória com taxas de cisalhamento entre 1 e 100rad/s). Foi obtida boa correlação entre as medições convencionais e as feitas por ultra-som, mas os resultados numéricos tiveram pouca concordância. Essa concordância foi pior para as misturas mais viscosas. Foi concluído que para obter valores numéricos iguais, deve-se usar uma freqüência de trabalho muito menor que o inverso do tempo de relaxação do líquido ( $f \ll 1 / \tau_{m}$ ). Além disso, foi mostrado que o modelo de Maxwell fornece uma descrição qualitativa do comportamento da viscosidade com a freqüência.

Mais recentemente, Dixon e Lanyon (2005) usaram a mudança de fase das ondas de cisalhamento na monitoração do processo de cura de resinas epóxicas, mostrando ser uma ferramenta importante que fornece valiosa informação. Já Balasubramaniam et al. (2004), apresentam um enfoque interessante que, usando um cristal de quartzo que gera ondas de cisalhamento e com uma linha de retardo em cada uma das suas faces, faz simultaneamente as aquisições com a amostra líquida e com o fluido de referencia. Esse enfoque permite realizar um maior número de medições, à mesma temperatura, sem ter limpar o dispositivo. 


\section{PROPAGAÇÃO DE ONDAS ACÚSTICAS EM MEIOS ISOTRÓPICOS}

Neste capítulo faz-se a revisão dos conceitos básicos necessários para a abordagem da medição de viscosidade de líquidos por ultra-som. Trata-se o tema da propagação de ondas acústicas em meios isotrópicos: sólido perfeitamente elástico, líquido perfeitamente viscoso ou Newtoniano e meio viscoelástico. Inicialmente, é deduzida a equação de onda para meios sem perdas. Depois, é introduzido o conceito de viscosidade como principal mecanismo de perdas no meio. A partir da equação de onda para meios com perdas viscosas são deduzidas as relações básicas para meios viscoelásticos isotrópicos e são discutidos os modelos mecânicos mais importantes para esses materiais. É definida a impedância acústica e, para finalizar o capítulo, é discutido o fenômeno da incidência de uma onda na interface entre dois meios de diferentes impedâncias acústicas.

\subsection{PROPAGAÇÃO DE ONDAS EM MEIOS SEM PERDAS}

As ondas acústicas mais importantes usadas na maioria das aplicações ultrasônicas são as longitudinais ou de pressão e as de cisalhamento. Os outros modos de vibração são em geral desprezados, por não interferirem nos cálculos. Os modos de vibração indesejáveis devem ser reduzidos ao máximo com um projeto adequado dos dispositivos. Para a medição da viscosidade por ultra-som, usam-se ondas de cisalhamento, mas, como os sólidos apresentam os dois tipos de ondas, é preciso o estudo também das ondas longitudinais. Uma vez que todas as grandezas físicas supostamente podem ser expressas na forma unidimensional, além da propagação de ondas planas, pode-se simplificar o problema de três a somente uma dimensão.

Inicialmente, define-se o modo de vibração de cada tipo de onda. Na figura 3.1(a), 
tem-se um cubo infinitesimal de material, onde é aplicada uma tensão normal $\left(T_{z z}\right)$ ao longo do eixo $z$, o que resulta em uma pequena mudança no volume do cubo, que afeta também as partículas vizinhas. Devido à natureza elástica do material, o cubo demora um pequeno tempo para se deformar e recuperar a sua forma inicial. Assim, a perturbação, chamada de onda longitudinal, propaga-se no material. No caso das ondas longitudinais, pode-se ver na figura 3.1(a) que o movimento das partículas é na mesma direção da propagação da onda. Na figura 3.1(b), tem-se o mesmo cubo de material com uma tensão de cisalhamento $\left(T_{z y}\right)$ aplicada em um plano perpendicular à direção $z$. Nesse caso, o movimento das partículas é perpendicular à direção de propagação da onda (eixo z) e a perturbação que se propaga no material é chamada de onda de cisalhamento (shear wave).

a)

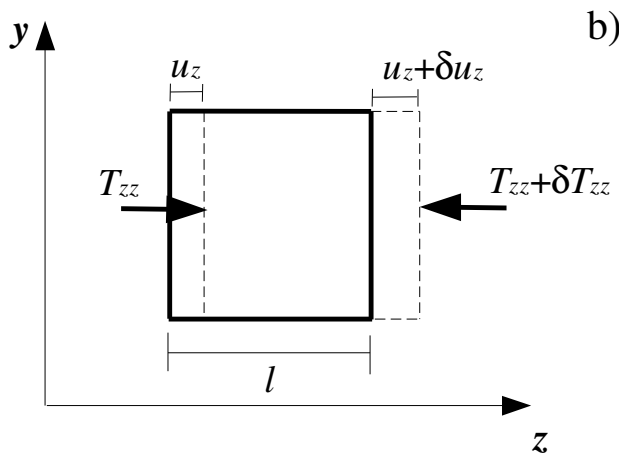

b)

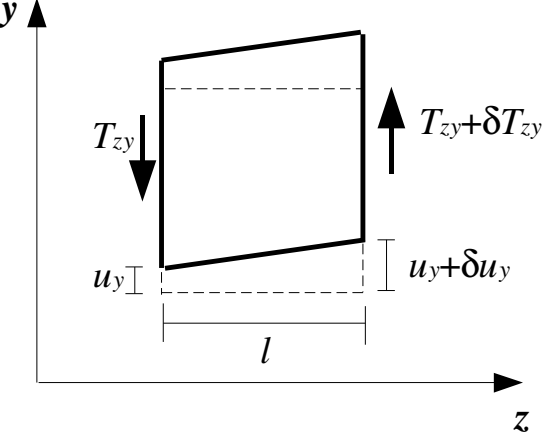

Figura 3.1. Geometria usada na dedução da equação da onda longitudinal (a) e de cisalhamento (b), ambas propagando-se ao longo do eixo $z$.

Como, em geral, as deduções feitas são válidas para ambos os tipos de ondas, utilizam-se simplesmente os termos "deslocamento" e "tensão", representados pelos símbolos $u$ e $T$, respectivamente, fazendo os esclarecimentos quando necessários.

Pode-se usar a série de Taylor para provar que as mudanças na tensão mecânica e no deslocamento, para um comprimento $l$ do volume elementar de material, são $\delta T$ e $\delta u$, respectivamente, onde:

$$
\begin{aligned}
& \delta T=\frac{\partial T}{\partial z} l, \\
& \delta u=\frac{\partial u}{\partial z} l=S l,
\end{aligned}
$$

onde $T$ é a tensão mecânica, $u$ é o deslocamento da partícula e $S$ é a deformação. As 
expressões 3.1 e 3.2 são válidas para pequenas tensões de forma que as deformações sejam proporcionais à tensão, satisfazendo a lei de Hooke:

$$
T=c S,
$$

onde $c$ é a constante de elasticidade do meio (ver seção 3.1.1).

Aplicando a segunda lei de Newton ao volume infinitesimal de material tem-se:

$$
\frac{\partial T}{\partial z} l=\rho l d z \frac{\partial^{2} u}{\partial t^{2}}
$$

onde $\rho$ é a densidade do meio. Substituindo 3.1, 3.2 e 3.3 na equação 3.4, pode-se obter a equação da onda plana e unidimensional em meios isotrópicos:

$$
\frac{\partial^{2} u}{\partial z^{2}}=\frac{1}{v^{2}} \frac{\partial^{2} u}{\partial t^{2}}
$$

As soluções para a equação diferencial anterior são da forma $f(t \pm z / v)$. Para excitação harmônica, considerando que todas as grandezas mudam com o tempo da forma $e^{j \omega t}$, as soluções são da forma $u_{0} e^{j \omega(t \pm z / v)}$. O sinal negativo corresponde a uma onda propagando-se para frente $(+z)$, o sinal positivo corresponde a uma onda propagando-se no sentido contrário $(-z)$ e $v$ é a velocidade de propagação da onda dada por:

$$
v=\sqrt{\frac{c}{\rho}} .
$$

\subsubsection{Lei de Hooke}

A lei de Hooke relaciona a tensão e a deformação em um material. No caso geral, pode ser representada usando a notação tensorial reduzida (Kino, 1987)

$$
T_{J}=c_{J K} S_{K} \text { para } J, K=1,2,3,4,5,6 .
$$

onde $c_{J K}$ são as constantes elásticas que para materiais isotrópicos, devido à simetria, ficam reduzidas a duas constantes, chamadas de constantes de Lamé, assim:

$$
\begin{aligned}
& c_{11}=c_{22}=c_{33}=\gamma+2 \mu, \\
& c_{12}=c_{13}=c_{23}=c_{21}=c_{31}=c_{32}=\gamma,
\end{aligned}
$$




$$
c_{44}=c_{55}=c_{66}=\frac{c_{11}-c_{12}}{2}=\mu \text {. }
$$

Para ondas longitudinais tem-se $c=c_{11}$, então, a velocidade de propagação fica:

$$
v_{l}=\sqrt{\frac{c_{11}}{\rho}}=\sqrt{\frac{\gamma+2 \mu}{\rho}},
$$

e para ondas de cisalhamento tem-se $c=c_{44}$ :

$$
v_{c}=\sqrt{\frac{c_{44}}{\rho}}=\sqrt{\frac{\mu}{\rho}} .
$$

Como, em geral, é mais fácil flexionar que esticar um sólido $\left(c_{44}<c_{11}\right)$, as ondas de cisalhamento propagam-se a menor velocidade que as longitudinais. Um tratamento mais geral e completo do problema é apresentada nos livros de Auld (1990) e de Kino (1987).

Como um líquido perfeitamente viscoso ou Newtoniano não pode suportar tensão de cisalhamento, dado que toda a energia é dissipada e o meio não recupera seu estado inicial, então, têm-se $\mu=0, c_{11}=c_{12}=\gamma$ e $c_{44}=0$, a velocidade de propagação das ondas longitudinais pode ser calculada usando a equação 3.11 .

\subsection{PROPAGAÇÃO DE ONDAS EM MEIOS COM PERDAS}

$\mathrm{Na}$ realidade os sistemas não são perfeitamente elásticos e, como não é armazenada toda a energia, apresenta-se dissipação. As forças viscosas presentes entre partículas vizinhas com diferente velocidade são a maior causa de atenuação das ondas em sólidos e líquidos. Tem-se, então, uma tensão viscosa adicional entre as partículas do meio que, segundo a lei de Newton para fluidos perfeitamente viscosos, é proporcional à velocidade das partículas onde a constante de proporcionalidade $(\eta)$ é chamada de coeficiente de viscosidade, viscosidade ou viscosidade dinâmica (Massey, B. S., 1983). Assim, a tensão total pode ser dada por:

$$
T=c S+\eta \frac{\partial S}{\partial t}
$$

O termo "viscosidade" faz referência à viscosidade em baixa freqüência que é o 
valor mais conhecido e medido, por exemplo, com um viscosímetro rotacional. Substituindo a equação 3.13 na equação 3.4 e mediante algumas manipulações algébricas, a equação de onda para um meio elástico com perdas viscosas é:

$$
\rho \frac{\partial^{2} u}{\partial t^{2}}=c \frac{\partial^{2} u}{\partial z^{2}}+\eta \frac{\partial^{3} u}{\partial z^{2} \partial t}
$$

Para excitação harmônica, a equação 3.14 pode ser reduzida à equação de Helmholtz, assim:

$$
\frac{d^{2} u}{d z^{2}}+\left[\frac{\rho \omega^{2}}{c+j \omega \eta}\right] u=0 .
$$

Assim, essa equação deve ser resolvida para as condições de contorno requeridas. A solução mais importante é obtida para um meio semi-infinito, como mostra a seguinte equação:

$$
u=u_{0} \exp [j \omega t-\Gamma z]
$$

onde $\Gamma$ é a constante complexa de propagação dada por:

$$
-\Gamma^{2}=\frac{\rho \omega^{2}}{c+j \omega \eta} .
$$

Define-se agora a velocidade de propagação complexa que descreve a velocidade de propagação e a atenuação da onda como:

$$
v^{*}=v_{r}+j v_{i}=\sqrt{\frac{c+j \omega \eta}{\rho}},
$$

então, a solução dada pela equação 3.16 pode ser escrita (Sherrit, 1998):

$$
u=u_{0} \exp (-\alpha z) \exp [j \omega(t-z / v)]
$$

onde $\alpha$ é a constante de atenuação e $v$ a velocidade de propagação da onda. $\mathrm{O}$ coeficiente de atenuação tem unidades de Nepper por metro $(\mathrm{Np} / \mathrm{m})$; o valor $z_{0}=1 / \alpha$, chamado de profundidade de penetração, corresponde à distância na qual a amplitude da onda decresce num fator de $1 / e$. Define-se agora o fator de qualidade mecânica $\left(Q_{m}\right)$ como a razão entre a quantidade de energia armazenada $\left(E_{a}\right)$ e a quantidade de energia dissipada $\left(E_{d}\right)$, assim: 


$$
Q_{m}=\frac{E_{a}}{E_{d}} \simeq \frac{\omega}{2 \alpha v} \simeq \frac{v_{r}}{2 v_{i}},
$$

e a velocidade de propagação complexa pode ser expressa como:

$$
v^{*}=v_{(S P)} \sqrt{\left(1+\frac{j}{Q_{m}}\right)},
$$

onde o subscrito $(S P)$ representa as propriedades de um meio sem perdas.

Embora as perdas viscosas sejam as mais importantes, existem outras formas de perda. Uma é a condução térmica que resulta da compressão não adiabática do material, cuja atenuação varia com o quadrado da freqüência. Outra forma de perda é o espalhamento devido ao tamanho finito dos grãos do material ou às discordâncias no sólido; para evitar perdas devido ao espalhamento, deve-se ter um comprimento de onda muito maior que o tamanho do grão do material. Além disso, também há uma mudança no estado induzida pela onda ultra-sônica em sólidos ou líquidos, por exemplo, a água exibe estrutura cristalina parcial e a onda acústica perde energia ao gerar distorção na estrutura (Kino, 1987).

\subsection{MEIOS VISCOELÁSTICOS}

De um modo geral, um material viscoelástico é definido como aquele que apresenta um comportamento tensão-deformação complexo dependente do tempo, ou simplesmente um material que apresenta propriedades intermediárias entre um sólido perfeitamente elástico e um fluido perfeitamente viscoso (Whorlow, 1992). Nesta seção, todas as tensões mencionadas são tensões de cisalhamento. Na equação (3.15), podemse considerar três casos importantes:

1. $c \neq 0$ e $\eta=0$ : $\quad \mathrm{O}$ material comporta-se como um sólido perfeitamente elástico, ou seja, toda a energia é armazenada sem perdas viscosas, neste caso, a tensão e o deslocamento das partículas encontram-se em fase $\left(\phi=0^{\circ}\right)$.

2. $\mathrm{c}=0$ e $\eta \neq 0$. $\quad \mathrm{O}$ material comporta-se como um líquido perfeitamente viscoso (líquido Newtoniano), ou seja, toda a energia é 
dissipada pelas perdas viscosas, neste caso, a tensão e o deslocamento das partículas encontram-se $90^{\circ}$ fora de fase $\left(\phi=90^{\circ}\right)$.

3. $\mathrm{c} \neq 0$ e $\eta \neq 0$ : $\quad \mathrm{O}$ material comporta-se como um fluido viscoelástico, onde a energia é tanto armazenada elasticamente quanto dissipada pelas perdas viscosas, neste caso, a tensão e o deslocamento das partículas encontram-se fora de fase num ângulo $0<\phi<90^{\circ}$.

Define-se o módulo de cisalhamento complexo $\left(G^{*}\right)$ como a razão entre a amplitude da tensão complexa e a amplitude do deslocamento complexo, podendo ser expresso por:

$$
G^{*}=c+j \omega \eta=G^{\prime}+j G^{\prime \prime},
$$

onde $G^{\prime}$ é o módulo de armazenamento ou módulo elástico e $G^{\prime \prime}$ é o módulo de perda, então:

$$
\begin{aligned}
& \tan (\phi)=\frac{G^{\prime \prime}}{G^{\prime}}, \\
& Q_{m}=\frac{G^{\prime}}{G^{\prime \prime}}=\frac{1}{\tan (\phi)} .
\end{aligned}
$$

Das equações $3.16,3.17$ e 3.19 pode-se achar que

$$
\Gamma=\frac{1}{z_{0}}+j \frac{2 \pi}{\lambda}=\alpha+j \frac{\omega}{v},
$$

onde $\lambda$ é o comprimento de onda. Das equações $3.17,3.22$ e 3.25 podem ser achadas as seguintes expressões para o módulo de cisalhamento complexo:

$$
\begin{aligned}
& G^{*}=\frac{-\rho \omega^{2}}{\Gamma^{2}}=\frac{-\rho \omega^{2}}{\left(\alpha+j \frac{\omega}{v}\right)^{2},} \\
& G^{\prime}=\rho \omega^{2}\left(\frac{\omega^{2}}{v^{2}}-\alpha^{2}\right) /\left(\frac{\omega^{2}}{v^{2}}+\alpha^{2}\right)^{2},
\end{aligned}
$$




$$
G^{\prime \prime}=\rho \omega^{2}\left(\frac{2 \omega \alpha}{v}\right) /\left(\frac{\omega^{2}}{v^{2}}+\alpha^{2}\right)^{2},
$$

onde:

$$
v=\frac{\lambda \omega}{2 \pi} .
$$

\subsubsection{Modelos para materiais viscoelásticos}

Existem vários modelos simples que permitem descrever de forma qualitativa o comportamento de materiais viscoelásticos usando simples arranjos de molas e amortecedores que definem a relação entre a tensão e a deformação. Os modelos mais importantes devido a sua simplicidade e seu amplo emprego, além de que são a base para outros mais sofisticados, são os modelos de Maxwell e de Kelvin-Voigt mostrados na figura 3.2, onde $G$ é o módulo elástico instantâneo de cisalhamento. Entretanto, $G_{\infty} \mathrm{e}$ $G^{\prime}$ podem representar quantidades distintas em cada modelo (Whorlow, 1992).

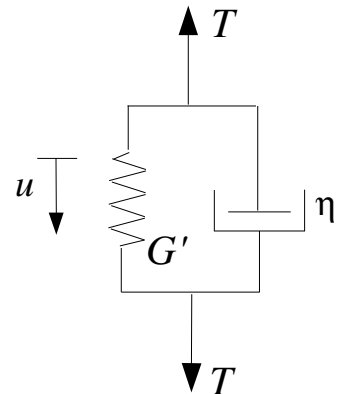

(a)

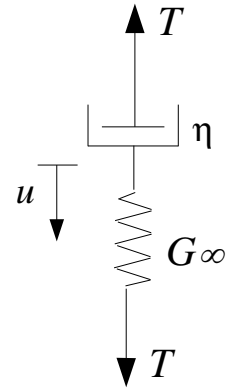

(b)

Figura 3.2. Modelos de (a) Kelvin-Voigt e (b) Maxwell

Para o modelo de Kelvin-Voigt com excitação harmônica $G=G^{\prime}=c$, a relação tensão-deformação fica sendo a expressão dada na equação 3.13 e as expressões obtidas até agora, neste capítulo, nele se baseiam.

A relação tensão-deformação para o modelo de Maxwell é:

$$
\frac{\partial S}{\partial t}=\frac{T}{\eta}+\frac{1}{G_{\infty}} \frac{\partial T}{\partial t}
$$

onde os componentes do módulo de cisalhamento complexo são: 


$$
\begin{aligned}
& G^{\prime}=\frac{G_{\infty} \omega^{2} \tau_{m}^{2}}{1+\omega^{2} \tau_{m}^{2}}, \\
& G^{\prime \prime}=\frac{G_{\infty} \omega \tau_{m}}{1+\omega^{2} \tau_{m}^{2}},
\end{aligned}
$$

onde $\tau_{m}$ é a constante de tempo do meio, ou constante de relaxação de Maxwell:

$$
\tau_{m}=\frac{\eta}{G_{\infty}}
$$

Se a taxa de deformação $(\partial S / \partial t)$ for instantaneamente interrompida, a tensão decairá exponencialmente a zero com a constante de tempo $\tau_{m}$.

A resposta de um meio depende da frequiência da excitação e do tempo de relaxação, que corresponde ao tempo que tardam as moléculas em retornar a sua posição de equilíbrio. Se o período da tensão de cisalhamento é longo comparado com o tempo de relaxação $\left(\omega \tau_{m}<<1\right)$, as moléculas têm tempo suficiente para se acomodar (escoar) e o meio vai ter comportamento inteiramente viscoso. Ao contrário, se o período é pequeno comparado com a constante de tempo $\left(\omega \tau_{m}>>1\right)$, as moléculas não têm tempo para escoar e a energia vai ser armazenada, o que significa comportamento elástico. Finalmente, se o período da tensão é da mesma ordem do tempo de relaxação, o meio tem comportamento viscoelástico (Harrison e Barlow, 1981; Buiochi, 2000).

Define-se a viscosidade dinâmica dependente da freqüência do meio viscoelástico como $\eta_{d}=G^{\prime \prime} / \omega$ (More et al., 1967; Cohen-Tenoudji, 1987). Das Eqs. 3.33 e 3.34, temse:

$$
\eta_{d}=\frac{\eta}{\left(1+\omega^{2} \tau_{m}^{2}\right)}
$$

Das equações. 3.22, 3.18, 3.32 e 3.33, a velocidade de propagação complexa é:

$$
v^{*}=\sqrt{\frac{j \omega \eta}{\rho\left(1+j \omega \tau_{m}\right)}},
$$

mostrando que $v^{*}$ também é dependente da frequiência.

Na figura 3.3 pode-se ver a variação das componentes normalizadas do módulo de 
cisalhamento complexo e a viscosidade em função da freqüência normalizada, para o modelo de Maxwell. Observa-se que a viscosidade de alta freqüência é igual à viscosidade a baixa freqüência para frequiências muito menores que $1 / \tau_{m}$, e depois decresce rapidamente com a freqüência.

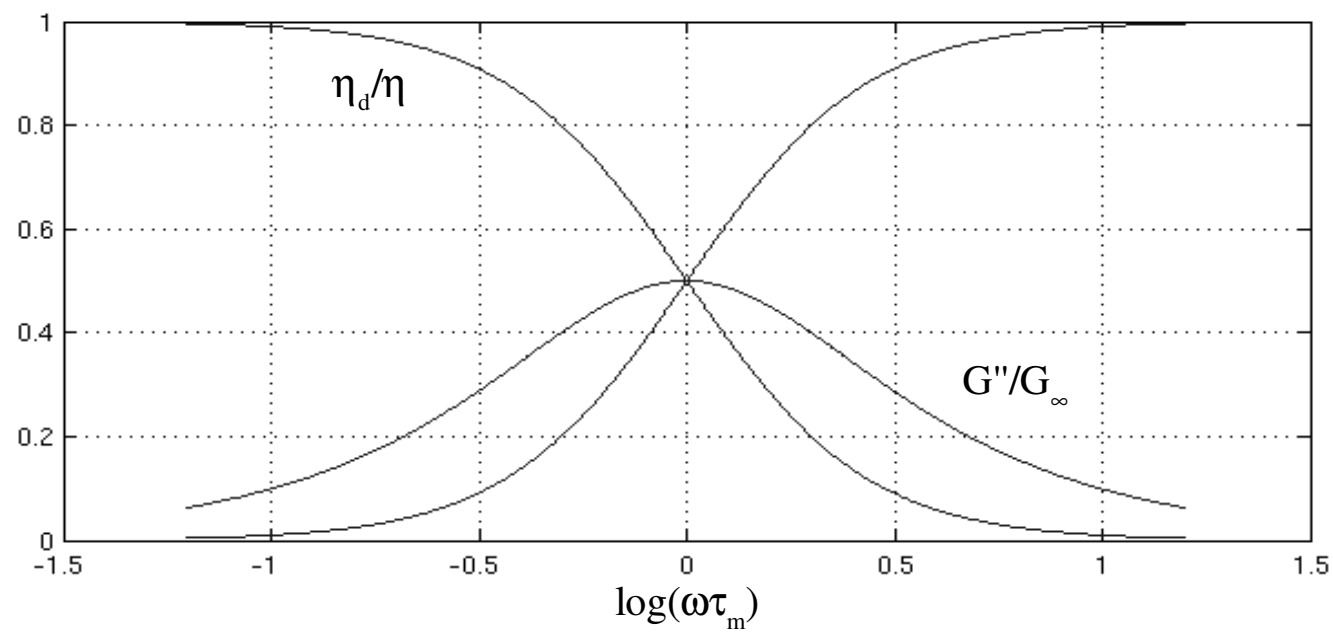

Figura 3.3. Variação do modulo de cisalhamento e a viscosidade normalizados em função da freqüência normalizada para o modelo de Maxwell.

Fazendo uma boa escolha dos parâmetros, os modelos anteriores podem descrever bem o comportamento de muitos materiais em determinadas faixas de freqüência. Existem ainda outros modelos mais sofisticados que usam um maior número de parâmetros, ou seja, um arranjo mais complexo de molas e amortecedores. Eles podem descrever o comportamento de outros tipos de materiais, ou um grupo de materiais, que de outra maneira precisariam de um modelo diferente para cada um, ou seja, modelos mais gerais. Esses modelos, devido à linearidade assumida, são implementados de uma maneira relativamente fácil usando técnicas bem conhecidas de análise de sistemas lineares como, por exemplo, o princípio de superposição.

\subsection{IMPEDÂNCIA ACÚSTICA.}

A impedância acústica $(Z)$, mais formalmente chamada de impedância acústica específica, está definida como:

$$
Z=-\frac{T}{\dot{u}}
$$

onde $\dot{u}$ é a velocidade da partícula $(\dot{u}=\partial u / \partial t)$. A impedância acústica é uma 
característica própria do meio e representa a facilidade que possui em transmitir uma vibração acústica. Para uma onda plana em um meio perfeitamente elástico e propagando-se para frente, a impedância acústica é:

$$
Z=-\frac{T_{F}}{\dot{u}_{F}}=\sqrt{\rho c}=\rho v,
$$

onde o subscrito $F$ indica uma onda propagando-se para frente. $\mathrm{O}$ conceito de impedância acústica é análogo ao conceito de impedância elétrica da teoria eletromagnética.

É importante expressar os resultados obtidos na seção 3.3 em termos da impedância acústica do meio. Então, a partir das equações 3.18 e 3.38 tem-se:

$$
Z=\sqrt{\rho(c+j \omega \eta)}=\sqrt{\rho G^{*}}=\frac{G^{*} \Gamma}{j \omega},
$$

que para um sólido perfeitamente elástico $(\eta=0)$ reduz-se à equação 3.38 e para um líquido perfeitamente viscoso $(c=0)$ fica:

$$
Z=\sqrt{j \omega \rho \eta}=\sqrt{\frac{\omega \rho \eta}{2}}(1+j) .
$$

Por se tratar de uma grandeza complexa, é conveniente escrever a impedância em termos de seus componentes real e imaginário:

$$
Z=R+j X
$$

onde $R$ é chamado resistência acústica e $X$ reatância acústica, então:

$$
\begin{aligned}
& G^{\prime}=\frac{R^{2}-X^{2}}{\rho}, \\
& G^{\prime \prime}=\frac{2 R X}{\rho} .
\end{aligned}
$$




\subsection{REFLEXÃO NA INTERFACE ENTRE DOIS MEIOS}

\subsubsection{Incidência normal}

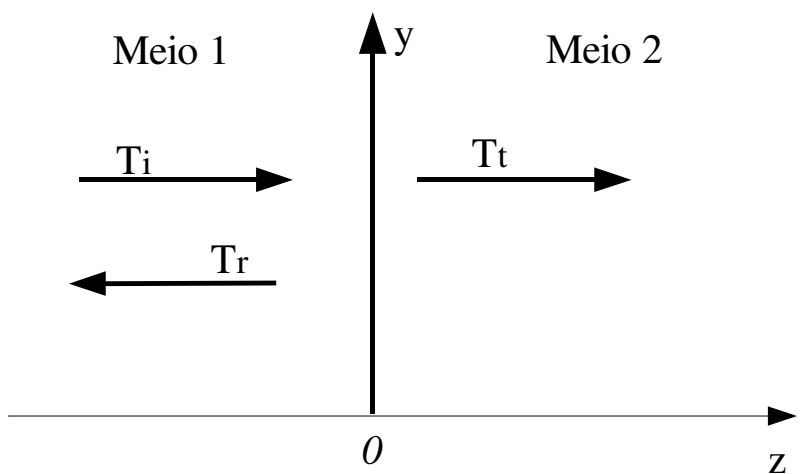

Figura 3.4. Incidência normal de uma onda na interface entre dois meios de impedância acústica diferente localizada em $z=0$.

Resolvendo a equação 3.14 para o caso de um meio semi-infinito, limitado por um meio rígido, pode-se provar que a onda é completamente refletida pela superfície. De forma mais geral, se o meio está limitado por outro meio parcialmente rígido, uma parte da onda é refletida e a outra é transmitida. A amplitude da onda refletida ou transmitida ao outro meio depende das impedâncias acústicas dos dois meios. Como não pode haver descontinuidade na tensão e no deslocamento na interface, conforme a figura 3.4, podese escrever:

$$
\begin{aligned}
& T_{t}=T_{i}-T_{r}, \\
& u_{t}=u_{i}+u_{r},
\end{aligned}
$$

onde os subscritos $i, r$ e $t$ fazem referência à onda incidente, refletida e transmitida, respectivamente. Da equação 3.16 e da definição da deformação, pode-se mostrar que:

$$
T=G^{*} S=G^{*} \frac{\partial u}{\partial z}=T_{0} e^{(j \omega t-\Gamma z)}
$$

onde:

$$
T_{0}=-G^{*} \Gamma u_{0}
$$

e para $z=0: T_{i}=T_{0} e^{j \omega t}$. Escrevendo equação 3.47 para cada onda, substituindo na 
equação 3.45 e eliminando $T_{t}$, tem-se:

$$
\frac{T_{r}}{T_{i}}=\frac{G_{2}^{*} \Gamma_{2}-G_{1}^{*} \Gamma_{1}}{G_{2}^{*} \Gamma_{2}+G_{1}^{*} \Gamma_{1}}=R_{12},
$$

agora eliminando $T_{r}$ tem-se:

$$
\frac{T_{t}}{T_{i}}=\frac{2 G_{2}^{*} \Gamma_{2}}{G_{2}^{*} \Gamma_{2}+G_{1}^{*} \Gamma_{1}}=T_{12},
$$

onde $G_{1}^{*}, \Gamma_{1}$ e $G_{2}^{*}, \Gamma_{2}$ são o módulo de cisalhamento complexo e a constante de propagação complexa para os meios 1 e 2 , respectivamente. $R_{12}$ e $T_{12}$ são os coeficientes de reflexão e transmissão, respectivamente. Usando a equação 3.39, pode-se escrever os coeficientes em termos da impedância característica dos meios:

$$
\begin{aligned}
& R_{12}=\frac{Z_{2}-Z_{1}}{Z_{2}+Z_{1}}, \\
& T_{12}=\frac{2 Z_{2}}{Z_{2}+Z_{1}} .
\end{aligned}
$$

Da equação 3.50, pode-se concluir que se a onda atinge uma interface rígida, ou seja, $Z_{2}=\infty, R_{12}=+1$ e a onda é refletida completamente sem mudança de fase. Entretanto, se a onda atinge o espaço livre (vácuo ou, na prática, o ar), $R_{12}=-1$ e tem-se também reflexão total mas com mudança de fase de $180^{\circ}$. Em geral, $R_{12}$ e $T_{12}$ são complexos. Pode-se escrever a equação 3.50 da seguinte maneira:

$$
Z_{2}=Z_{1} \frac{1+R_{12}}{1-R_{12}}
$$

Assim, fazendo a medição do coeficiente de reflexão e conhecendo a impedância característica do meio 1 é possível achar a impedância do meio 2.

Os resultados obtidos nesta seção são válidos para ambos os tipos de ondas e para qualquer meio. Quando a incidência é normal, as ondas refletidas e transmitidas são do mesmo tipo da onda incidente, por exemplo, se a onda incidente é longitudinal, as ondas refletidas e transmitidas são também longitudinais. No caso das ondas de cisalhamento, o comportamento é igual para a incidência normal. 


\subsubsection{Incidência oblíqua}

$A$ incidência oblíqua de ondas planas na interface entre dois meios é, em geral, um fenômeno complexo que pode envolver conversão de modo, ou seja, a conversão de ondas longitudinais para ondas de cisalhamento ou vice-versa. Segundo Oliner (1969), os problemas de contorno envolvendo ondas elásticas em sólidos são geralmente muito intrincados e de difícil solução.

Nos sólidos é possível ter três tipos de ondas: uma onda longitudinal, também chamada de onda $P$, e dois tipos de ondas de cisalhamento, chamadas de onda $S H$ (horizontal $S$-wave) e onda $S V$ (vertical $S$-wave). Nas ondas de cisalhamento, a velocidade das partículas é perpendicular à direção de propagação e as ondas podem ter diferente polarização. Segundo o gráfico da figura 3.5, a onda $S H$ tem deslocamento das partículas paralelo ao plano de incidência (plano $x y$ ) e a onda $S V$ tem deslocamento das partículas perpendicular ao deslocamento das partículas na onda $S H$, onde $\varphi$ é o ângulo de incidência e $\psi$ o ângulo de refração.

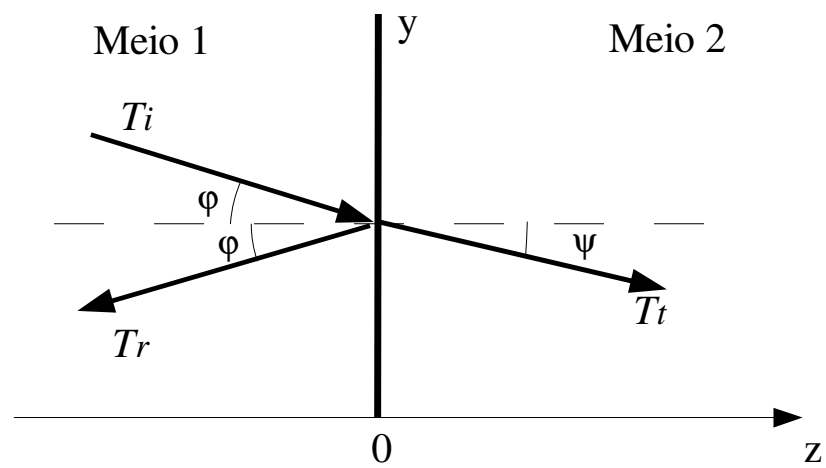

Figura 3.5. Incidência oblíqua de uma onda $S H$ na interface entre dois meios de impedância acústica diferente localizada em $z=0$.

Quando ambos os meios são sólidos e a onda que incide obliquamente é uma onda $P$ ou uma onda $S V$, pode-se ter duas ondas $(P$ e $S V$ ) refratadas e duas ondas $(P$ e $S V)$ refletidas. A geração de um tipo de onda diferente à incidente em uma interface chamase conversão de modo. A conversão de modo ocorre devido às partículas na interface se movimentarem em mais de uma direção, ou seja, podem ter movimento normal e perpendicular à interface. $\mathrm{O}$ movimento normal gera ondas $P$ e o movimento perpendicular gera ondas de cisalhamento. No trabalho de Franco et al. (2005), pode-se achar uma análise mais detalhada do fenômeno, além de um modelo matemático que 
permite calcular os coeficientes de reflexão para uma onda $P$ incidente. Quando a onda incidente é uma onda $S H$, somente tem-se uma onda $S H$ refratada, pois neste caso o deslocamento das partículas na interface tem somente componente perpendicular. $\mathrm{Na}$ medição de viscosidade, somente são usadas ondas $S H$, no caso de incidência oblíqua.

O'Neil (1949) mostrou que o efeito da incidência oblíqua de uma onda $S H$ na interface sólido-líquido, equivale a multiplicar a impedância do meio sólido pelo cosseno do ângulo de incidência $(\cos \varphi)$, e a impedância do meio líquido pelo cosseno do ângulo de refração $(\cos \psi)$. Então, a partir da equação 3.50, pode-se escrever:

$$
R_{12}=\frac{Z_{2} \cos \psi-Z_{1} \cos \varphi}{Z_{2} \cos \psi+Z_{1} \cos \varphi}
$$

e a expressão da impedância para o meio 2 (líquido) fica:

$$
Z_{2}=\frac{\cos \varphi}{\cos \psi}\left[\frac{1+R_{12}}{1-R_{12}}\right] Z_{1} \text {. }
$$

Em geral, as impedâncias acústicas dos meios e o coeficiente de reflexão são quantidades complexas. 


\section{MEDIÇÃO DE VISCOSIDADE PELO MÉTODO DA REFLEXÃO DE ONDAS DE CISALHAMENTO}

As ondas de cisalhamento são tão atenuadas em líquidos, que somente conseguem percorrer distâncias muito pequenas, da ordem de micrômetros, antes de serem completamente absorvidas pelas altíssimas perdas viscosas. Assim, considera-se que essas ondas não se propagam em líquidos. Então, para determinar as propriedades do meio deve-se medir o coeficiente de reflexão complexo quando uma onda de cisalhamento incide na interface entre um sólido e o líquido em teste. Desse modo, pode-se medir a impedância acústica de cisalhamento do fluido, que está relacionada com suas propriedades viscosas e elásticas.

O coeficiente de reflexão complexo é determinado com relação a uma outra reflexão realizada com um fluido de calibração de viscosidade conhecida como, por exemplo, água destilada ou ar. Neste trabalho, é usado ar como fluido de calibração, devido à imensa diferença de impedância que impede que a energia seja transmitida, tendo-se uma reflexão completa, ou seja, um coeficiente de reflexão de cisalhamento igual a um.

\subsection{CONCEITOS TEÓRICOS}

Quando a reflexão é feita com o líquido, uma pequena quantidade da energia da onda é transmitida ao fluido, diminuindo sua amplitude e mudando sua fase. $\mathrm{O}$ coeficiente de reflexão é uma quantidade complexa, dada por uma magnitude $(r)$ e uma fase $(\theta)$. O ângulo representa a variação de fase (desfasagem) da onda refletida pela interface sólido-líquido quando comparada com a onda refletida na interface sólido-ar. Então, o coeficiente de reflexão complexo é (Mason et al., 1948; Moore et al., 1967): 


$$
R_{12}^{*}=r e^{j(\pi-\theta)}=-r e^{-j \theta} .
$$

Usando a identidade de Euler e substituindo na equação 3.52, pode-se calcular a impedância de cisalhamento do líquido a partir da magnitude e da fase medida do coeficiente de reflexão:

$$
Z_{L}^{*}=Z_{S}\left[\frac{1-r^{2}+2 j r \sin \theta}{1+r^{2}+2 r \cos \theta}\right]
$$

onde $Z_{S}$ e $Z_{L}$ representam a impedância acústica de cisalhamento do sólido e do líquido, respectivamente. Devido à atenuação no sólido ser muito pequena comparada com a atenuação no líquido, a impedância acústica no sólido é considerada real e com valor $Z_{S}=\rho_{S} v_{S}$ (Cohen-Tenoudji, 1987; Buiochi, 2000). A resistência acústica e a reatância acústica (Eq. 3.41) podem ser expressas em termos do coeficiente de reflexão:

$$
\begin{aligned}
& R_{L}=Z_{S}\left[\frac{1-r^{2}}{1+r^{2}+2 r \cos \theta}\right], \\
& X_{L}=Z_{S}\left[\frac{2 r \sin \theta}{1+r^{2}+2 r \cos \theta}\right] .
\end{aligned}
$$

Então, as equações 3.42 e 3.43 podem ser usadas para calcular as componentes do módulo de cisalhamento complexo:

$$
\begin{aligned}
& G^{\prime}=\left[\frac{r^{4}-2\left(1+2 \sin ^{2} \theta\right) r^{2}+1}{\left(1+r^{2}+2 r \cos \theta\right)^{2}}\right] \frac{Z_{S}^{2}}{\rho_{L}}, \\
& G^{\prime \prime}=\left[\frac{4 r\left(1-r^{2}\right) \sin \theta}{\left(1+r^{2}+2 r \cos \theta\right)^{2}}\right] \frac{Z_{S}^{2}}{\rho_{L}},
\end{aligned}
$$

onde $\rho_{L}$ é a densidade do líquido. Então, a viscosidade dinâmica na freqüência $\omega / 2 \pi$, definida na seção 3.3, fica (Longin, Verdier e Piau, 1998; Buiochi, 2000):

$$
\eta_{d}=\frac{G^{\prime \prime}}{\omega}=\frac{2 R_{L} X_{L}}{\rho_{L} \omega}=\left[\frac{4 r\left(1-r^{2}\right) \sin \theta}{\left(1+r^{2}+2 r \cos \theta\right)^{2}}\right] \frac{Z_{S}^{2}}{\rho_{L} \omega} .
$$

A equação anterior mostra que é possível medir a viscosidade do líquido (meio 2) se for conhecida a impedância acústica do meio sólido e a densidade do líquido.

Pela natureza do coeficiente de reflexão, sua magnitude sempre vai ter um valor 
entre zero e um $(0 \leq r \leq 1)$ e, devido à definição feita na Eq. 4.1, sua fase, um valor positivo $(\theta>0)$.

\subsection{SIMPLIFICAÇÃO NO CASO DE LÍQUIDO NEWTONIANO}

Se o líquido é Newtoniano, ou seja, tem comportamento perfeitamente viscoso, o módulo de elasticidade $\left(G^{\prime}\right)$ deve ser zero (Sheen, Chien and Raptis, 1990). Conclui-se, a partir da Eq. 3.42, que a resistência e a reatância acústica do meio líquido devem ser iguais $\left(R_{L}=X_{L}\right)$, então:

$$
\eta_{d}=\frac{2 R_{L}^{2}}{\rho_{L} \omega} .
$$

Além disso, como $\theta$ é sempre um ângulo pequeno, $\cos \theta \approx 1$, podendo-se escrever:

$$
\eta_{d}=\frac{2 Z_{S}^{2}}{\rho_{L} \omega}\left[\frac{1-r}{1+r}\right]^{2}
$$

A simplificação anterior é importante porque permite calcular a viscosidade dinâmica a partir somente da magnitude do coeficiente de reflexão. A condição que se deve cumprir para considerar líquido Newtoniano é $\omega \tau_{m} \ll 1$, onde $\tau_{m}$ é o tempo de relaxação de Maxwell definido na seção 3.3. Segundo Barlow (1981), pode-se testar se o líquido está se comportando como Newtoniano fazendo a medição da magnitude e da fase do coeficiente de reflexão e depois calcular a impedância acústica do líquido. Devese cumprir que $R_{L} \approx X_{L}$.

\subsection{DETERMINAÇÃO EXPERIMENTAL DO COEFICIENTE DE REFLEX̃̃O}

O coeficiente de reflexão é determinado comparando-se os sinais refletidos nas interfaces sólido-ar e sólido-líquido, respectivamente, $a_{a r}(t)$ e $a_{l i q}(t)$. Para isso, esses sinais são adquiridos com os mesmos ajustes na taxa de amostragem, no atraso, no número de pontos e na amplificação. Os dispositivos de medição podem usar incidência normal ou oblíqua. Além disso, pode-se usar a primeira reflexão (técnica da reflexão relativa) ou uma das sucessivas reflexões (técnica das múltiplas reflexões). Os métodos apresentados nesta seção para a determinação experimental do coeficiente de reflexão aplicam-se à técnica da reflexão relativa com incidência normal. Neste trabalho, não vai 
ser usada a técnica das múltiplas reflexões.

\subsubsection{Domínio do tempo}

No domínio do tempo, a magnitude do coeficiente de reflexão é obtida normalizando a amplitude do sinal refletido na interface sólido-líquido com relação ao sinal refletido na interface sólido-ar:

$$
r=\frac{a_{l i q}}{a_{a r}}
$$

O valor da fase pode ser obtido usando o valor máximo da função de correlação dos sinais (Adamowski et al., 1995). A função de correlação dos sinais $a_{a r}(t)$ e $a_{l i q}(t)$ é dada por:

$$
R_{a_{a r} a_{\text {liq }}}(\tau)=\int_{-\infty}^{\infty} a_{a r}(t) a_{l i q}(t+\tau) d t
$$

Se os sinais $a_{a r}(t)$ e $a_{\text {liq }}(t)$ são adquiridos com janelas temporais que começam nos tempos $t_{a r}$ e $t_{l i q}$, respectivamente, e a função de correlação (Eq. 4.11) tem máxima amplitude num tempo $\tau_{\max }=t_{m}$, então, o atraso temporal entre os sinais é:

$$
\Delta t=t_{l i q}-t_{a r}+t_{m},
$$

e a diferença de fase é:

$$
\theta=2 \pi f|\Delta t|
$$

onde $f$ é a freqüência central da onda (ponto de maior amplitude no seu espectro de Fourier).

O método do valor máximo da função de correlação tem precisão igual ao período de amostragem dos sinais. Segundo Higuti (2001), essa precisão pode ser melhorada usando a transformada de Hilbert ou a fase do sinal analítico, uma vez que essas funções cruzam pelo zero quando a correlação é máxima e de uma forma linear nas vizinhanças. Isso permite estimar, por meio de interpolação entre as amostras, um valor mais exato do cruzamento pelo zero. O trabalho de Adamowski et al. (1995) mostra que o valor de atraso fornecido pela função de correlação não é afetado pela atenuação. 


\subsubsection{Domínio da freqüência}

Sejam $A_{a r}(f)$ e $A_{\text {liq }}(f)$ as transformadas de Fourier dos sinais $a_{a r}(t)$ e $a_{\text {liq }}(t)$, respectivamente. Então, a magnitude e a fase do coeficiente de reflexão na freqüência $f_{i}$ é dada, respectivamente, por (Cohen-Tenoudji, 1987; Buiochi, 2000):

$$
\begin{aligned}
& r=\frac{\left|A_{\text {liq }}\left(f_{i}\right)\right|}{\left|A_{a r}\left(f_{i}\right)\right|}, \\
& \theta=\left|\phi_{\text {liq }}\left(f_{i}\right)-\phi_{a r}\left(f_{i}\right)\right|,
\end{aligned}
$$

onde $\phi\left(f_{i}\right)$ é a fase dos sinais na freqüência $f_{i}$ dada por:

$$
\phi=\arctan \left[\frac{\mathfrak{I}\left[A\left(f_{i}\right)\right]}{\mathfrak{R}\left[A\left(f_{i}\right)\right]}\right],
$$

onde $\mathfrak{R}$ e $\mathfrak{I}$ são, respectivamente, a parte real e imaginária de um número complexo.

\subsubsection{Considerações sobre a medição do coeficiente de reflexão}

A determinação experimental do coeficiente de reflexão é o passo mais crítico na medição de viscosidade de líquidos por ultra-som, já que as variações das quantidades mesuráveis que devem ser detectadas são muito pequenas. Por exemplo, o óleo automotivo SAE40 com viscosidade a baixa freqüência de aproximadamente 0,2Pa.s a $20^{\circ} \mathrm{C}$ apresenta uma redução na amplitude da onda de $2,7 \%$ e uma mudança de fase de $2,0^{\circ}$ quando se comparam os sinais de $1 \mathrm{MHz}$ refletidos nas interfaces acrílico-óleo e acrílico-ar. Essas pequenas diferenças são facilmente afetadas por fatores externos, como ruído nos sinais, variação da temperatura e instabilidade na eletrônica, além de imperfeições na fabricação do dispositivo de medição (paralelismo, dimensões laterais pequenas, camadas de cola, etc.), que levam a ecos espúrios e incidência das ondas na interface com ângulo errado. A difração das ondas também induz a erros na medição, devendo ser reduzida ao máximo, principalmente, através da diminuição da distância percorrida pela onda.

A medição da magnitude do coeficiente é relativamente fácil. Os sistemas de aquisição de dados atuais apresentam resolução suficiente e, além disso, as propriedades dos meios que afetam a amplitude das ondas, principalmente a atenuação, variam pouco na faixa definida pela precisão no controle da temperatura. Já no caso da fase, a medição 
torna-se difícil, além das altas taxas de amostragem necessárias, a velocidade de propagação das ondas muda rapidamente com a temperatura. No caso da taxa de amostragem, se a resolução máxima na medição da fase é igual a um período de amostragem, por exemplo, com freqüência da onda de $1 \mathrm{MHz}$, para ter precisão na medição da fase de 1/10 de grau, precisa-se de uma freqüência de amostragem de 3,6 GHz. Contudo, como foi discutido na seção 4.3.1, usando a técnica da transformada de Hilbert é possível ter resoluções melhores do que um período de amostragem. Com relação à temperatura, dependendo do dispositivo usado, pode-se ter uma variação de vários graus na fase para uma mudança na temperatura de alguns décimos de grau Célsius. Então, levando em conta que as variações de fase devido à presença do líquido são de uns poucos graus, a estabilidade térmica é fundamental para a medição da fase e constitui a maior limitação na hora de usar o método fora do ambiente controlado do laboratório.

\subsubsection{Normalização}

A normalização do sinal refletido na interface de medição, com relação ao sinal refletido por uma outra interface (referência), definida pela descontinuidade no material sólido da linha de retardo, permite reduzir os efeitos indesejados ocasionados por fatores externos como a variação da temperatura e instabilidade da eletrônica, ou os erros devidos à difração das ondas (Cohen-Tenoudji et al. 1987; Shah e Balasubramaniam, 2000). Na figura 4.1 tem-se uma montagem com dois sólidos e duas interfaces: a interface de referência e a interface de medição. A interface de referência fornece uma referência constante para cada uma das medições (ar e líquido), permitindo compensar as diferenças na velocidade das ondas que se propagam entre o transdutor e a interface de referência entre as duas medições.

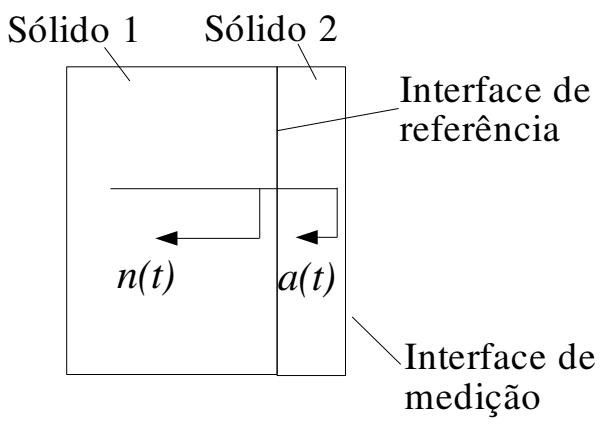

Figura 4.1. Princípio de normalização. 
Assim, pode-se calcular no domínio do tempo a magnitude do coeficiente de reflexão:

$$
r=\frac{a_{l i q} / n_{l i q}}{a_{a r} / n_{a r}},
$$

onde $n_{a r}$ e $n_{l i q}$ são os sinais de referência quando a medição foi feita com a amostra de ar e com a amostra líquida, respectivamente. No domínio da freqüência a magnitude do coeficiente de reflexão é dada por:

$$
r=\frac{\left|A_{\text {liq }}\left(f_{i}\right)\right|}{\left|A_{a r}\left(f_{i}\right)\right|} \frac{\left|N_{a r}\left(f_{i}\right)\right|}{\left|N_{l i q}\left(f_{i}\right)\right|},
$$

onde $N_{a r}$ e $N_{l i q}$ são as transformadas de Fourier dos sinais $n_{a r}$ e $n_{l i q}$, respectivamente.

O cálculo da fase no domínio do tempo é feito por meio das diferenças de tempo entre os sinais e seus respectivos sinais de referência, como mostrado a seguir:

$$
\theta=2 \pi f\left(\Delta t_{l i q}-\Delta t_{a r}\right) \text {, }
$$

onde $\Delta t_{l i q}$ é a diferença de tempo entre os sinais $a_{l i q}$ e $n_{l i q}$, e $\Delta t_{a r}$ é a diferença de tempo entre os sinais $a_{a r}$ e $n_{a r}$. No domínio da freqüência, tem-se:

$$
\theta=\left|\phi_{\text {liq }}\left(f_{i}\right)-\psi_{\text {liq }}\left(f_{i}\right)-\phi_{\text {ar }}\left(f_{i}\right)+\psi_{\text {ar }}\left(f_{i}\right)\right|,
$$

onde $\psi\left(f_{i}\right)$ é a fase do sinal de referência, $\phi\left(f_{i}\right)$ é a fase do sinal refletido na interface de medição e $f_{i}$ é a freqüência de análise.

\subsection{PARÂMETROS QUE AFETAM A MEDIÇÃo}

Existem vários parâmetros que afetam a medição, no caso de incidência normal os mais importantes são: impedância acústica do material sólido, densidade do líquido e frequiência de operação. Nesta seção, foi usado o modelo de líquido Newtoniano $\left(G^{\prime}=0\right)$ para analisar a influência dos parâmetros mencionados, usando as equações 3.40 e 3.50 para simular o comportamento do coeficiente de reflexão.

Foram usados acrílico $\left(\rho=1178 \mathrm{~kg} / \mathrm{m}^{3}\right.$ e $\left.v_{s}=1323 \mathrm{~m} / \mathrm{s}\right)$ e alumínio $\left(\rho=2700 \mathrm{~kg} / \mathrm{m}^{3}\right.$ e $v_{s}=3040 \mathrm{~m} / \mathrm{s}$ ) como meios sólidos. 


\subsubsection{Influência do sólido na medição}

A escolha do material sólido é fundamental neste método de medição. A comparação entre as medições feitas com ar e com amostra líquida é dependente do casamento de impedância entre os meios. A sensibilidade do método às mudanças de viscosidade aumenta à medida que a diferença de impedância entre os meios sólido e líquido diminui (Shah e Balasubramaniam, 1996).

a)

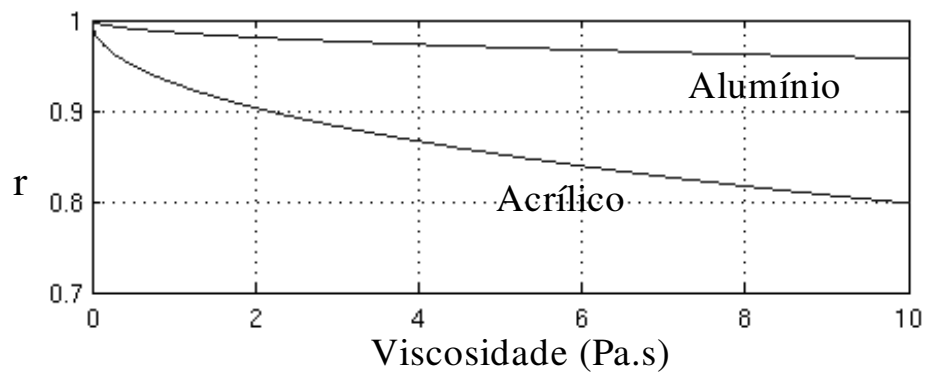

b)

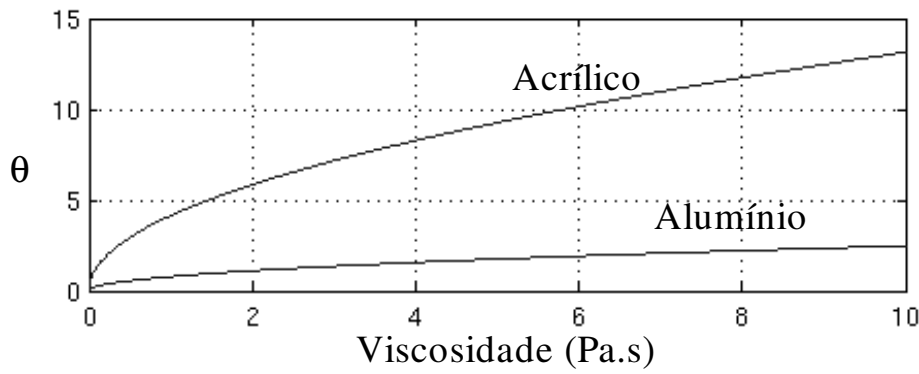

Figura 4.2. Efeito dos materiais sólidos acrílico e alumínio sobre o coeficiente de reflexão (modelo de líquido Newtoniano): a) magnitude e b) fase em graus.

Na figura 4.2 é mostrado o comportamento do coeficiente de reflexão, na faixa de viscosidade de 0 a 10Pa.s, utilizando dois materiais sólidos: acrílico e alumínio. Foi usado um líquido com densidade igual a $1000 \mathrm{~kg} / \mathrm{m}^{3}$ e uma freqüência de operação de $1 M H z$. A inclinação das curvas de magnitude e fase do coeficiente de reflexão controlam a sensibilidade da medição, devido a uma variação maior no coeficiente de reflexão para uma mesma variação na viscosidade. Pode-se ver que o acrílico tem melhor casamento da impedância com o líquido, apresenta-se uma maior inclinação nas curvas da magnitude e da fase do coeficiente, ou seja, apresenta uma melhor sensibilidade na medição.

$\mathrm{Na}$ figura 4.3 apresenta-se a mesma simulação da figura 4.2, porém para uma faixa de viscosidade entre 0 e 3000Pa.s. Pode-se ver que a curva da magnitude do coeficiente apresenta um valor mínimo de 0,4142 , depois desse valor começa a aumentar novamente, tendendo a 1 quando a viscosidade tende ao infinito. Já a fase, é sempre 
crescente e vai se aproximando, assintoticamente, a $180^{\circ}$ quando a viscosidade tende ao infinito. Também pode-se ver na figura 4.3(a) que a posição do mínimo é fortemente dependente do casamento de impedâncias, acontecendo a uma viscosidade muito menor para o caso do acrílico. Esse valor mínimo também é dependente da frequiência e fica a uma viscosidade menor quando a freqüência de operação aumenta.

a)

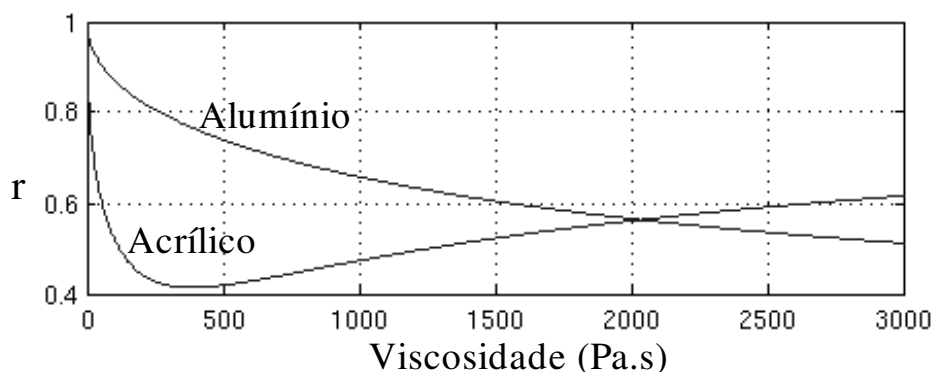

b)

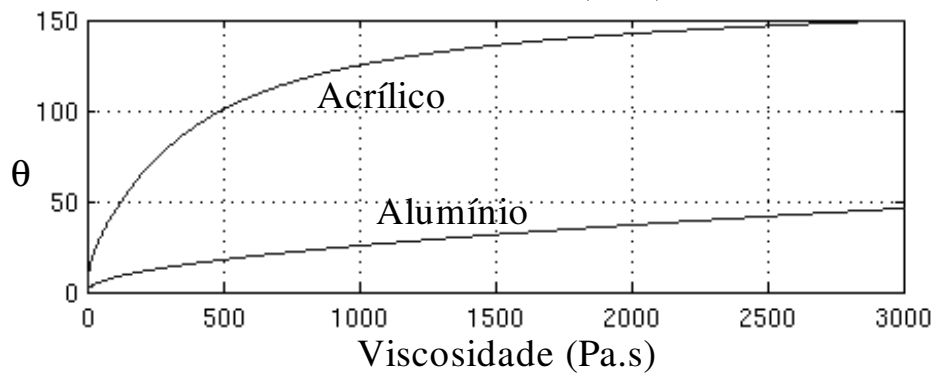

Figura 4.3. Efeito do material sólido sobre o coeficiente de reflexão (modelo de líquido Newtoniano): a) magnitude e b) fase em graus.

Realmente, esse valor mínimo é somente teórico, na prática não acontece (Sheen, Chien e Raftis, 1990), dado que a suposição de líquido Newtoniano é válida, somente, até um valor relativamente pequeno da viscosidade. Neste trabalho é mostrado que, por exemplo, no caso dos óleos automotivos com uma viscosidade maior a 1 Pa.s, utilizando uma freqüência de operação de $1 \mathrm{MHz}$, o comportamento do líquido é, predominantemente, não Newtoniano. Além disso, já foi verificado experimentalmente por Sheen et al. (1996) que a magnitude medida pode ser menor que 0,4142 para líquidos altamente viscosos.

\subsubsection{Influência da densidade do líquido na medição}

Na figura 4.4, pode-se ver como varia o coeficiente de reflexão, na faixa entre 0 e 5Pa.s, considerando um líquido com densidade igual a $800 \mathrm{~kg} / \mathrm{m}^{3}$ e outro igual a $1000 \mathrm{~kg} / \mathrm{m}^{3}$, e o acrílico como meio sólido. A frequiência de operação adotada foi $1 \mathrm{MHz}$. Verifica-se que ao aumentar a densidade do líquido, aumenta a inclinação das curvas de 
magnitude e fase do coeficiente de reflexão, ou seja, um aumento da sensibilidade. Esse resultado é razoável, levando em conta que ao aumentar a densidade do líquido aumenta a sua impedância acústica e, como o sólido sempre vai ter maior impedância que o líquido, tem-se um melhor casamento.

a)

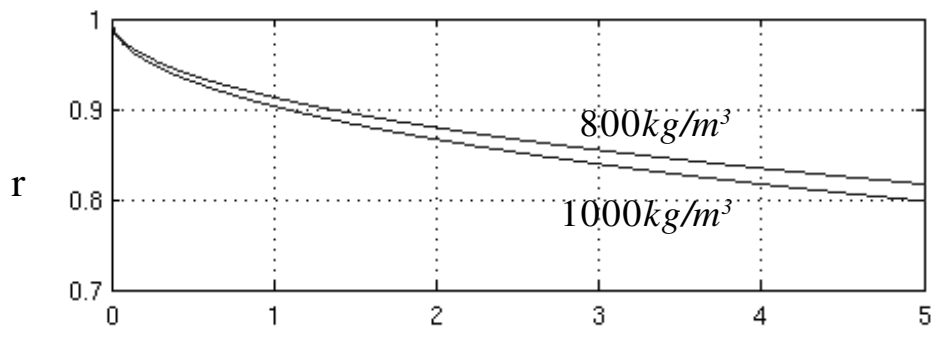

b)

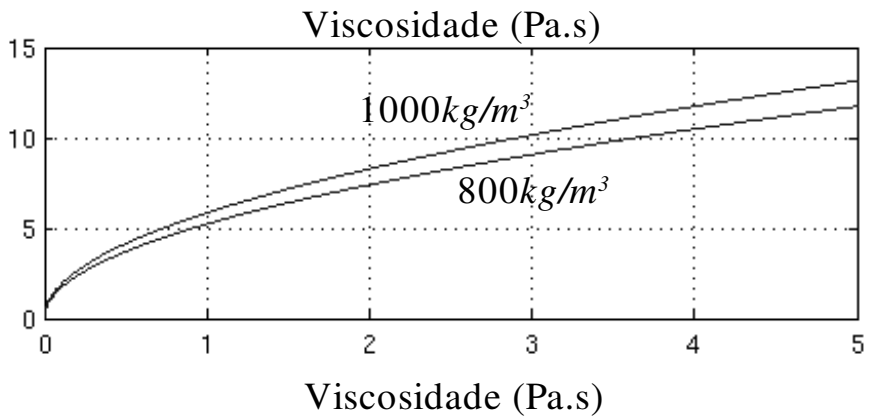

Figura 4.4. Efeito da densidade do líquido sobre o coeficiente de reflexão (modelo de líquido Newtoniano): a) magnitude e b) fase em graus.

\subsubsection{Influência da frequiência na medição}

Na figura 4.5 é mostrada a simulação do coeficiente de reflexão, segundo o modelo de líquido Newtoiano, para um líquido de densidade $1000 \mathrm{~kg} / \mathrm{m}^{3}$ na faixa entre 0 e 5Pa.s e acrílico como meio sólido, utilizando três frequiências de operação: $0,5,1$ e 3,5MHz. Pode-se ver um aumento da sensibilidade com a freqüência.

A escolha da frequiência de operação é um fator fundamental na medição de viscosidade por ultra-som, além de influir na sensibilidade, limita a faixa de viscosidade na qual o líquido comporta-se como líquido Newtoniano. Como foi visto na seção 3.3, deve-se cumprir que a taxa de cisalhamento seja muito menor que a constante de tempo $\left(\tau_{m}\right)$ para ter comportamento Newtoniano. 
a)

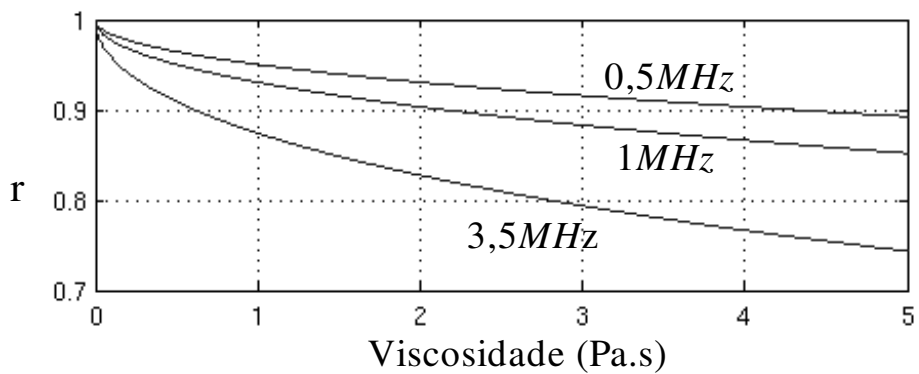

b)

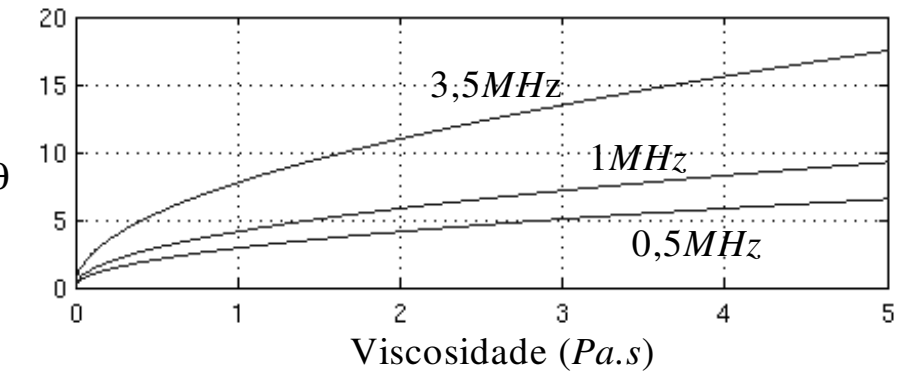

Figura 4.5. Efeito da freqüência de operação sobre o coeficiente de reflexão (modelo de líquido Newtoniano): a) magnitude e b) fase em graus.

\subsection{COMPARAÇÃO ENTRE O MODELO NEWTONIANO E O MODELO DE MAXWELL NA PREDIÇÃO DO COEFICIENTE DE REFLEXÃO}

Nesta seção, é feita uma comparação entre os valores simulados do coeficiente de reflexão obtidos usando os modelos de líquido Newtoniano e de Maxwell. Foi usado un líquido com densidade de $1000 \mathrm{~kg} / \mathrm{m}^{3}$, acrílico como meio sólido e frequiência de $1 \mathrm{MHz}$. No modelo de Maxwell foram usados três valores diferentes de $G_{\infty}: 1.10^{8}, 2.10^{9} \mathrm{e}$ $1.10^{11} \mathrm{~Pa}$.

a)

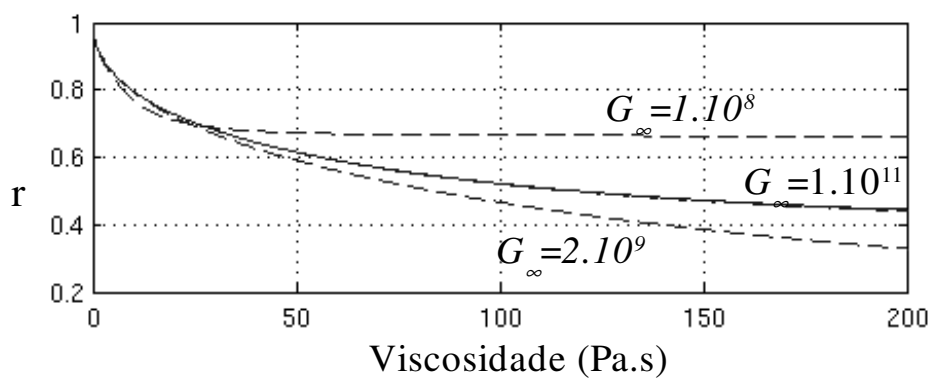

b)

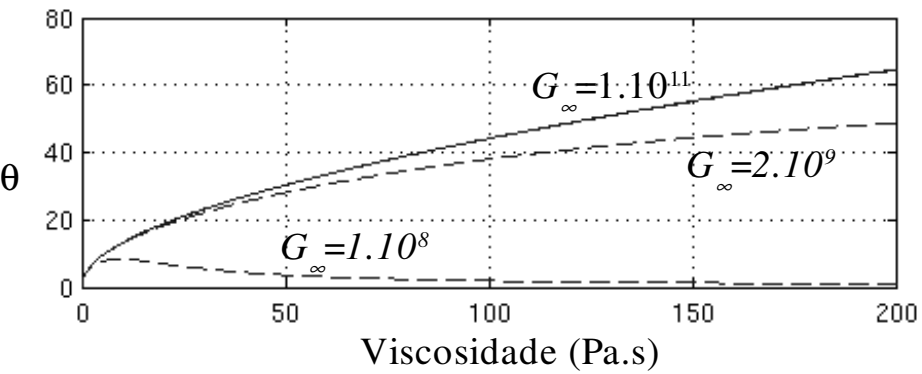

Figura 4.6. Simulação do coeficiente de reflexão, na faixa de viscosidade entre 0 e 200Pa.s, usando o modelo de líquido Newtoniano (linha sólida) e o modelo de Maxwell (linha tracejada) para vários valores de $G_{\infty}$ a) magnitude e b) fase em graus. 
A figura 4.6 mostra os resultados da simulação para a faixa de viscosidade entre 0 e 200Pa.s. Como é esperado, aumentando o valor de $G_{\infty}$, o modelo de Maxwell aproxima-se ao modelo de líquido Newtoniano, já que a constante de tempo de Maxwell do líquido $\left(\tau_{m}\right)$ diminui (equação 3.34 ). Pode-se ver que no caso de $G_{\infty}=1.10^{11} P a$, as curvas da magnitude e da fase do coeficiente de reflexão para o modelo de Maxwell ficam sobrepostas às curvas para o modelo de líquido Newtoniano.

a)

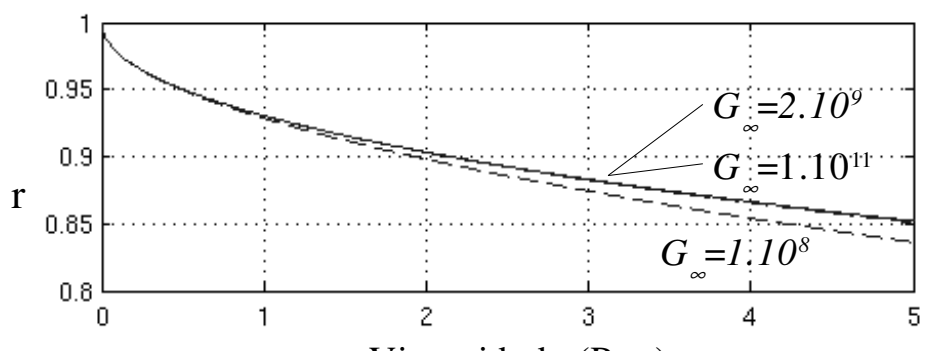

b)

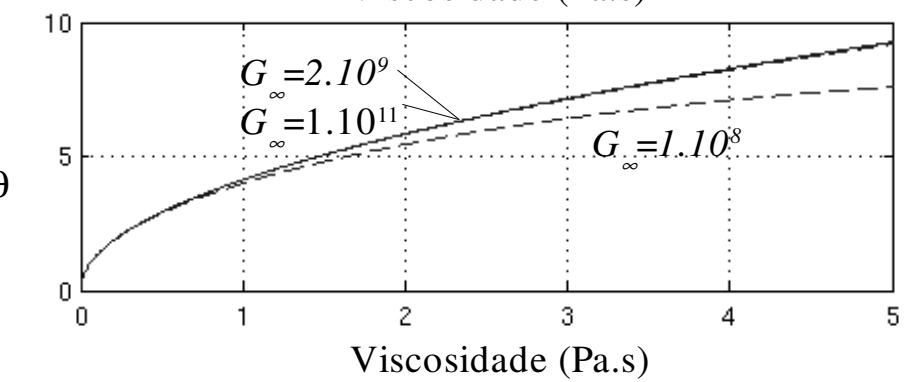

Figura 4.7. Simulação do coeficiente de reflexão, na faixa de viscosidade entre 0 e $5 P a . s$, usando o modelo de líquido Newtoniano (linha sólida) e o modelo de Maxwell (linha tracejada) para vários valores de $G_{\infty}$ : a) magnitude e b) fase em graus.

$\mathrm{Na}$ figura 4.7, pode ver a mesma simulação da figura 4.6 para uma faixa de viscosidade entre 0 e 5Pa.s. Para essa faixa de viscosidade, somente as curvas de $G_{\infty}$ $=1.10^{8} \mathrm{~Pa}$ são diferentes das curvas do modelo de líquido Newtoniano.

Nas figuras 4.8 e 4.9, são mostrados os resultados da simulação, em função da freqüência, do coeficiente de reflexão para dois líquidos de viscosidade 1 e 10Pa.s, respectivamente. Como esperado, a diferença entre os modelos de líquido Newtoniano e de Maxwell é maior para freqüências mais altas.

$\mathrm{Na}$ parte experimental deste trabalho, foram usados líquidos com viscosidade menor que 20Pa.s e densidade que varia entre 850 e $1200 \mathrm{~kg} / \mathrm{m}^{3}$ e as freqüências de operação foram: $0,5,1,2,25,3,5$ e $5 \mathrm{MHz}$. Vai-se mostrar que os líquidos menos viscosos têm comportamento Newtoniano nessas freqüências de operação. Já para os líquidos mais viscosos, o comportamento é viscoelástico, que pode ser descrito 
qualitativamente pelo modelo de Maxwell.

a)

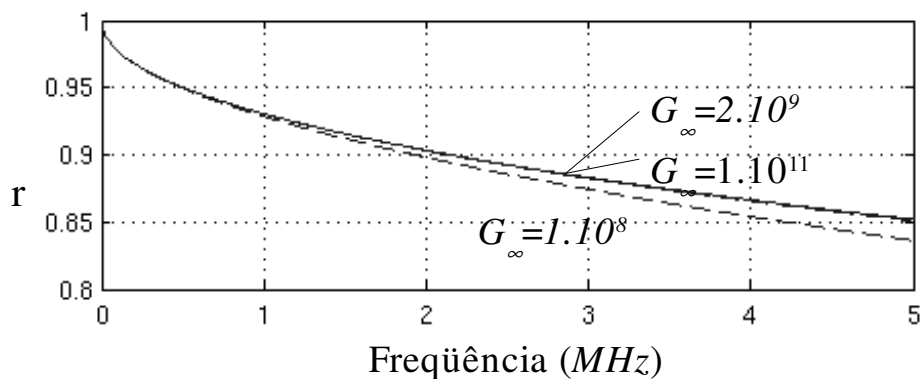

b)

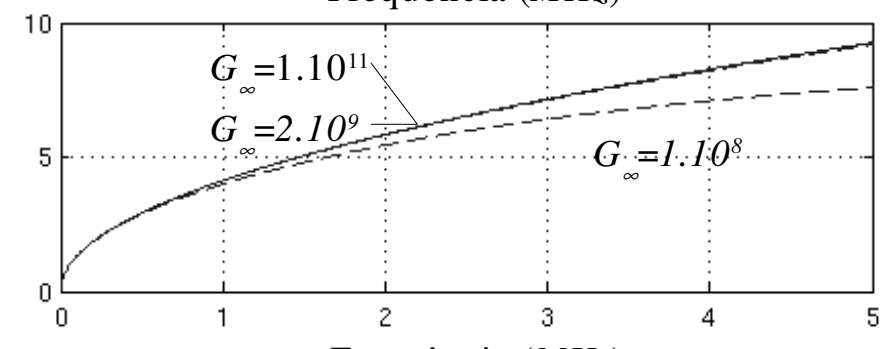

Freqüência $(\mathrm{MHz})$

Figura 4.8. Simulação do coeficiente de reflexão, em função da frequiência, para um líquido com viscosidade de 1 Pa.s, usando o modelo de líquido Newtoniano (linha sólida) e o modelo de

Maxwell (linha tracejada) para vários valores de $G_{\infty}$ : a) magnitude e b) fase em graus.

a)

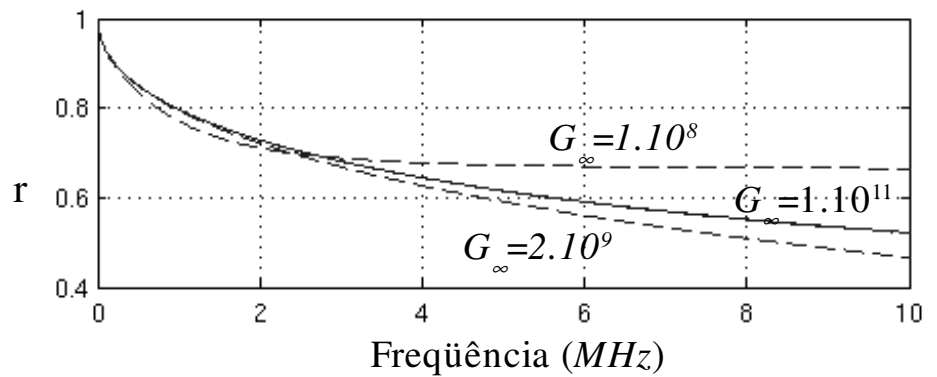

b)

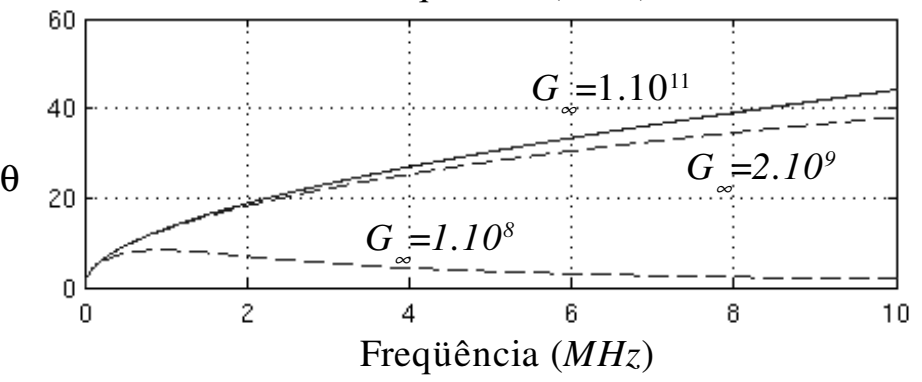

Figura 4.9. Simulação do coeficiente de reflexão, em função da freqüência, para um líquido com viscosidade de 10Pa.s, usando o modelo de líquido Newtoniano (linha sólida) e o modelo de Maxwell (linha tracejada) para vários valores de $G_{\infty}$ : a) magnitude e b) fase em graus. 


\section{MODELAGEM MATRICIAL DE TRANSDUTORES ULTRA- SÔNICOS}

Os transdutores de ultra-som são dispositivos eletromecânicos que convertem energia elétrica em energia mecânica e vice-versa, sendo os transdutores piezelétricos os mais utilizados. Podem ser utilizados em diversas aplicações, tais como caracterização de líquidos, ensaios não destrutivos, imagens médicas, limpeza de peças, etc. Neste capítulo são apresentados uma breve descrição de um transdutor básico e do fenômeno da piezeletricidade. Depois, é apresentado mais a fundo o tema da modelagem de transdutores usando um modelo matricial.

\subsection{CARACTERÍSTICAS BÁSICAS DE UM TRANSDUTOR DE ULTRA-SOM}

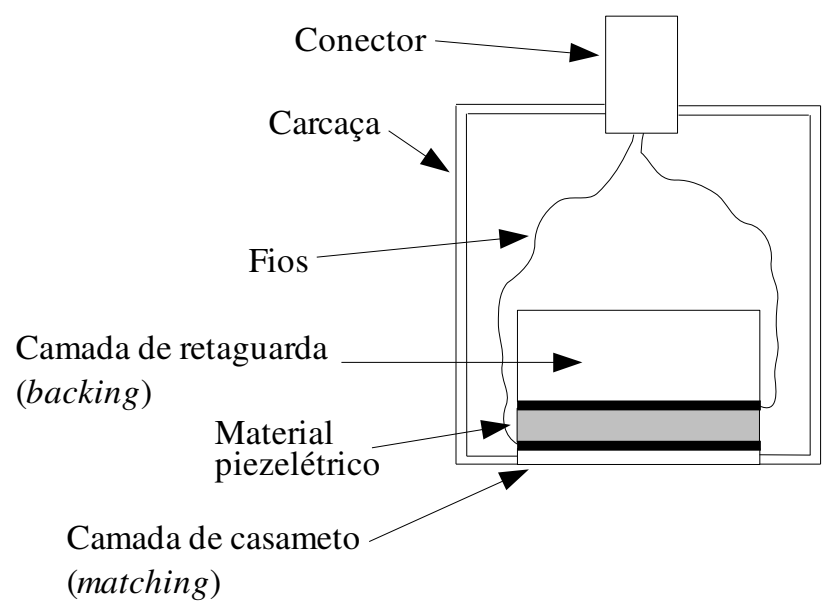

Figura 5.1. Esquema básico de um transdutor de ultra-som

Basicamente um transdutor de ultra-som consiste de um material piezelétrico (material ativo) em forma de disco, anel, paralelepípedo, etc., com duas faces metalizadas, onde são soldados os contatos elétricos, formando um capacitor de placas paralelas. Além disso, pode-se ter uma ou várias camadas de outro material não 
piezelétrico (material passivo), as camadas de acoplamento ou matching e as camadas de retaguarda ou backing. A figura 5.1 apresenta um esquema de montagem de um transdutor piezelétrico.

A função principal da camada de acoplamento é adaptar as impedâncias acústicas do meio e do material piezelétrico para conseguir a máxima transferência de energia. A espessura dessa camada é normalmente igual a um quarto do comprimento da onda nesse material. Em algumas aplicações é preciso ter uma camada mais espessa ou camadas adicionais, chamadas de linha de retardo, cuja função é, geralmente, evitar a sobreposição dos ecos no tempo. A camada de retaguarda é importante para determinar a resposta em freqüência do transdutor, pois define o amortecimento do material piezelétrico. Se a resposta do transdutor apresenta muitos ciclos de senóide, tem-se uma função de transferência que maximiza a amplitude na freqüência central do sinal e decai rapidamente fora desta freqüência, então, fala-se de um transdutor de banda estreita. Entretanto, se a resposta do transdutor apresenta poucos ciclos de senóide, tem-se uma função de transferência que inclui uma maior faixa de frequiência e, então, fala-se de um transdutor de banda larga. Os transdutores de banda estreita são usados principalmente como ressonadores para aplicações de potência e os de banda larga para ensaios não destrutivos e imagens ultra-sônicas, entre outras aplicações.

As características mais importantes de todo transdutor são sua frequiência de ressonância, a geometria da superfície que irradia as ondas e o tipo de onda que emite e/ou recebe. Os transdutores mais comuns são do tipo pistão plano para ondas longitudinais ou de cisalhamento e podem ser encontrados na faixa de centenas de $\mathrm{kHz}$ até dezenas de $\mathrm{MHz}$.

\subsection{MATERIAIS PIEZELÉTRICOS}

A piezeletricidade é a habilidade que possuem alguns materiais de gerar uma tensão elétrica em resposta a uma tensão mecânica aplicada. O efeito é reversível, visto que ao aplicar uma tensão elétrica externa nesses materiais, aparece uma pequena deformação. Embora essas deformações sejam muito pequenas, geralmente da ordem de nanômetros, foram achadas muitas aplicações para os materiais piezelétricos: geração e detecção de ondas acústicas, geração de altas voltagens, ressonadores para circuitos eletrônicos, focalização fina em equipamentos óticos etc. A piezeletricidade foi predita e 
provada experimentalmente no ano 1880 pelos irmãos Pierre e Jacques Curie em cristais de quartzo, topázio, turmalina e Rochelle Salt (sodium potassium tartrate tetrahydrate), onde o quartzo e o Rochelle Salt foram os cristais que apresentaram maior piezeletricidade. A meados do século XX, foram descobertas cerâmicas piezelétricas, como o PZT (zirconato titanato de chumbo), que é atualmente o material piezelétrico mais amplamente usado.

Desprezando efeitos magnéticos e de variações da entropia, o fenômeno da piezeletricidade pode ser representado de forma simplificada por (Eiras, 2004):

$$
\begin{aligned}
& T_{i}=c_{i j}^{E} S_{j}-e_{m i} E_{m}, \\
& D_{m}=e_{i m} S_{i}+\epsilon_{m n}^{S} E_{m} .
\end{aligned}
$$

Para $i, j=1,2, \ldots, 6$ e $m, n=1,2,3$. Onde:

$\begin{array}{ll}S_{j}- & \text { Vetor das deformações } \\ T_{i}- & \text { Vetor das tensões mecânicas } \\ \mathrm{c}_{\mathrm{ij}}- & \text { Matriz de constantes elásticas } \\ \epsilon_{i j}- & \text { Matriz de constantes de permissividade elétrica } \\ e_{i j}- & \text { Matriz de coeficientes piezelétricos } \\ D_{m}- & \text { Vetor do deslocamento elétrico } \\ E_{m}- & \text { Vetor do campo elétrico }\end{array}$

Os superescritos $E$ e $S$ significam que as propriedades do material são medidas a campo elétrico e deformação constantes, respectivamente. Existem formas alternativas para as equações 5.1 e 5.2, dependendo de quais variáveis são escolhidas como independentes e dependentes.

As equações 5.1 e 5.2 devem ser particularizadas para cada tipo de material piezelétrico. Por exemplo, uma cerâmica de PZT polarizada na direção do eixo 3 tem simetria $6 m m$ e as relações ficam (Auld, 1990):

$$
\left|\begin{array}{l}
T_{1} \\
T_{2} \\
T_{3} \\
T_{4} \\
T_{5} \\
T_{6}
\end{array}\right|=\left[\begin{array}{cccccc}
c_{11}^{E} & c_{12}^{E} & c_{13}^{E} & 0 & 0 & 0 \\
c_{12}^{E} & c_{11}^{E} & c_{13}^{E} & 0 & 0 & 0 \\
c_{13}^{E} & c_{13}^{E} & c_{33}^{E} & 0 & 0 & 0 \\
0 & 0 & 0 & c_{44}^{E} & 0 & 0 \\
0 & 0 & 0 & 0 & c_{44}^{E} & 0 \\
0 & 0 & 0 & 0 & 0 & \frac{c_{11}^{E}-c_{12}^{E}}{2}
\end{array} \mid\left(\begin{array}{l}
S_{1} \\
S_{2} \\
S_{3} \\
S_{4} \\
S_{5} \\
S_{6}
\end{array}\right)-\left[\begin{array}{ccc}
0 & 0 & e_{31} \\
0 & 0 & e_{31} \\
0 & 0 & e_{33} \\
0 & e_{15} & 0 \\
e_{15} & 0 & 0 \\
0 & 0 & 0
\end{array}\right]\left(\begin{array}{l}
E_{1} \\
E_{2} \\
E_{3}
\end{array}\right),\right.
$$




$$
\left(\begin{array}{l}
D_{1} \\
D_{2} \\
D_{3}
\end{array}\right)=\left[\begin{array}{cccccc}
0 & 0 & 0 & 0 & e_{15} & 0 \\
0 & 0 & 0 & e_{15} & 0 & 0 \\
e_{31} & e_{31} & e_{33} & 0 & 0 & 0
\end{array}\right]\left(\begin{array}{l}
S_{1} \\
S_{2} \\
S_{3} \\
S_{4} \\
S_{5} \\
S_{6}
\end{array}\right)+\left[\begin{array}{ccc}
\epsilon_{11}^{S} & 0 & 0 \\
0 & \epsilon_{11}^{S} & 0 \\
0 & 0 & \epsilon_{33}^{S}
\end{array}\right)\left(\begin{array}{l}
E_{1} \\
E_{2} \\
E_{3}
\end{array}\right) .
$$

Geralmente, as equações anteriores ficam mais simplificadas se o campo elétrico é aplicado à cerâmica em somente uma direção. Além disso, fazendo uma escolha adequada da geometria, pode-se, com boa aproximação, supor uma ou mais tensões iguais a zero.

\subsection{MODELO MATRICIAL PARA TRANSDUTORES DE MÚLTIPLOS ELEMENTOS}

Neste trabalho, é usado o modelo matricial apresentado por Lamberti et al. (1987) para a modelagem dos dispositivos de medição. Um transdutor multielemento é composto de várias camadas ativas e passivas que podem ser modeladas como linhas de transmissão acústicas ou eletroacústicas, resultando num modelo unidimensional que pode ser implementado usando somente operações matriciais.

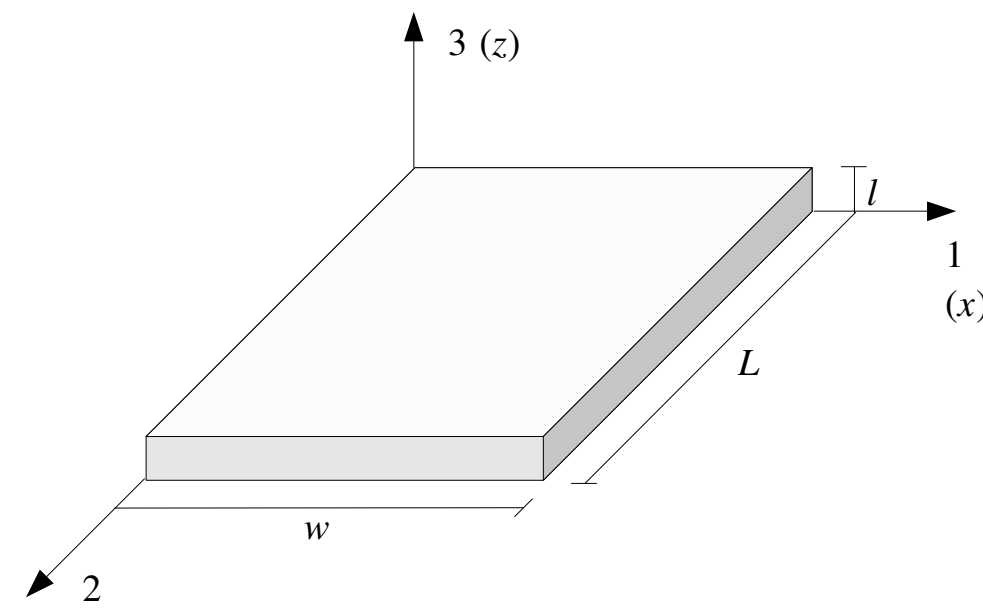

$(x)$

(y)

Figura 5.2. Geometria usada no desenvolvimento do modelo.

O modelo é desenvolvido particularizando as equações 5.3 e 5.4 para a geometria mostrada na figura 5.2, sendo possível fazer as seguintes aproximações: como $L$ e $w$ são muito maiores que $l(L, w \gg l)$ então $S_{l}=S_{2} \approx 0$. Além disso, como a cerâmica é 
polarizada na direção 3 e o campo elétrico é aplicado somente nessa direção (as faces paralelas ao plano $x y$ são mentalizadas), então $D_{l}=D_{2}=0$ e $E_{l}=E_{2}=0$. São consideradas nulas as tensões de cisalhamento, $T_{4}=T_{5}=T_{6} \approx 0$, e os deslocamentos de cisalhamento, $S_{4}=S_{5}=S_{6} \approx 0$. Essas hipóteses implicam em um modelo unidimensional do material piezelétrico que é representado pelas seguintes equações:

$$
\begin{aligned}
& T_{3}=c_{33}^{E} S_{3}-e_{33} E_{3}, \\
& D_{3}=e_{33} S_{3}+\epsilon_{33}^{S} E_{3} .
\end{aligned}
$$

Como o campo elétrico é constante na direção 3, devido às faces metalizadas formarem um capacitor de placas paralelas, a partir da lei de Gauss pode-se concluir que:

$$
\frac{\partial D_{3}}{\partial z}=0
$$

Agora, como $S_{3}=\partial u_{3} / \partial z$, utilizando as equações 5.5, 5.6 e 5.7 e aplicando a segunda lei de Newton a um volume elementar de material, pode-se achar a equação da onda que governa o movimento da cerâmica na direção 3:

$$
\frac{\partial^{2} u_{3}}{\partial t^{2}}=\left(V_{A}^{D}\right)^{2} \frac{\partial^{2} u_{3}}{\partial z^{2}}
$$

onde $u_{3}$ é o deslocamento na direção $3, V_{A}^{D}$ é a velocidade de propagação da onda no material piezelétrico, dada por:

$$
V_{A}^{D}=\sqrt{\frac{c_{33}^{E}}{\rho}\left[1+\frac{\left(e_{33}\right)^{2}}{\epsilon_{33}^{S} c_{33}^{E}}\right]}
$$

e $\rho$ é a densidade do material.

Pode-se mostrar que a seguinte relação satisfaz a equação de onda (equação 5.8):

$$
u_{3}=\left[A \sin \left(\frac{\omega z}{V_{A}^{D}}\right)+B \cos \left(\frac{\omega z}{V_{A}^{D}}\right)\right] e^{j \omega t},
$$

então, a equação 5.10 é a solução geral, onde as constante $A$ e $B$ devem ser obtidas para as condições de contorno desejadas. 


\subsubsection{Solução 1: cerâmica vibrando sem troca de energia com o meio externo}

Quando a cerâmica vibra sem troca de energia, ou seja, está imersa no vácuo, a força exercida sobre as faces da cerâmica é nula. Assim, as condições de contorno são $T_{3}(0)=T_{3}(l)=0$. Para excitação da forma $D_{3}=D_{0} e^{j \omega t}$ (harmônica), achando as constantes $A$ e $B$ da equação 5.10 tem-se a seguinte solução particular:

$$
u_{3}=\frac{e_{33} D_{0}}{\rho \omega \epsilon_{33}^{S} V_{A}^{D}}\left[\sin \left(\frac{\omega z}{V_{A}^{D}}\right)-\tan \left(\frac{\omega z}{2 V_{A}^{D}}\right) \cos \left(\frac{\omega z}{V_{A}^{D}}\right)\right] e^{j \omega t}
$$

Como a corrente elétrica e o deslocamento elétrico estão relacionados por:

$$
I=\frac{\partial q}{\partial t}=\frac{\partial D_{3}}{\partial t} L w=j \omega D_{3} A_{R}
$$

onde $q$ é a carga elétrica na cerâmica e $A_{R}=L w$ é a área transversal. A tensão elétrica pode ser achada integrando o campo elétrico:

$$
V(l)-V(0)=\int_{0}^{l} E_{3}(z) d z .
$$

Então, como $u_{3}(0)=-u_{3}(l)$ e $S_{3}=\partial u_{3} / \partial z$, das equações 5.5 e 5.6 pode ser achada uma expressão para a impedância elétrica da cerâmica vibrando no vácuo:

$$
Z_{e}=\frac{V}{I}=\frac{1}{j \omega C_{0}}\left[1-\frac{2 K_{A}^{2}\left(V_{A}^{D}\right)^{2}}{\omega l} \tan \left(\frac{\omega l}{2 V_{A}^{D}}\right)\right],
$$

onde $C_{0}$ é a capacitância e $K_{A}$ é o fator de acoplamento eletromecânico:

$$
\begin{aligned}
& C_{0}=\frac{\epsilon_{33}^{S} A_{R}}{l}, \\
& K_{A}^{2}=\frac{\left(e_{33}\right)^{2}}{c_{33}^{E} \epsilon_{33}^{S}+\left(e_{33}\right)^{2}} .
\end{aligned}
$$

\subsubsection{Solução 2: cerâmica vibrando com troca de energia com o meio externo}

Considerando que a cerâmica está imersa num meio diferente do vácuo e troca energia com ele, verifica-se que as forças sobre as faces são diferentes de zero. Dessa maneira, para as condições de contorno, impõe-se a continuidade da velocidade nas 
faces: $\quad \dot{u}_{3}(0)=v_{1}$ e $\dot{u}_{3}(l)=v_{2}$. A figura 5.3 mostra um esquema da cerâmica piezelétrica com a representação das forças e velocidades usadas nas faces da cerâmica. Para a excitação harmônica igual a usada na seção anterior, tem-se a seguinte solução:

$$
u_{3}=\frac{1}{j \omega}\left[v_{1} \cos \left(\frac{\omega z}{V_{A}^{D}}\right)-\frac{v_{2}+v_{1} \cos \beta}{\sin \beta} \sin \left(\frac{\omega z}{V_{A}^{D}}\right)\right]
$$

onde $\beta=\omega l / V_{A}^{D}$.

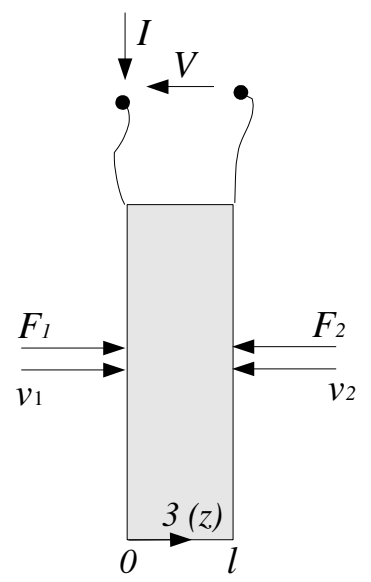

Figura 5.3. Cerâmica piezelétrica vibrando num meio diferente do vácuo.

Lembrando que $S_{3}=\partial u_{3} / \partial z$ e que a tensão mecânica nas faces da cerâmica é igual à força exercida dividida pela sua área transversal, das equações 5.5, 5.6, 5.12, 5.13 e 5.17 pode-se obter o seguinte sistema de equações:

$$
\left\{\begin{array}{l}
F_{1}=\frac{Z_{A O}}{j \tan \beta} v_{1}+\frac{Z_{A O}}{j \sin \beta} v_{2}+\frac{e_{33}}{j \omega \epsilon_{33}^{S}} I \\
F_{2}=\frac{Z_{A O}}{j \sin \beta} v_{1}+\frac{Z_{A O}}{j \tan \beta} v_{2}+\frac{e_{33}}{j \omega \epsilon_{33}^{S}} I \\
V=\frac{e_{33}}{j \omega \epsilon_{33}^{S}} v_{1}+\frac{e_{33}}{j \omega \epsilon_{33}^{S}} v_{2}+\frac{1}{j \omega C_{0}} I
\end{array}\right.
$$

onde $Z_{A O}=\rho V_{A}^{D} A_{R}$ é a impedância acústica da cerâmica piezelétrica.

\subsubsection{Representação matricial dos elementos ativos}

Os elementos ativos são considerados aqueles que apresentam uma interação entre as propriedades elétricas e acústicas, neste caso, tratam-se dos materiais piezelétricos 
usados para emitir e receber as ondas, que podem ser: cerâmicas, cristais de quartzo, polímeros piezelétricos, etc. O elemento ativo, modelado pelo sistema de equações 5.18, é representado por um sistema de três portas, duas portas acústicas e uma porta elétrica, como mostra a figura 5.4. $V$ e $I$ são a voltagem e a corrente elétrica na porta elétrica, respectivamente, $F_{i}$ e $v_{i}$ são as forças e as velocidades da partícula nos terminais acústicos, $i=1,2$.

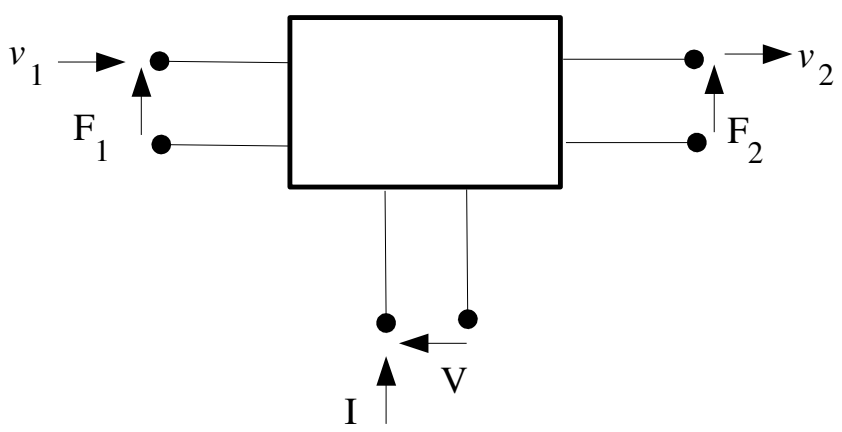

Figura 5.4. Modelo do elemento ativo.

Se há uma camada de retaguarda com impedância $Z_{B}$ no terminal acústico 1 , a seguinte relação é válida:

$$
F_{1}=-Z_{B} v_{1}
$$

Assim, a voltagem $(V)$ e a corrente elétrica $(I)$ ficam relacionadas com a força $\left(F_{2}\right)$ e a velocidade $\left(v_{2}\right)$ no terminal acústico 2 :

$$
\left(\begin{array}{l}
V \\
I
\end{array}\right)=\left[\begin{array}{ll}
A_{11} & A_{12} \\
A_{21} & A_{22}
\end{array}\right]\left(\begin{array}{l}
F_{2} \\
v_{2}
\end{array}\right)=\boldsymbol{A}_{\mathbf{0}}\left(\begin{array}{l}
F_{2} \\
v_{2}
\end{array}\right),
$$

onde:

$$
\begin{aligned}
& A_{11}=\frac{\epsilon_{33}^{S}}{e_{33} C_{0}} \frac{\cos (\beta)+j \zeta \sin (\beta)}{\cos (\beta)-1+j \zeta \sin (\beta)}-\frac{e_{33}}{\omega \epsilon_{33}^{S} Z_{0}} \frac{\sin (\beta)}{\cos (\beta)-1+j \zeta \sin (\beta)}, \\
& A_{12}=-\frac{e_{33}}{j \omega \epsilon_{33}^{S}} \frac{2(\cos (\beta)-1)+j \zeta \sin (\beta)}{\cos (\beta)-1+j \zeta \sin (\beta)}+\frac{\epsilon_{33}^{S}}{e_{33} C_{0}} \frac{Z_{0}[\zeta \cos (\beta)+j \sin (\beta)]}{\cos (\beta)-1+j \zeta \sin (\beta)}, \\
& A_{21}=\frac{j \omega \epsilon_{33}^{S}}{e_{33}} \frac{\cos (\beta)+j \zeta \sin (\beta)}{\cos (\beta)-1+j \zeta \sin (\beta)},
\end{aligned}
$$




$$
A_{22}=\frac{j \omega \epsilon_{33}^{S}}{e_{33}} \frac{Z_{0}[\zeta \cos (\beta)+j \sin (\beta)]}{\cos (\beta)-1+j \zeta \sin (\beta)},
$$

$C_{0}=\epsilon_{33}^{S} A_{R} / l$ é a capacitância, $\zeta=Z_{B} / Z_{0}$ é a razão das impedâncias da camada de retaguarda e do elemento piezelétrico, $A_{R}$ e $l$ são a área transversal e a espessura do elemento, respectivamente, $\epsilon_{33}^{S}$ é a constante dielétrica, $e_{33}$ é a constante piezelétrico e $\omega$ é a freqüência angular.

As perdas mecânicas são consideradas usando a equação 3.21 que define a velocidade de propagação complexa, e as perdas dielétricas com a seguinte equação (Sherrit e Mukherjee, 1998):

$$
\epsilon_{33}^{S}=\epsilon_{33(S P)}^{S}\left(1-\frac{j}{Q_{d}}\right),
$$

onde $Q_{d}$ é o fator de qualidade dielétrica e o subscrito $(S P)$ representa as propriedades de um meio sem perdas.

\subsubsection{Representação matricial dos elementos passivos}

Em geral, os transdutores ultra-sônicos podem apresentar várias camadas passivas que têm a finalidade de adaptar as impedâncias dos meios, modificar a resposta em freqüência do transdutor ou simplesmente retardar a propagação da onda, sendo chamadas de camadas de casamento (matching), de retaguarda (backing) e linhas de retardo (delay lines), respectivamente. Se cada camada tem espessura $d_{i}$, constante de propagação $k_{i}$ e impedância acústica $Z_{i}=\rho_{i} v_{i} A_{R}$, uma onda propagando-se no meio pode ser representada pela seguinte relação:

$$
\left(\begin{array}{c}
F_{i 1} \\
v_{i 1}
\end{array}\right)=\left[\begin{array}{cc}
\cos \left(k_{i} d_{i}\right) & j Z_{i} \sin \left(k_{i} d_{i}\right) \\
\frac{j}{Z_{0}} \sin \left(k_{i} d_{i}\right) & \cos \left(k_{i} d_{i}\right)
\end{array}\right]\left(\begin{array}{c}
F_{i 2} \\
v_{i 2}
\end{array}\right)=\boldsymbol{B}_{i}\left(\begin{array}{c}
F_{i 2} \\
v_{i 2}
\end{array}\right) .
$$

A equação anterior pode ser obtida a partir das equações 5.18(a) e 5.18(b), simplesmente zerando o coeficiente piezelétrico ( $e_{33}=0$ ). Além disso, pode-se ver que a equação 5.18(c) resulta na relação voltagem-corrente de um capacitor de placas paralelas. Pode-se ver na figura 5.5 o modelo do elemento passivo com somente duas portas acústicas. 


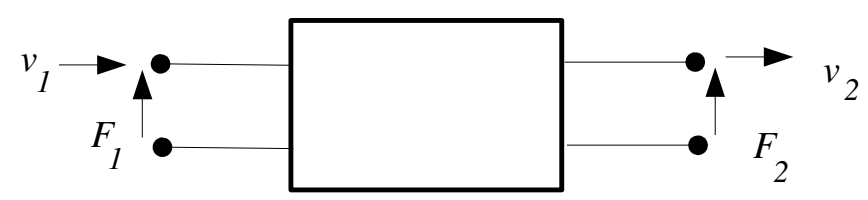

Figura 5.5. Modelo do elemento passivo.

\subsubsection{Modelagem do transdutor multielemento}

O modelo apresentado permite a modelagem de transdutores com múltiplas camadas de casamento e de retaguarda, como representado pelo diagrama da figura 5.6, onde $Z_{B 0}$ é a impedância do meio semi-infinito, $B_{1}, B_{2}, \ldots, B_{m}$ representam as camadas de retaguarda, $A_{0}$ é a matriz da cerâmica piezelétrica, $M_{1}, M_{2}, \ldots, M_{m}$ representam as camadas de casamento de impedância e $Z_{L}$ representa a carga.

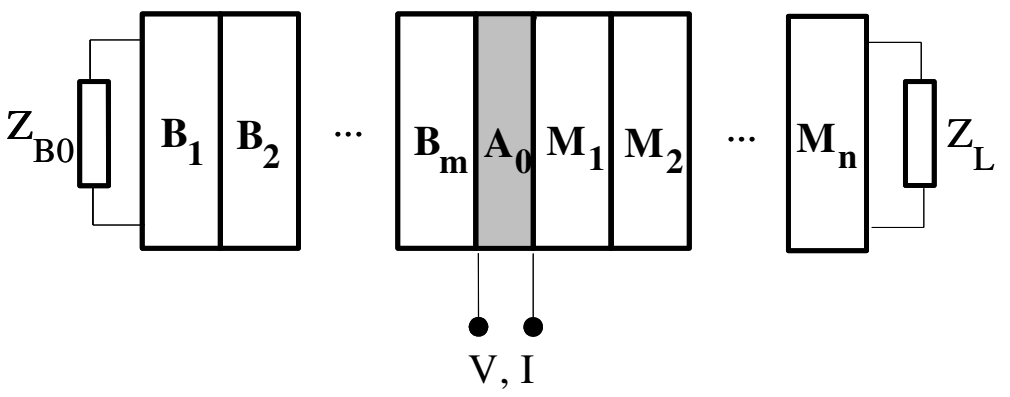

Figura 5.6. Transdutor multielemento.

Considerando que cada camada de retaguarda seja representada por uma matriz $B_{i}$ (equação 5.22), a impedância equivalente de todas as camadas de retaguarda é dada por:

$$
Z_{B}=\frac{B_{11} Z_{B 0}+B_{12}}{B_{21} Z_{B 0}+B_{22}},
$$

onde $B_{i j}$ são os elementos da matriz resultante do produto de todas as matrizes que modelam as camadas passivas de retaguarda:

$$
B=B_{m} B_{m-1} \ldots B_{1}
$$

As camadas passivas de casamento são pós-multiplicadas à matriz do elemento ativo $A_{0}$ (equação 5.20):

$$
M=A_{0} M_{1} M_{2} \ldots M_{n},
$$

Assim, o transdutor multielemento pode ser representado por um único elemento 
com um terminal elétrico e outro acústico com a impedância de carga $Z_{L}$. Na figura 5.7 é mostrado o transdutor operando como emissor (figura 5.7(a)) ou receptor (figura 5.7(b)).

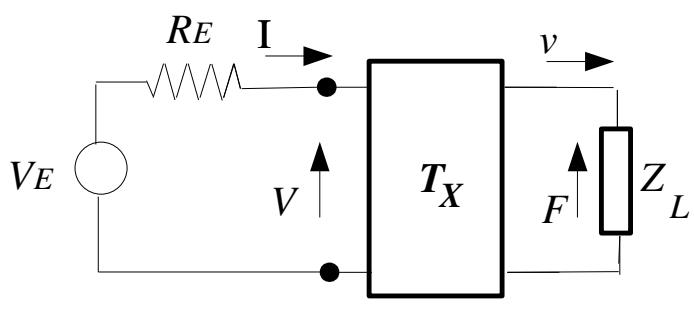

(a)

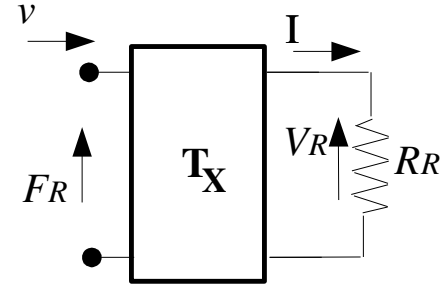

(b)

Figura 5.7. Modelo do transdutor em modo (a) emissor e (b) receptor

A função de transferência para o transdutor operando como emissor (FTE) é definida como a razão entre a força exercida na carga $(F)$ e a voltagem aplicada pelo gerador $\left(V_{E}\right)$ :

$$
F T E=\frac{F}{V_{E}}=\frac{Z_{L}}{M_{11} Z_{L}+M_{12}+R_{E}\left(M_{21} Z_{L}+M_{22}\right)},
$$

onde $M_{i j}$ são os elemento da matriz $M$ da equação 5.25 e $R_{E}$ é a resistência interna do gerador.

A função de transferência para o transdutor operando como receptor $(F T R)$ é definida como a razão entre a voltagem medida no circuito detector $\left(V_{R}\right)$ e a força na face do transdutor $\left(F_{R}\right)$ :

$$
F T R=\frac{V_{R}}{F_{R}}=\frac{R_{R}}{M_{12}+R_{R} M_{22}},
$$

onde $R_{R}$ é a resistência interna do circuito detector.

Tem-se ainda uma outra função de transferência, a função de transferência de emissão-recepção (FTER), que é a mais usada na prática e é definida como a razão entre a voltagem medida no receptor e a voltagem aplicada no emissor, assim:

$$
\begin{gathered}
\text { FTER }=\frac{V_{R}}{V_{E}}=\left[\frac{Z_{L}}{M_{11} Z_{L}+M_{12}+R_{E}\left(M_{21} Z_{L}+M_{22}\right)}\right] \\
{\left[\frac{2 R_{R}}{M_{11} Z_{L}+M_{12}+R_{R}\left(M_{21} Z_{L}+M_{22}\right)}\right]}
\end{gathered}
$$

As equações das funções de transferência são dependentes da freqüência. Assim, a 
resposta em freqüência do transdutor pode ser obtida calculando os valores das funções nas faixas de freqüência desejadas. Depois, a resposta impulsiva pode ser obtida calculando a transformada inversa de Fourier.

\subsection{SIMULAÇÃO DAS CÉLULAS DE MEDIÇÃO}

A partir do modelo matricial apresentado neste capítulo, pode-se simular o funcionamento das células de medição e analisar os vários fatores envolvidos na medição da viscosidade de líquidos por ultra-som tais como: o comportamento do coeficiente de reflexão em função da viscosidade e da freqüência, o efeito da largura de banda do transdutor sobre a medição, ruído nos sinais e as mudanças na propagação das ondas induzidas por fatores externos (como a temperatura). $\mathrm{O}$ efeito da temperatura é o fator mais importante a ser analisado.

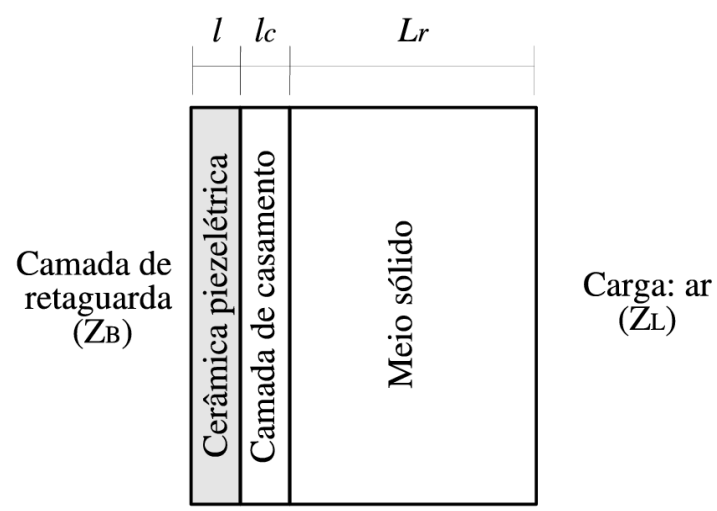

Figura 5.8. Modelo da célula de medição sem conversão.

A simulação é feita aplicando o método matricial apresentado ao modelo unidimensional apropriado da célula de medição. A figura 5.8 mostra o modelo usado para um dispositivo sem conversão de modo, que consiste simplesmente num transdutor comercial colado sobre um tarugo de aço inox, com densidade de $7900 \mathrm{~kg} / \mathrm{m}^{3}$, velocidade de propagação das ondas de $5900 \mathrm{~m} / \mathrm{s}$ e espessura $\left(L_{r}\right)$ de $37,8 \mathrm{~mm}$. O transdutor é representado pela cerâmica piezelétrica (PZT-5A), a camada de casamento e um meio semi-infinito como camada de retaguarda. A impedância acústica da camada de retaguarda tem um valor próximo ao da impedância da cerâmica, melhorando o casamento de impedâncias, o que viabiliza a obtenção de um pulso mais estreito. $\mathrm{Na}$ camada de casamento é usado um material teórico com impedância acústica igual à 
media geométrica das impedâncias da cerâmica e da linha de retardo e espessura de meio comprimento de onda, a fim de aumentar a quantidade de energia transmitida da cerâmica à linha de retardo. A carga é um meio semi-infinito de ar, com impedância acústica de 420 Rayl.

O resultado é obtido calculando a FTER (equação 5.28) numa faixa de frequiências ampla o suficiente para abranger todo o espectro do sinal. Nesse caso, o cálculo foi feito entre 0 e $40 \mathrm{MHz}$ para obter uma boa resolução temporal. Foram usados valores de $R_{E}=50 \Omega$ e $R_{R}=1 M \Omega$, as propriedades do PZT-5A foram obtidos do livro de Kino (1987) e a velocidade de propagação da onda no aço inox foi medida. Finalmente é calculada a transformada inversa de Fourier da FTER para obter a resposta temporal. Essa resposta temporal representa a resposta impulsiva do sistema que, devido à excitação pulsada usada para os transdutores experimentalmente, é uma excelente aproximação do caso real. Para ajustar a forma de onda, variaram-se a impedância acústica da camada de retaguarda e o fator de qualidade mecânica do sólido, resultando no amortecimento dos ecos sucessivos.

a)

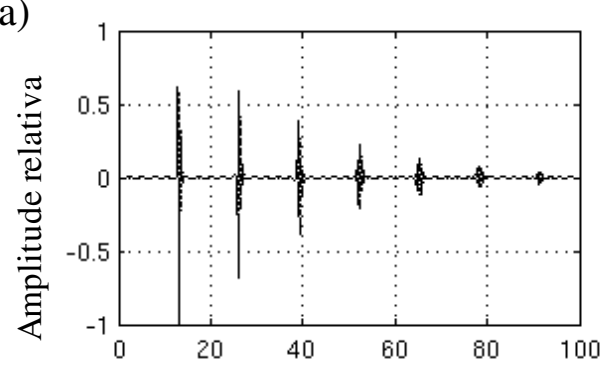

c)

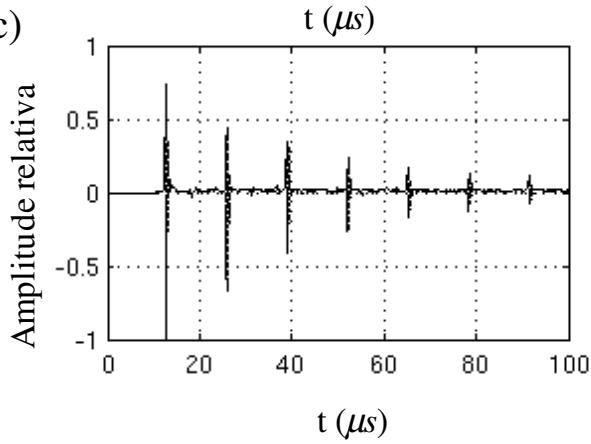

b)

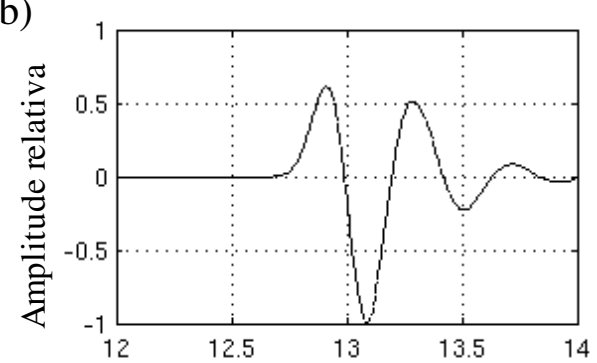

d)

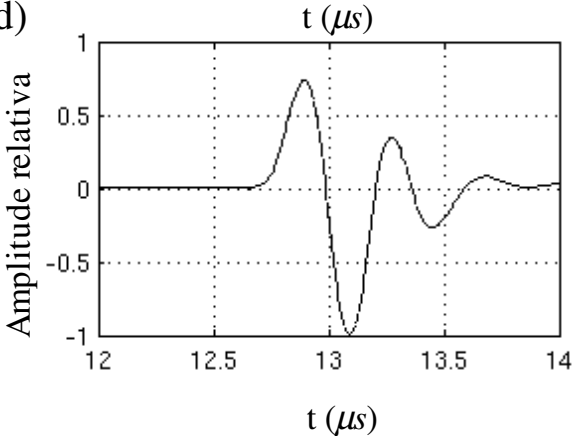

Figura 5.9. Resposta temporal do dispositivo da figura 5.8: a) e b) resposta temporal e forma de onda simulados, c) e d) resposta temporal e forma de onda experimentais.

A figura 5.9 mostra os resultados obtidos nos casos simulado e experimental. As simulações da resposta temporal e o detalhe do primeiro eco refletido na linha de retardo são mostrados nas figuras 5.9(a) e 5.9(b), respectivamente. As figuras 5.9(c) e 
5.9(d) mostram, respectivamente, a resposta temporal e o detalhe do primeiro eco obtidos experimentalmente. As amplitudes das ondas foram normalizadas. Nota-se uma boa concordância entre as ondas simulada e experimental, embora a simulada apresente um menor amortecimento. A localização no tempo dos ecos refletidos apresenta uma razoável concordância, levando em conta que não é conhecido o tipo do material piezelétrico do transdutor comercial, bem como da camada de adaptação de impedâncias. Pode-se concluir que usando corretamente o modelo matricial é possível modelar com boa precisão o comportamento dos dispositivos de medição.

Na figura 5.10 é mostrado o modelo unidimensional usado para modelar a célula de medição com conversão de modo. Na célula de medição real existe uma linha de retardo de água e uma de alumínio (prisma). Devido à interface água-alumínio ser inclinada, nenhuma reflexão proveniente dessa interface chega ao receptor. Entretanto, esses dois meios são modelados usando somente uma linha de retardo de alumínio, com um comprimento $\left(L_{r}\right)$ apropriado, de forma a garantir o mesmo tempo de propagação, evitando múltiplas reflexões. O meio sólido em contato com a amostra, usado em todos os testes e simulações, é o acrílico. Na carga é usado novamente um meio semi-infinito, sendo uma excelente aproximação devido à carga ser sempre um fluido (ar e líquido), onde as ondas de cisalhamento propagam-se por distâncias muito pequenas. Foram usados os mesmos parâmetros do dispositivo mostrado na figura 5.8.

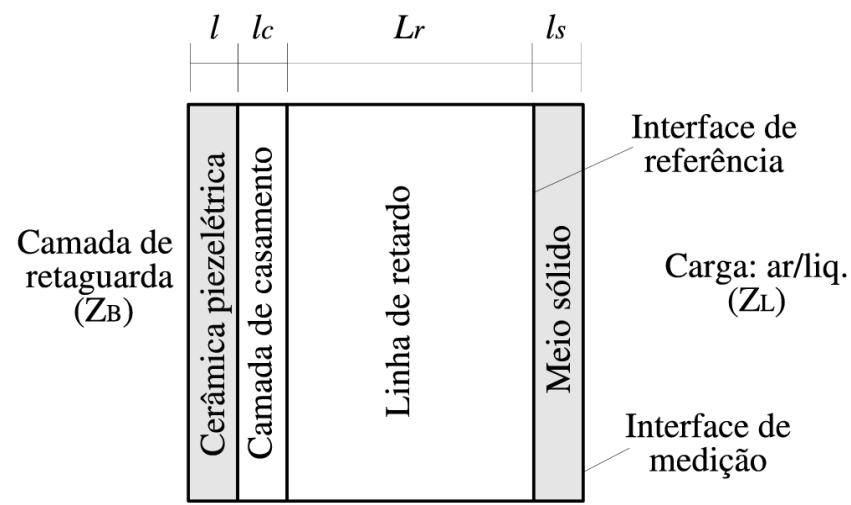

Figura 5.10. Modelo da célula de medição com conversão de modo.

A impedância acústica do líquido é fornecida pelos modelos para líquidos viscoelásticos estudados no capítulo 3. A relação entre a impedância acústica e o módulo de cisalhamento complexo para meios viscoelásticos, segundo o modelo de Voigt (equação 3.40), é usada na equação da FTER (equação 5.28). Esse valor, como é 
dependente da freqüência, deve ser calculado para todas as freqüências do espectro analisado.

A figura 5.11 mostra os sinais simulados no caso do óleo SAE 250 a $20^{\circ} \mathrm{C}$, com viscosidade de 6,54Pa.s e frequiência de $1 \mathrm{MHz}$. O gráfico 5.11(a) mostra os sinais refletidos pela interface de referência $(n(t))$ e de medição $(a(t))$ no ar e no líquido. No gráfico 5.11(b) são mostrados em detalhe os ecos provenientes da interface de medição, e observa-se a variação na magnitude e na fase com a presença do líquido. Nessas simulações são obtidos valores de $r=0,842$ e $\theta=9,91^{\circ}$, que substituídos na equação 4.7 , fornecem, novamente, o valor inicial da viscosidade adotado. As propriedades físicas do sólido e dos líquidos testados, usadas nas simulações, são apresentadas no próximo capítulo (seções 6.3 e 6.4).

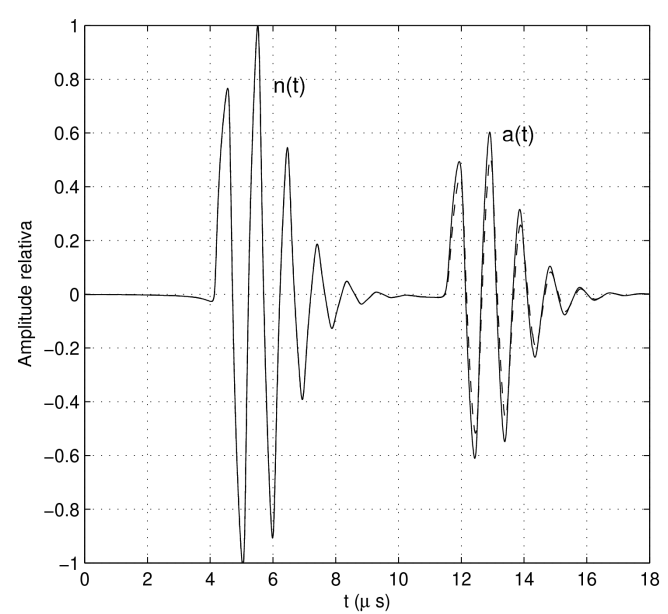

(a)

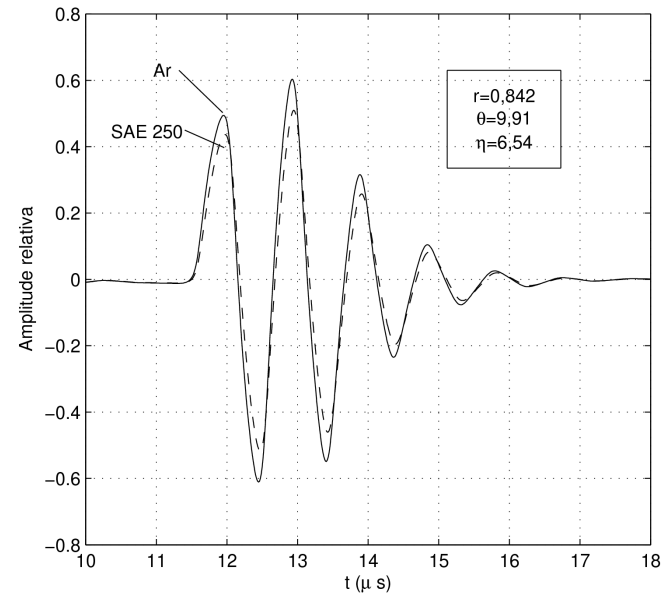

(b)

Figura 5.11. Simulação dos sinais nos casos com ar e com óleo SAE 250 a $20^{\circ} \mathrm{C}$ e $1 M H z$ : a) sinais refletidos pelas interfaces de referência $(n(t))$ e de medição $(a(t))$ e b) sinais refletidos pela interface de medição.

\subsubsection{Estudo do efeito da variação da temperatura sobre a medição}

Como já foi dito, a variação da temperatura é o principal fator que induz erro na medição. Nesta seção é usado o modelo matricial para avaliar a dependência de variações na temperatura do meio sólido (acrílico) e da linha de retardo de alumínio, sobre o coeficiente de reflexão e a viscosidade, na célula de medição mostrada na figura 5.10 .

Inicialmente foi analisado o caso da temperatura da amostra ser diferente da 
temperatura da célula, causando um gradiente de temperatura no meio sólido. Foi empregada uma relação linear da velocidade de propagação da onda de cisalhamento (no acrílico), com a temperatura, na faixa entre 15 e $30^{\circ} \mathrm{C}$ (ver seção 6.3.2). Considerou-se no meio sólido uma temperatura $T_{1}$ em uma da suas faces e $T_{1}+\Delta T$ na outra. Dessa forma calculou-se a velocidade de cisalhamento média no acrílico:

$$
\hat{v_{c}}(T)=a_{0}\left[T_{1}+\frac{\Delta T}{2}\right]+a_{1},
$$

onde $a_{o}$ e $a_{1}$ são os coeficientes da reta ajustada experimentalmente. A simulação foi feita calculando os sinais com ar para $T=T_{l}$ e depois calculando os sinais com o líquido (SAE 40) para $T=T_{l}+\Delta T$, onde $T_{l}=20^{\circ} C$ e $\Delta T$ varia entre $-0,5$ e $0,5^{\circ} C$.
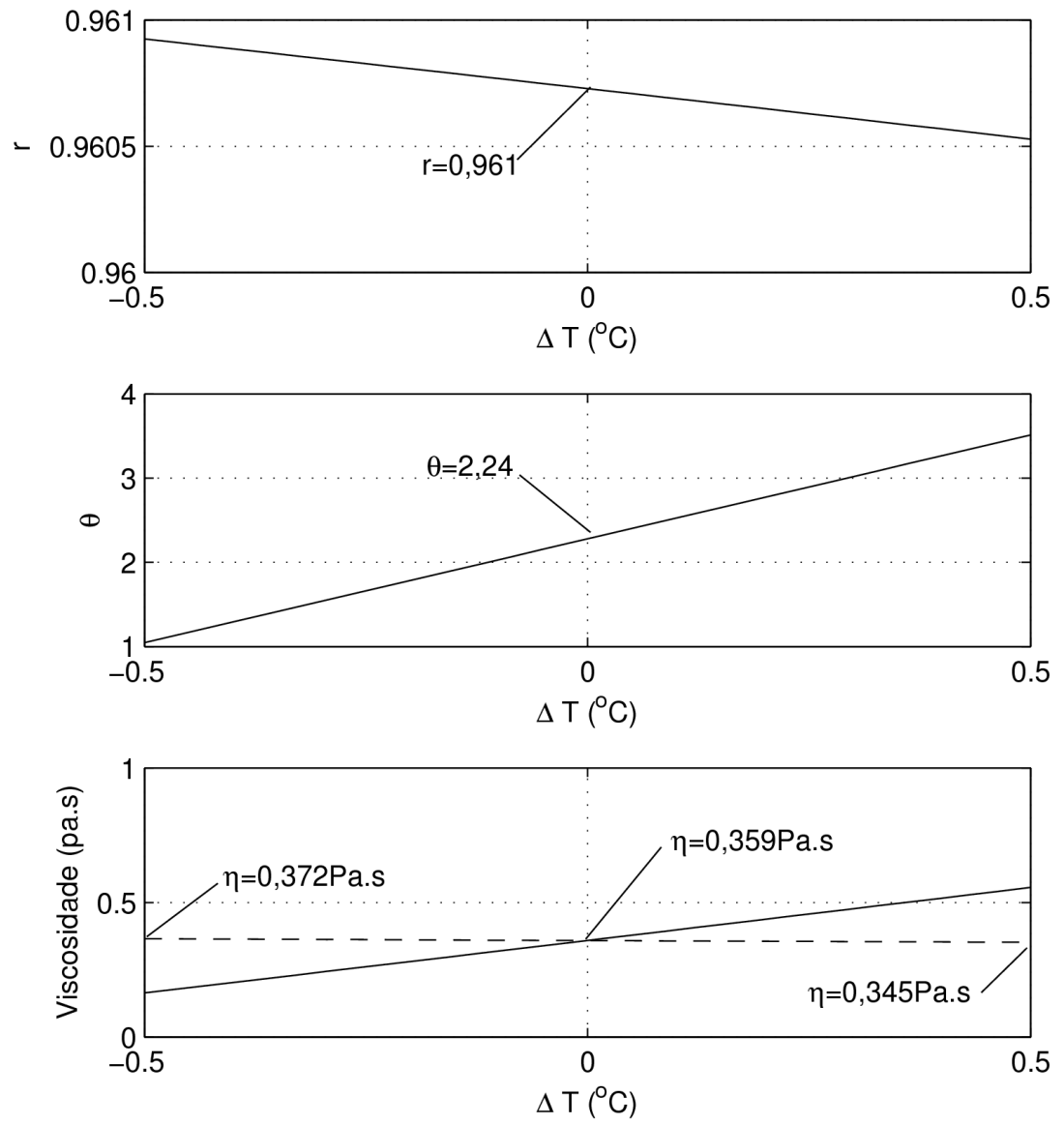

Figura 5.12. Variação do coeficiente de reflexão e da viscosidade em função de um gradiente linear de temperatura no meio sólido.

A figura 5.12, mostra os efeitos sobre o coeficiente de reflexão e a viscosidade para uma variação linear de temperatura no meio sólido. Observa-se um leve decréscimo 
da magnitude do coeficiente de reflexão devido à redução da impedância acústica do sólido. Além disso, com esse aumento da temperatura, tem-se um pequeno aumento da viscosidade do líquido. Já no caso da fase, a mudança é muito grande, mostrando a grande dependência dessa grandeza com a temperatura. No gráfico da viscosidade, a linha tracejada representa o valor real da viscosidade e a linha sólida o valor obtido na simulação. O valor da viscosidade na simulação foi calculado com normalização, mas observou-se que o valor calculado sem normalização é igual ao apresentado no gráfico. Assim, verifica-se que a normalização não ajuda a reduzir os erros induzidos por variações na temperatura quando ocorrem no sólido em contato com a amostra. A variação de $0,5^{\circ} \mathrm{C}$ na temperatura da amostra gerou um erro na medição da viscosidade maior que $50 \%$.
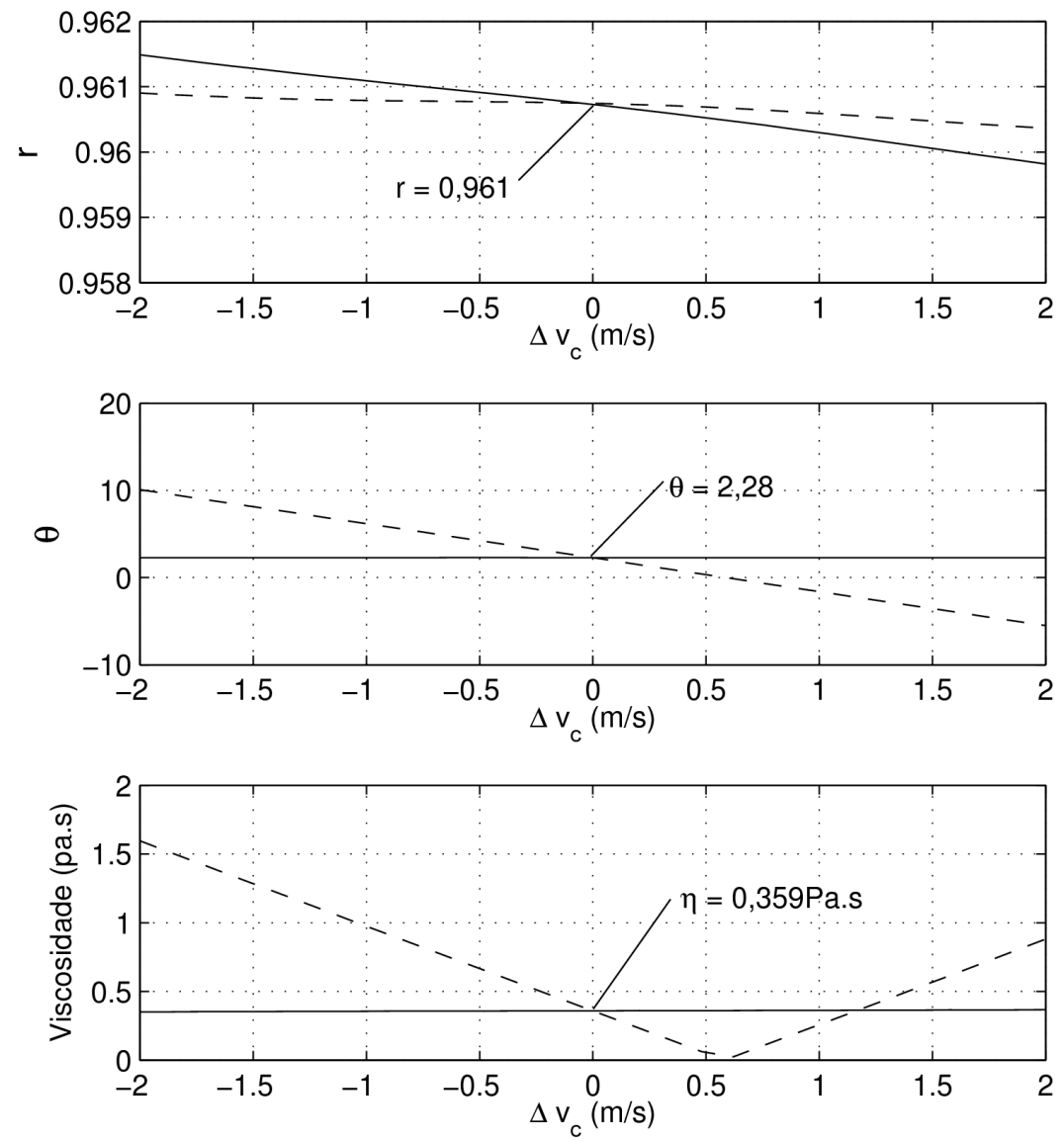

Figura 5.13. Variação do coeficiente de reflexão e da viscosidade em função da variação de velocidade na linha de retardo, nos casos com (linha sólida) e sem (linha tracejada) normalização. 
A figura 5.13 mostra o efeito sobre a medição da mudança da velocidade de propagação da onda na linha de retardo de alumínio. A simulação foi feita calculando o sinal no caso do ar com uma velocidade na linha de retardo de $v_{c}=3040 \mathrm{~m} / \mathrm{s}$ e depois calculando os sinais no caso do líquido para uma velocidade $v_{c}=3040+\Delta v_{c}$, onde $\Delta v_{c}$ varia entre -2 e $2 \mathrm{~m} / \mathrm{s}$. A linha sólida representa os valores calculados com normalização e a linha tracejada sem normalização. Observa-se uma pequena redução na variação da magnitude do coeficiente, devido principalmente à variação da impedância acústica. Essa variação é maior no caso com normalização embora as variações sejam pequenas e praticamente não afetem a medição. Com relação à fase, a variação é muito grande no caso sem normalização, e com normalização a fase praticamente não varia. Isso demonstra a importância de se usar a normalização nas medições com ar e com líquido Para a viscosidade, nota-se, como consequiência da mudança de fase, o grande erro no caso sem normalização, ao tempo que no caso com normalização a viscosidade permanece constante no valor esperado. 
CAPÍTULO 6

\section{METODOLOGIA EXPERIMENTAL}

Neste capítulo são apresentados os dispositivos de medição implementados e os métodos experimentais usados. É feita a determinação das propriedades acústicas do material sólido usado na interface de medição: acrílico, além das propriedades dos líquidos testados: óleos automotivos e alimentícios. É analisado o efeito sobre o coeficiente de reflexão devido a fatores externos: temperatura e instabilidade na eletrônica, e como a normalização melhora consideravelmente a medição do coeficiente. Finalmente, é feita uma análise experimental da influência da largura de banda do sinal na determinação do coeficiente de reflexão.

\subsection{DISPOSITIVOS DE MEDIÇÃO IMPLEMENTADOS}

Neste trabalho, foram usados dois dispositivos de medição: um com conversão de modo e outro sem. Ambos os dispositivos empregam incidência normal na interface de medição.

\subsubsection{Dispositivo 1: Célula de incidência normal sem conversão de modo}

O dispositivo de incidência normal sem conversão de modo, mostrado na figura 6.1, consiste de um tarugo de acrílico de $150 \mathrm{~mm}$ de diâmetro e $50 \mathrm{~mm}$ de espessura, com um transdutor de ondas de cisalhamento colado no centro de uma das suas faces. A resina usada para fixar o transdutor foi Araldite de cura rápida (2min), vendido pela empresa Brascola. Foi usado na sua mistura a metade do endurecedor para obter menor resistência, a fim de permitir que o transdutor seja desprendido facilmente do material sólido sem danificá-lo. 


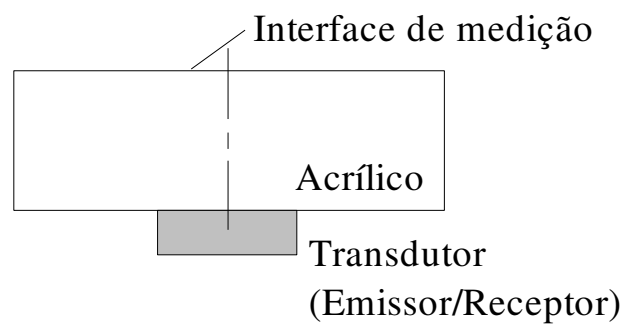

Figura 6.1. Esquema do dispositivo 1: Célula de incidência normal sem conversão de modo.

Nesta montagem, foi usado somente um transdutor de cisalhamento (Panametrics V151) de 0,5MHz com uma polegada de diâmetro para os testes, já que para freqüências maiores a atenuação no acrílico é muito alta.

O dispositivo é colocado num banho a temperatura controlada para reduzir ao máximo gradientes de temperatura no acrílico. A face do acrílico contrária ao transdutor é deixada ao ar livre, para colocar a amostra líquida nela. Esse é o principal problema dessa montagem, não se tem um bom controle da temperatura tanto do dispositivo como da amostra.

A metodologia de medição adotada é a seguinte: coloca-se o dispositivo no banho termostático a uma temperatura desejada, a amostra líquida é colocada numa seringa que também é colocada no banho, e aguarda-se mais de uma hora para a temperatura estabilizar (ver seção 6.5.3) e realizar o teste. Inicialmente, são feitas 5 aquisições sem líquido, ou seja, com ar, sendo que cada uma das aquisições é realizada em aproximadamente 30 segundos. Após isso, é colocado o líquido na face livre do acrílico (interface de medição) até formar uma camada uniforme em toda a sua superfície, e são feitas outras 5 aquisições. Procura-se sempre realizar o teste no menor tempo possível a fim de garantir que as mudanças, principalmente na fase, ocasionadas pela temperatura sejam pequenas.

A digitalização dos sinais é feita usando um osciloscópio Infinium $54820 A$ da Hewlett Packard que tem uma resolução vertical de 12bits em modo repetitivo de amostragem (Infinium 54820A, service guide). Em todas as medições foram usadas 256 médias (modo averaged). Foi usada a máxima frequiência de amostragem do osciloscópio, $2 \mathrm{GHz}$, para ter a melhor resolução possível no cálculo da fase. Os sinais adquiridos são transferidos a um microcomputador, via rede LAN (Local Area Network) para seu posterior processamento. O processamento dos dados é feito mediante 
programas desenvolvidos no software $M a t l a b^{T M}$. Para a excitação do transdutor e a recepção dos sinais, é usado o pulsador/receptor Panametrics 5072PR.

\subsubsection{Dispositivo 2: Célula de incidência normal com conversão de modo}

A figura 6.2 mostra um esquema do dispositivo 2 (célula de incidência normal com conversão de modo). A montagem consiste de um transdutor emissor/receptor de ondas longitudinais, um prisma de alumínio para realizar a conversão de modo e uma linha de retardo de acrílico como meio sólido na interface de medição. Entre o transdutor e o prisma há uma linha de retardo de água e a conversão de modo tem lugar na face inclinada do prisma, ou seja, na interface água/alumínio. Na outra face do prisma está colada à linha de retardo de acrílico que tem $5 \mathrm{~mm}$ de espessura. A reflexão na interface alumínio-acrílico é usada para realizar a normalização no cálculo do coeficiente de reflexão. O ângulo do prisma está calculado para assegurar incidência normal na interface de medição com o líquido. O líquido é colocado numa câmara fechada e todo o sistema é mantido a temperatura constante num banho termostático.

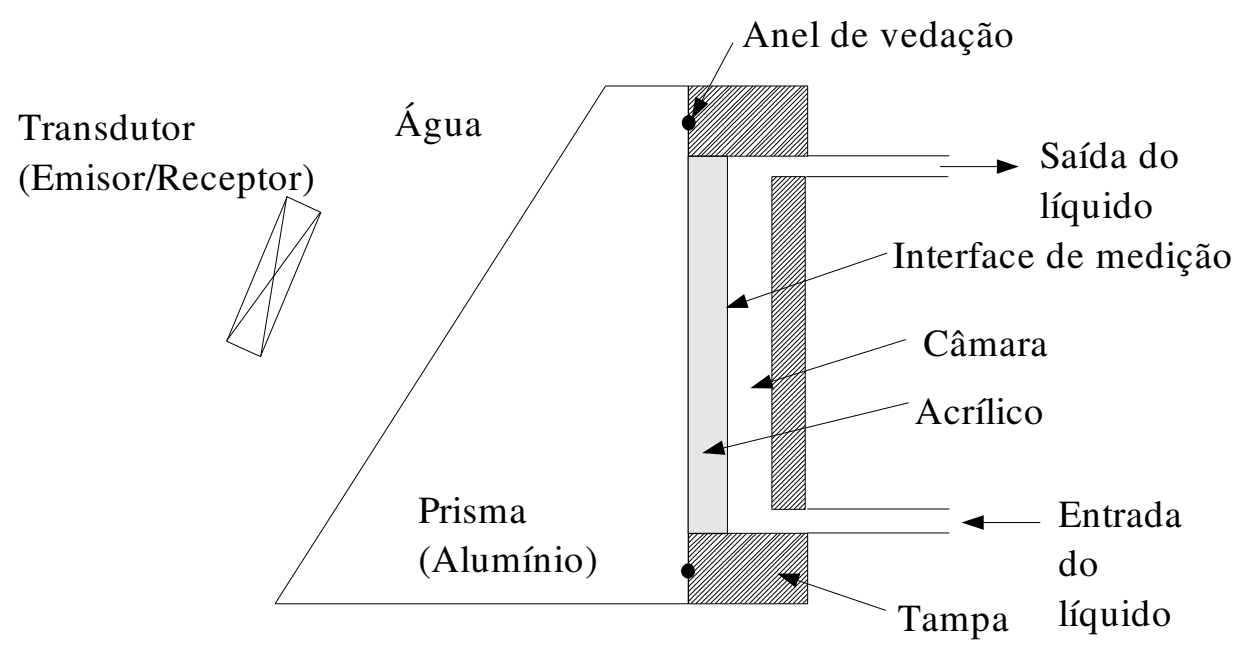

Figura 6.2. Esquema do dispositivo 2: Célula de incidência normal com conversão de modo.

O processo de medição é análogo ao descrito na seção anterior para o dispositivo 1. A principal diferença é vista na forma de colocar a amostra líquida na câmara, ou seja, a amostra é injetada na câmara com uma seringa, em lugar de somente ser espalhada sobre a superfície do acrílico. Isso fornece um melhor controle da temperatura, tanto do dispositivo de medição como do líquido, porque não tem 
superfícies fora do banho, além disso, a seringa e as mangueiras que levam o líquido à câmara também permanecem imersas.

\subsubsection{Outros dispositivos utilizados}

Além dos dispositivos das seções 6.1.1 e 6.1.2, foram usados outros dois com resultados pouco satisfatórios. Ambos os dispositivos usavam conversão de modo com o mesmo prisma do dispositivo 2, transdutores de ondas longitudinais para gerar as ondas e uma membrana de PVDF na recepção.

$\mathrm{Na}$ primeira montagem foi usado um transdutor duplo elemento com duas linhas de retardo de acrílico, uma entre o emissor e o receptor e outra entre o receptor e a linha de retardo de água, com a finalidade de proteger a membrana. Como as ondas tinham que se propagar numa grande distância no acrílico, a atenuação foi muito alta e somente foi possível usar uma frequiência de operação de $0,5 \mathrm{MHz}$. Entretanto, ainda nessa frequiência, a relação sinal-ruido foi muito baixa e os resultados das medições estiveram muito longe do esperado.

$\mathrm{Na}$ segunda montagem, para corrigir o efeito da atenuação foi implantado como receptor uma membrana de PVDF sem nenhuma linha de retardo sólida. Então, entre o emissor e a membrana, assim como entre a membrana e o prisma, tinham-se linhas de retardo de água. Nesse caso, a atenuação foi muito menor, mas, como a membrana se movimentava junto com a água, a medição da fase resultou impossível. Nessa montagem, igual ao caso anterior, verificou-se um valor baixo para a relação sinal-ruído, quando comparado com os resultados obtidos com o dispositivo da seção 6.1.2.

\subsection{MONTAGEM EXPERIMENTAL USADA}

Neste trabalho foi usada somente excitação pulsada, no modo pulso-eco nos dispositivos 1 e 2, e transmissão-recepção no dispositivo com membrana de PVDF, embora, nos dois casos a montagem foi a mesma. Consta de um pulsador/receptor, um osciloscópio e um microcomputador que armazena as aquisições (ver seção 6.1.1). O pulsador cumpre as funções de excitar o transdutor com um pico de alta voltagem e curta duração para gerar uma onda que se propaga nas linhas de retardo dos dispositivos de medição, receber os ecos que retornam ao transdutor e sincronizar as aquisições por meio do sinal de trigger. O osciloscópio digitaliza os sinais tirando a média de 256 
aquisições, o resultado é armazenado, via rede LAN, no microcomputador. Um esquema da montagem é mostrada na figura 6.3. Todos os cabos usados tiveram o mínimo comprimento possível, e foram feitos de fio coaxial de $50 \Omega$ com conectores BNC.

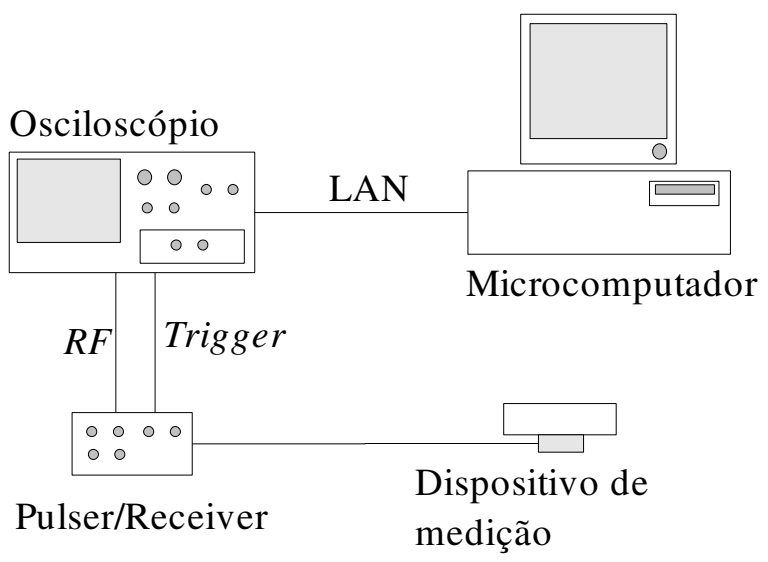

Figura 6.3. Montagem experimental usada para excitação em banda larga.

\subsection{PROPRIEDADES ACÚSTICAS DO MATERIAL SÓLIDO USADO}

Para os dois dispositivos implementados neste trabalho foi usado acrílico como meio sólido. Apesar dos dois materiais terem sido comprados em tempos e de fornecedores diferentes, as suas propriedades foram consideradas iguais. Então, foi usado o tarugo de acrílico do dispositivo 1 para determinar a densidade e a linha de retardo do dispositivo 2 para a velocidade de cisalhamento.

\subsubsection{Densidade do acrílico}

A densidade do tarugo de acrílico foi determinada calculando seu volume e seu peso à temperatura ambiente. Admitiu-se que a densidade do acrílico não varia na faixa de temperatura usada neste trabalho. O resultado é mostrado na tabela 6.1. 
Tabela 6.1. Densidade do acrílico.

\begin{tabular}{|l|c|c|}
\hline & Densidade $\left(\mathrm{kg} / \mathrm{m}^{3}\right)$ & Temperatura $\left({ }^{\circ} \mathrm{C}\right)$ \\
\hline Acrílico & 1178,5 & 22,5 \\
\hline
\end{tabular}

\subsubsection{Velocidade de cisalhamento do acrílico}

Utilizou-se a linha de retardo do dispositivo 2 por apresentar uma menor espessura e, portanto, por ser mais fácil e rápido a sua estabilização térmica. Além disso, devido à interface alumínio-acrílico, pode-se usar a interface de referência para comparar e assim obter valores mais precisos. Foi usado o método da função de correlação e a transformada de Hilbert (seção 5.3.1) para determinar a velocidade. Foram feitas medições para várias temperaturas e nas frequiências de operação usadas, e foram ajustados polinômios (retas) para obter uma relação entre a velocidade e a temperatura. Os resultados são mostrados na figura 6.4, para as frequiências de 1, 2,25 e $3,5 \mathrm{MHz}$ na faixa entre 15 e $30^{\circ} \mathrm{C}$. Os círculos representam as medições feitas e as linhas sólidas os polinômios ajustados. A tabela 6.2 mostra as retas ajustadas e a faixa de temperatura na qual são válidos.

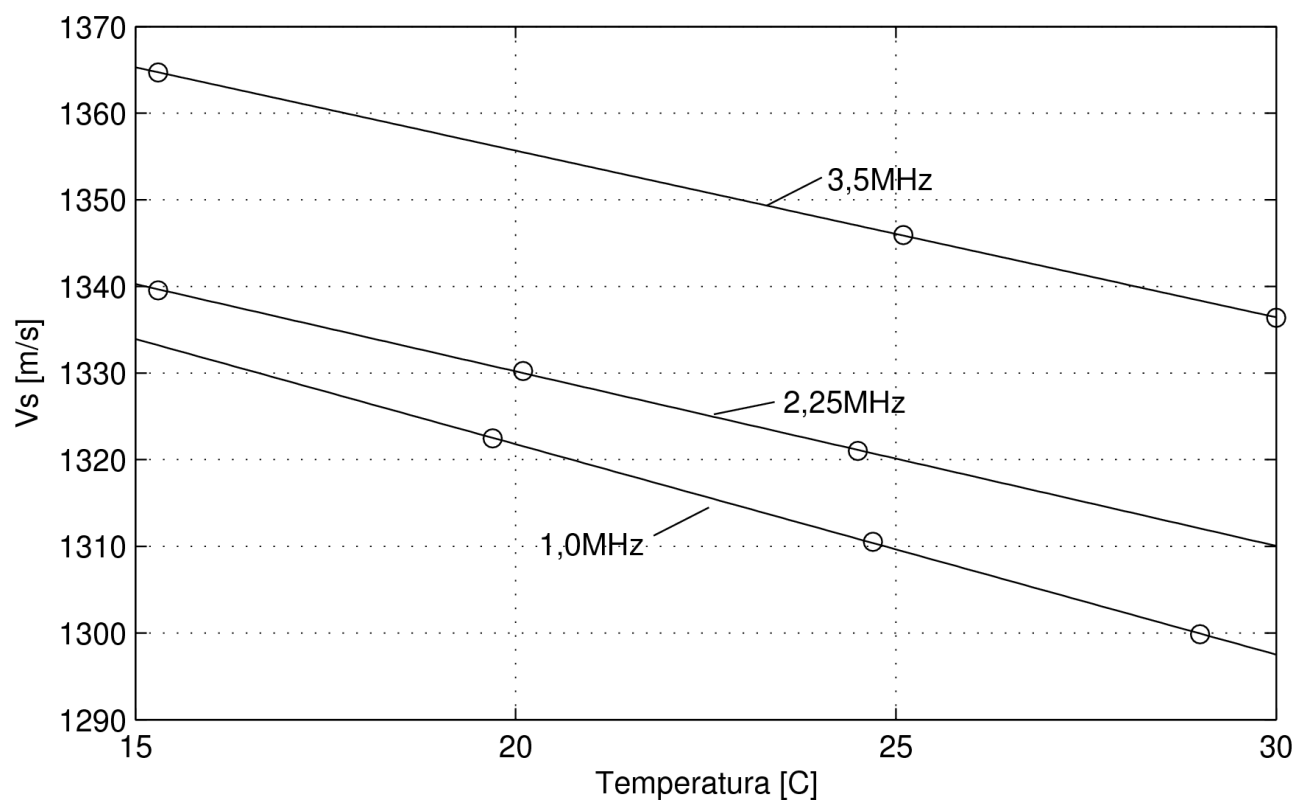

Figura 6.4. Velocidade de cisalhamento em função da temperatura para acrílico. 
Tabela 6.2. Velocidade de cisalhamento do acrílico: retas ajustadas.

\begin{tabular}{|l|r|c|}
\hline $\begin{array}{c}\text { Freqüência } \\
(\mathrm{MHz})\end{array}$ & Polinômio ajustado: $v_{s}=P\left(T^{\circ} \mathrm{C}\right)[\mathrm{m} / \mathrm{s}]$ & $\begin{array}{c}\text { Faixa de temperatura } \\
\left({ }^{\circ} \mathrm{C}\right)\end{array}$ \\
\hline 1,0 & $-2,4288 T+1370,4$ & $15-30$ \\
\hline 2,25 & $-2,0148 T+1370,5$ & \\
\hline 3,5 & $-1,9242 T+1394,2$ & \\
\hline
\end{tabular}

\subsection{Propriedades acústicas dos líquidos testados}

Neste trabalho, foram testados experimentalmente óleos automotivos e alimentícios. A tabela 6.3 mostra os líquidos testados, seu nome comercial e o fornecedor ou fabricante.

Tabela 6.3. Líquidos testados.

\begin{tabular}{|l|c|c|}
\hline \multicolumn{1}{|c|}{ Nome comercial } & Fornecedor \\
\hline Azeite de oliva & Rivoli - Extra virgem & Agro Aceitunera S.A., Argentina \\
\hline SAE 40 & Liza - óleo de milho & Cargill Agrícola S.A., Brasil \\
\hline SAE 90 & $\begin{array}{c}\text { SAE40 - Óleo para motor } \\
\text { SApóide }\end{array}$ & Texaco de Brasil S.A. \\
\hline SAE 140 & $\begin{array}{c}\text { SAE140 - Óleo para transmissão } \\
\text { hipóide }\end{array}$ & Petrobrás, Brasil \\
\hline SAE 250 & $\begin{array}{c}\text { EP250 - Óleo para caixa de } \\
\text { engranagem e redutor }\end{array}$ & Petrobrás, Brasil \\
\hline
\end{tabular}

\subsubsection{Densidade}

As densidades dos líquidos foram medidas à temperatura ambiente, que sempre esteve na faixa entre 19 e $24^{\circ} \mathrm{C}$, e foram consideradas constantes nas temperaturas de medição usadas neste trabalho. Para medir a densidade foi usado um picnômetro de $50 \mathrm{ml}$ calibrado com água destilada. A tabela 6.4 mostra os resultados obtidos e as temperaturas nas quais foram feitas as medições. 
Tabela 6.4. Densidade dos líquidos testados.

\begin{tabular}{|l|c|c|}
\hline & Densidade $\left(\mathrm{kg} / \mathrm{m}^{3}\right)$ & Temperatura $\left({ }^{\circ} \mathrm{C}\right)$ \\
\hline Azeite de oliva & 881,6 & 23,2 \\
\hline Óleo de milho & 885,6 & 23,2 \\
\hline SAE 40 & 857,2 & 24,1 \\
\hline SAE 90 & 871,2 & 21,9 \\
\hline SAE 140 & 876,6 & 22,7 \\
\hline SAE 250 & 913,8 & 22,7 \\
\hline
\end{tabular}

\subsubsection{Viscosidade a baixa freqüência}

Para medir a viscosidade foi usado o viscosímetro rotacional Rheotest 2.1 (MLW, Alemanha). O Rheotest 2.1 é um reômetro de cilindros concêntricos com uma ampla gama de taxas de cisalhamento, isso permite medir desde a viscosidade de fluidos como a água até graxas e pastas muito viscosas. O viscosímetro tem um sistema de circulação de água que permite controlar com precisão a temperatura da amostra. A medição de viscosidade de cada um dos líquidos e para cada temperatura foi feita para duas taxas de cisalhamento diferentes, depois foi tirada a média das duas medições para obter o resultado final. Finalmente, com os valores obtidos para cada temperatura foi ajustado um polinômio de segundo grau, que representa a variação da viscosidade na faixa de temperatura medida.

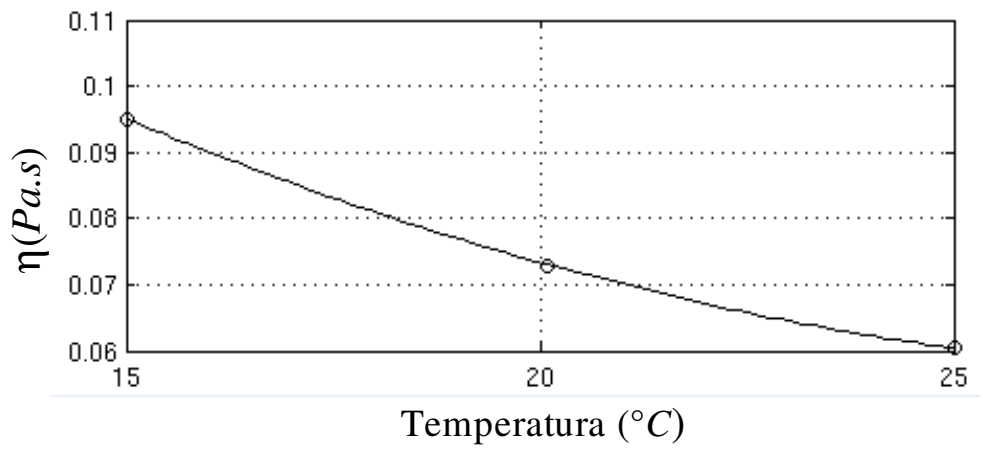

Figura 6.5. Viscosidade versus temperatura medida com o viscosímetro rotacional, para azeite de oliva: os círculo representam as medições feitas e a linha sólida o polinômio ajustado (ver tabela 6.2). 
A figura 6.5 mostra o resultado obtido no caso do azeite de oliva, os círculos representam as medições feitas e a linha sólida o polinômio ajustado. Percebe-se grande dependência da viscosidade com a temperatura. A tabela 6.5 mostra os resultados obtidos para todos os líquidos, incluindo a faixa de temperatura na qual é válido o polinômio ajustado.

Tabela 6.5. Viscosidade estática dos líquidos testados.

\begin{tabular}{|l|c|l|}
\hline & $\begin{array}{c}\text { Faixa de temperatura } \\
\left({ }^{\circ} \mathrm{C}\right)\end{array}$ & Polinômio ajustado: $\eta=P\left(T^{\circ} \mathrm{C}\right) \quad[$ Pa.s $]$ \\
\hline Azeite de oliva & $15-25$ & $1,7060 \times 10^{-4} T^{2}-0,0105 T+0,2133$ \\
\hline Óleo de milho & $15-40$ & $9,9835 \times 10^{-6} T^{2}-0,0034 T+0,1318$ \\
\hline SAE 40 & $15-25$ & $9,8501 \times 10^{-4} T^{2}-0,0661 T+1,2870$ \\
\cline { 1 - 1 } SAE 90 & & $0,0026 T^{2}-0,1683 T+2,9258$ \\
\cline { 3 - 4 } SAE 140 & & $0,0056 T^{2}-0,3479 T+6,1980$ \\
\cline { 3 - 4 } SAE 250 & & $0,0854 T^{2}-4,7510 T+70,359$ \\
\hline
\end{tabular}

\subsection{Análise dos fatores externos que afetam a medição}

Uma maneira interessante para analisar os resultados de um teste de medição de viscosidade por ultra-som, consiste em plotar a magnitude e a fase do coeficiente em função do tempo. A figura 6.6 mostra os gráficos do coeficiente de reflexão do azeite de oliva a $15^{\circ} \mathrm{C}$ e freqüência de operação de $1,0 M H z$. Nesse gráfico, pode-se ver que foi feito o teste descrito na seção 6.1.1: as cinco primeiras medições foram feitas no ar e as cinco seguintes com o azeite, num tempo de aproximadamente cinco minutos. Tanto a magnitude como a fase do coeficiente de reflexão foram normalizadas com as médias dos valores obtidos no ar, nesse caso, os valores obtidos para o líquido mostram os valores reais de magnitude e fase a serem usados no cálculo da viscosidade.

Esses gráficos são importantes porque permitem analisar o efeito dos fatores externos sobre a medição, principalmente, devido à variação da temperatura. No caso mostrado na figura 6.6, nota-se uma excelente estabilidade das grandezas medidas. Isso é devido à boa estabilidade térmica do sistema de medição imerso num banho com temperatura controlada e, principalmente, ao uso da normalização no cálculo do 
coeficiente de reflexão (ver seção 6.5.1.)
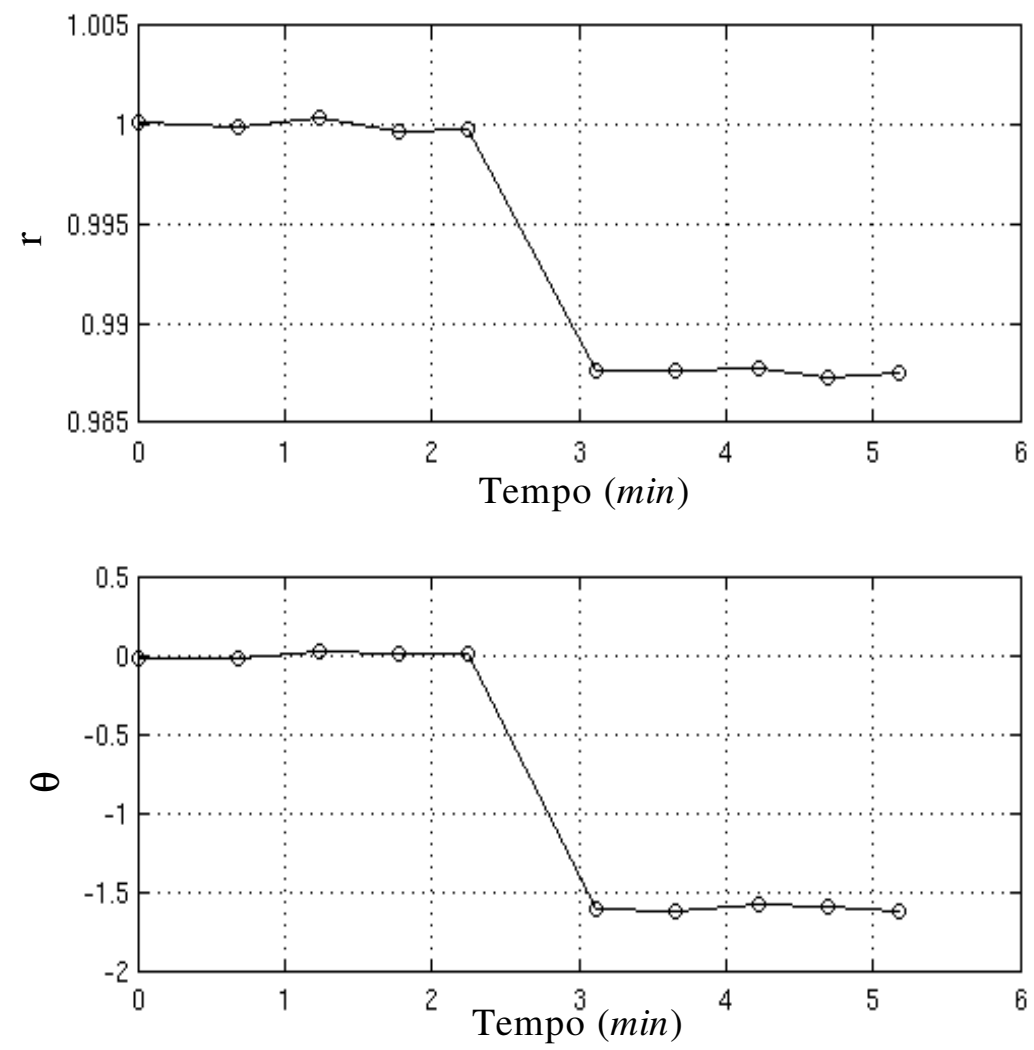

Figura 6.6. Magnitude e fase do coeficiente de reflexão versus tempo, para azeite de oliva a $15^{\circ} \mathrm{C}$ e freqüência de operação de $1,0 \mathrm{MHz}$.

Quando há gradientes de temperatura no meio sólido ou na amostra líquida, a curva da fase não apresenta os dois patamares vistos na figura 6.6. Foi verificado que quando a temperatura na linha de retardo muda lentamente, por exemplo $0,1^{\circ} \mathrm{C} / \mathrm{h}$, a velocidade de cisalhamento muda linearmente com a temperatura e também a fase do coeficiente de reflexão. A curva tem uma pendente cujo sinal depende se a temperatura está aumentando ou diminuindo. Com o dispositivo 2, sem usar normalização, foi medido um incremento na fase do coeficiente de reflexão de $13^{\circ}$ para uma mudança na temperatura de somente $0,4^{\circ} \mathrm{C}$. Levando em conta que as fases medidas são, geralmente, menores do que $10^{\circ}$, o erro induzido na medição por esse fator é muito grande. Ocasionalmente, somente a parte da curva de fase correspondente às medições com óleo apresenta dependência com a temperatura. Nesse caso, a temperatura da amostra ainda não se estabilizou com o resto do sistema. Na seção 6.5.2 é apresentado um estudo mais detalhado sobre o comportamento da fase.

No caso da magnitude do coeficiente, acredita-se que as variações são 
consequiência principalmente da instabilidade da eletrônica. Nesse caso, a normalização mostrou ser um meio efetivo para corrigir tal erro.

\subsubsection{Efeito da normalização na medição do coeficiente de reflexão}

Como foi mostrado na seção anterior, pequenas mudanças na temperatura ocasionam uma variação significativa na fase do coeficiente. Já no caso da magnitude, a instabilidade na eletrônica é a causa principal da sua variação. Como apresentado na seção 5.2.4, a normalização ajuda a eliminar esses erros. A figura 6.7 mostra o coeficiente de reflexão do óleo SAE 40 a $20^{\circ} \mathrm{C}$ medido na freqüência de operação de $0,5 \mathrm{MHz}$ para os casos com $(\mathrm{CN})$ e sem $(\mathrm{SN})$ normalização.
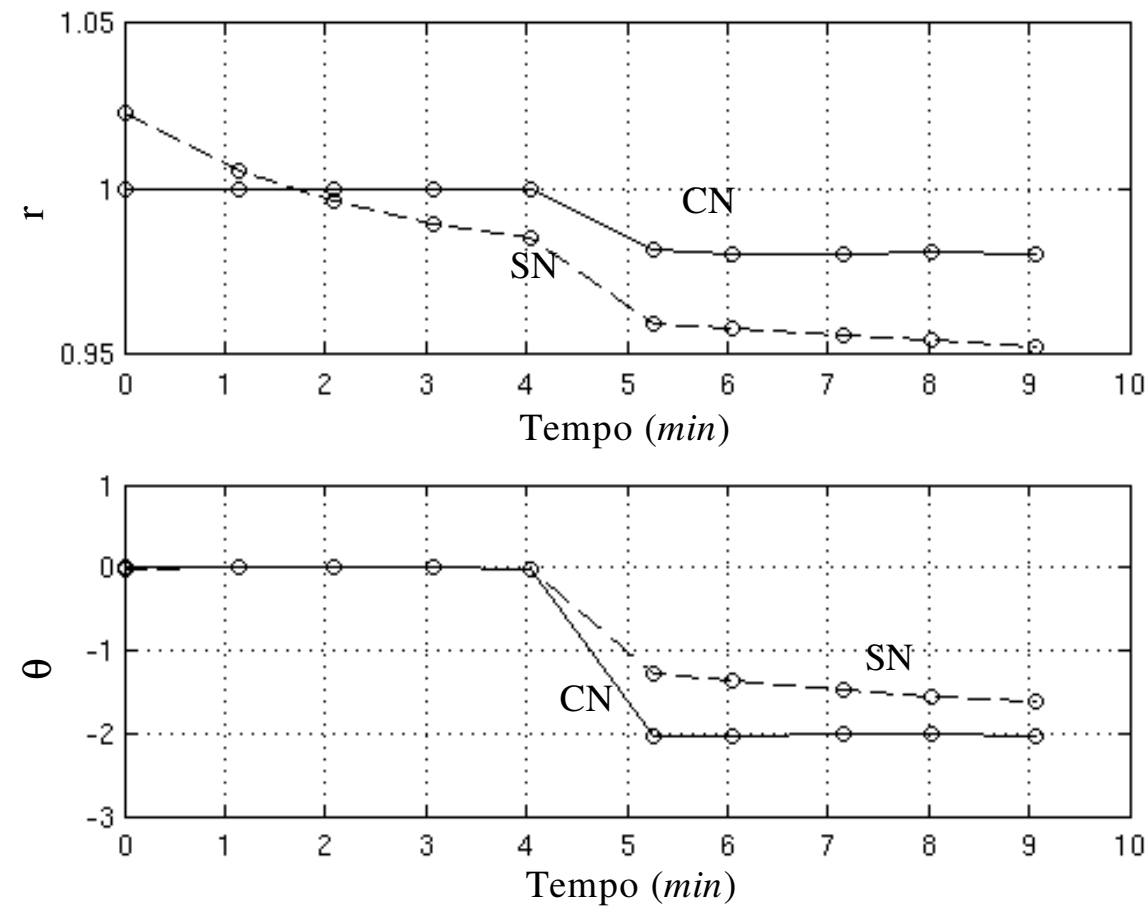

Figura 6.7. Efeito da normalização sobre a medição do coeficiente de reflexão do óleo SAE 40 a $20^{\circ} \mathrm{C}$ e freqüência de operação de $0,5 \mathrm{MHz}$ : $\mathrm{CN}$ com normalização e $\mathrm{SN}$ sem normalização.

$\mathrm{Na}$ figura, observa-se claramente o efeito da normalização sobre o coeficiente medido. As curvas de magnitude e fase praticamente não apresentam dependência do tempo. Além disso, o valor do coeficiente medido no caso com normalização foi o resultado esperado, já que nessa frequiência de operação esse óleo apresenta comportamento Newtoniano. O valor de viscosidade obtido está próximo do valor medido com o viscosímetro rotacional, sendo o desvio menor a 5,5\%. 


\subsubsection{Estudo experimental do comportamento da fase no tempo}

Devido às incoerências obtidas nos testes iniciais, analisou-se o comportamento no tempo da fase do coeficiente de reflexão. Usando o dispositivo 2, foram feitas aquisições sem líquido a intervalos de aproximadamente 15 minutos. Foi calculado o desvio da fase (sem normalização) de cada um dos sinais com respeito à fase do primeiro sinal, como mostra a figura 6.8. Pode-se ver claramente um incremento linear da fase com o tempo. No início do teste, a temperatura da água era de $19,5^{\circ} \mathrm{C}$ e ao final, após 6 horas, a temperatura medida foi de $19,9^{\circ} \mathrm{C}$ e o desvio na fase foi de $13^{\circ}$. Foi observado que a fase mudava a uma taxa de $32,5^{\circ} /{ }^{\circ} \mathrm{C}$, devido à variação da temperatura ambiente, que fez variar a temperatura da água e da célula de medição, por conseguinte, mudando a velocidade de propagação da onda. Verificou-se que a mudança na fase depende principalmente da temperatura, pois em testes posteriores, quando a temperatura ambiente desceu, a pendente da reta da mudança de fase em função do tempo ficou negativa.

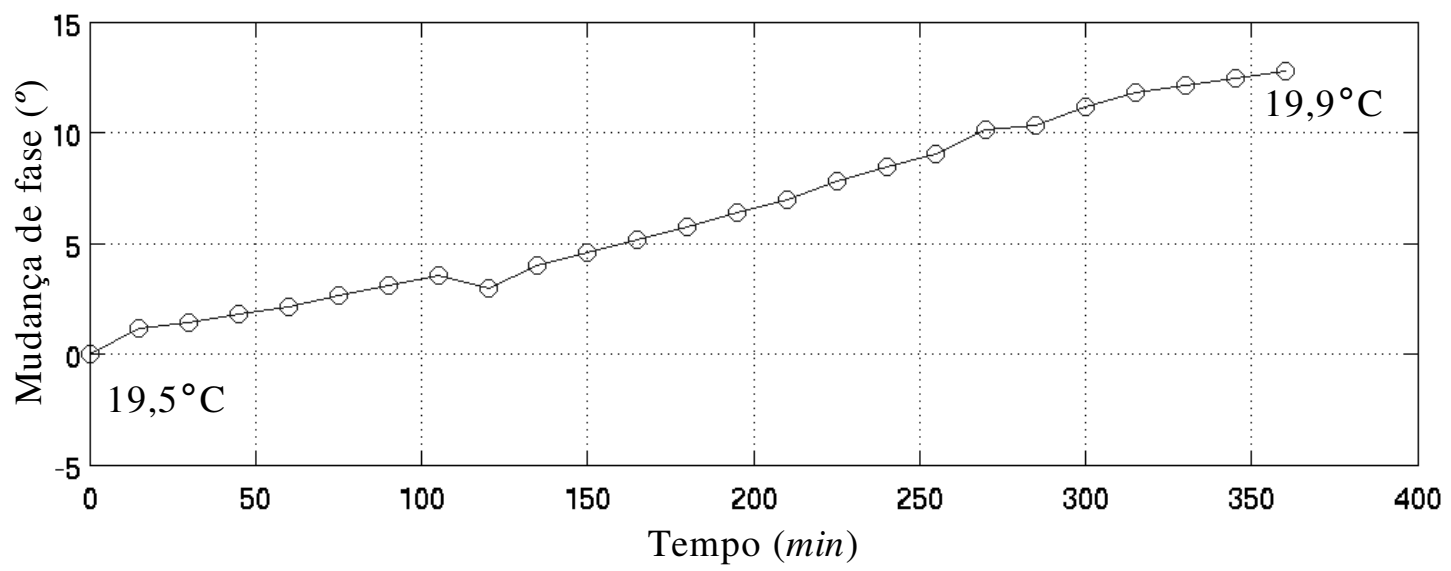

Figura 6.8 Mudança da fase com o tempo para SAE 40 a 1,0MHz (dispositivo 2).

Foi realizado um segundo teste para analisar o comportamento da fase quando o óleo é colocado dentro da câmara da célula. Foram feitas 6 aquisições no ar, foi injetado o óleo e depois foram feitas outras 7 aquisições. A figura 6.9 mostra os resultados obtidos plotados em função do tempo. Pode-se ver que a fase aumenta de forma linear ainda em um período grande de tempo, o óleo é injetado na célula depois da sexta aquisição. Acontece o deslocamento de fase devido à presença do líquido na interface de medição, depois a fase continua aumentando também de forma linear e com a mesma 
inclinação. Observa-se ainda a dependência da fase com o tempo, nesse caso, é possível calcular a mudança ocasionada pela presença do óleo, devido ao comportamento linear. Em outras medições, a mudança de fase obtida no caso da figura 6.7 (óleo SAE 40 a $20^{\circ} \mathrm{C}$ e a freqüência de $1,0 \mathrm{MHz}$ ) foi de 2 graus. Esse valor é obtido calculando a diferença entre as duas retas, por exemplo, usando regressão linear.

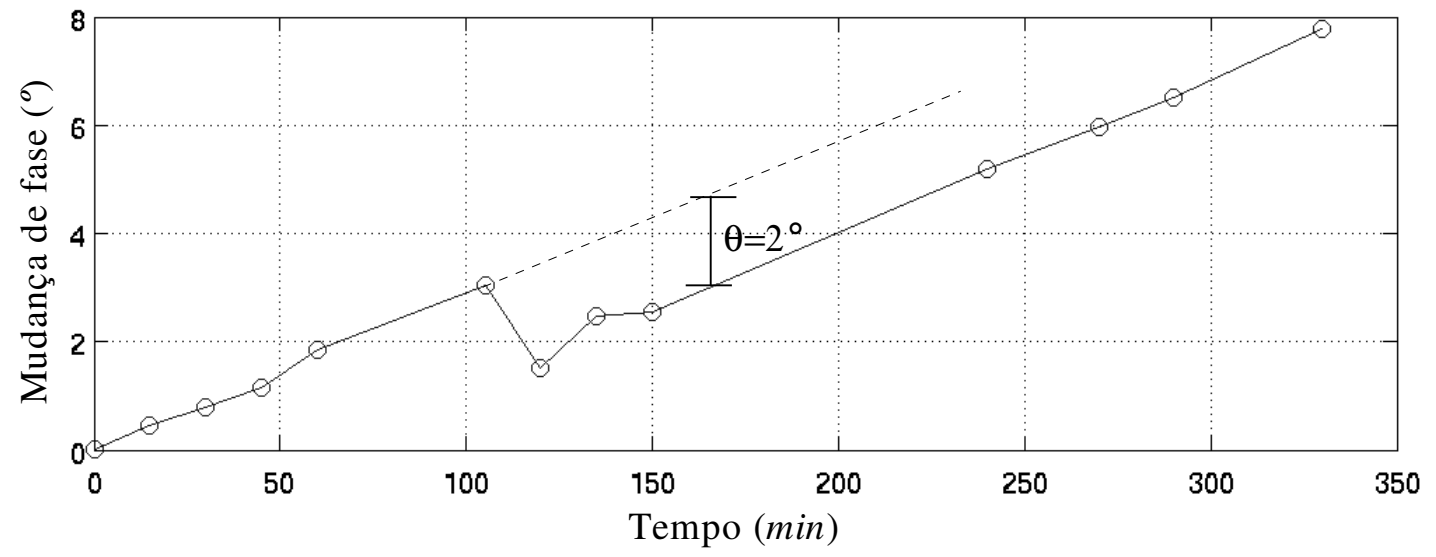

Figura 6.9 Mudança da fase com o tempo para SAE 40 a 1,0MHz (dispositivo 2).

Com base nos resultados desta seção, conclui-se que, ainda com a grande dependência da fase com a temperatura (inclusive na pequena faixa definida pela precisão do banho), a mudança é lenta o suficiente para que esse efeito seja desprezado se o teste é feito num período pequeno de tempo.

\subsubsection{Estabilidade térmica do sistema de medição}

Para estabelecer o tempo requerido pelo sistema de medição para atingir a estabilidade térmica, foi monitorado o comportamento da fase que está relacionada com a mudança da temperatura no sólido, como mostrado na seção anterior, e a temperatura da amostra líquida.

$\mathrm{O}$ dispositivo 2 , inicialmente à temperatura ambiente de $25^{\circ} \mathrm{C}$, foi colocado no banho a $30^{\circ} \mathrm{C}$ e a fase da onda foi medida em intervalos pequenos de tempo, sendo obtida a curva mostrada na figura 6.10. Verifica-se que a fase muda rapidamente no início do experimento e, depois de 16 minutos, está praticamente estável. 


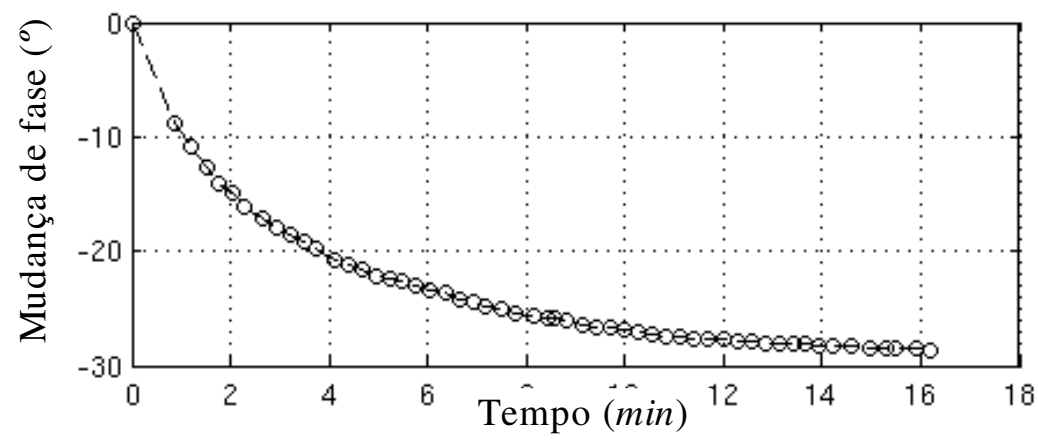

Figura 6.10 Mudança da fase com o tempo para SAE 40 a 1,0MHz (dispositivo 2).

Em outro teste, a amostra líquida, numa seringa e à temperatura ambiente de $25^{\circ} \mathrm{C}$, foi colocada no banho termostático a $30^{\circ} \mathrm{C}$. A temperatura da amostra foi medida a cada 5 minutos. $\mathrm{O}$ valor de $30^{\circ} \mathrm{C}$ foi obtido depois que a amostra permaneceu 30 minutos no banho.

Com base nos resultados mostrados nesta seção, foi estabelecido que um tempo mínimo de uma hora é necessário para se conseguir a estabilidade térmica do sistema de medição antes de realizar o teste.

\subsection{INFLUÊNCIA DA LARGURA DE BANDA DO TRANSDUTOR NA MEDIÇÃO DO COEFICIENTE DE REFLEXÃO}

Verificou-se que o coeficiente de reflexão pode ter valor diferente quando calculado no domínio do tempo e no domínio da frequiência, variando conforme a largura de banda do sinal, além de outros fatores como ruído e distorção na forma da onda. Na tabela 6.6, é mostrado o coeficiente de reflexão calculado no domínio do tempo e no domínio da freqüência, para $\operatorname{SAE} 40$ a $20^{\circ} C$, nas freqüências de 2,25 e 3,5MHz. Percebe-se que tanto a magnitude como a fase do coeficiente de reflexão apresentam valores diferentes a $2,25 \mathrm{MHz}$. Já na freqüência de $3,5 \mathrm{MHz}$, a diferença na fase é menor que no primeiro e a diferença na magnitude é nula.

Tabela 6.6. Comparação dos coeficientes de reflexão calculados nos domínios do tempo e da frequiência, para $\mathrm{SAE} 40$ a $20^{\circ} \mathrm{C}$ nas frequiências de 2,25 e $3,5 \mathrm{MHz}$.

\begin{tabular}{|c|c|c|c|c|}
\hline \multirow{2}{*}{} & \multicolumn{2}{|c|}{$2,25 \mathrm{MHz}$} & \multicolumn{2}{c|}{$3,5 \mathrm{MHz}$} \\
\hline$r$ & Tempo & Freqüência & Tempo & Freqüência \\
\hline$\theta$ & 0,9478 & 0,9520 & 0,9290 & 0,9290 \\
\hline
\end{tabular}


A figura 6.11 mostra a forma de onda e o espectro de Fourier dos sinais. Pode-se ver que o sinal de $3,5 \mathrm{MHz}$ tem maior número de ciclos de senóide. Nesse caso, a freqüência central do sinal está mais definida e a energia é transmitida ao líquido, principalmente, nessa freqüência. Já no caso do sinal de $2,25 \mathrm{MHz}$, devido a sua banda mais larga, a energia é transmitida em um espectro mais amplo de freqüências. Quando o coeficiente de reflexão é calculado no domínio da freqüência, se obtém o seu valor na freqüência $f_{i}$, entretanto, quando o cálculo é feito no domínio do tempo, se obtém um valor médio de todas as freqüências do espectro.
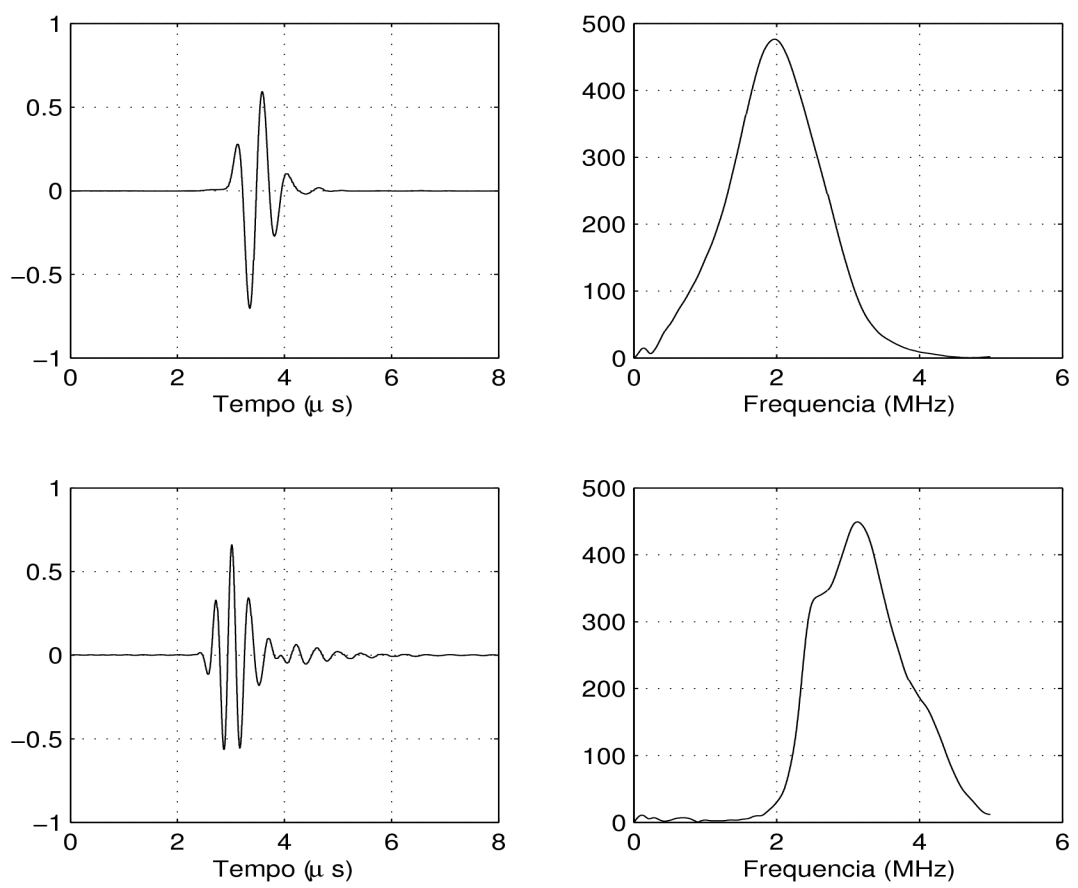

Figura 6.11. Forma de onda e espectro de Fourier dos sinais gerados pelos transdutores de 2,25 e $3,5 \mathrm{MHz}$, respectivamente.

Esse problema também é encontrado no trabalho de Wu (1996), onde é usada espectrometria ultra-sônica para medir as propriedades acústicas de materiais sólidos. Nesse trabalho, são usados transdutores de ondas longitudinais, funcionando no modo transmissão-recepção e imersos na água, com a amostra de material a caracterizar colocada entre os dois transdutores. São comparados os sinais nos casos com e sem amostra. A diferença na fase dos sinais é relacionada com a velocidade de propagação e a diferença de amplitude com a atenuação. O cálculo da diferença de amplitude e de fase pode ser feito nos domínios do tempo e da freqüência. Nesse trabalho, é concluído que o 
cálculo no domínio do tempo fornece valores de grupo, ou seja, o valor médio de todas as freqüências. Assim, para que esses valores sejam iguais aos valores calculados no domínio da freqüência (na freqüência central do sinal), o sinal deve ter uma banda suficientemente estreita de maneira que sua freqüência central seja bem definida e a atenuação no material sólido deve ser pequena, caso contrário o pulso fica distorcido e os valores obtidos no domínio do tempo levam a grandes erros.

\subsection{ANÁLISE DA PROPAGAÇÃO DO ERRO NA MEDIÇÃO}

No trabalho de Buiochi (2000), foi mostrado, usando a teoria de erros, que o desvio relativo na viscosidade medida por ultra-som $\left(\sigma_{\eta_{d}} / \eta_{d}\right)$, usando a equação 5.7, pode ser obtido a partir dos desvio relativos obtidos na determinação da magnitude ( $\left.\sigma_{r} / r\right)$ e da fase $\left(\sigma_{\theta} / \theta\right)$ do coeficiente de reflexão, da velocidade da onda de cisalhamento no sólido $\left(\sigma_{v_{s}} / v_{s}\right)$ e das densidades do sólido $\left(\sigma_{\rho_{s}} / \rho_{s}\right)$ e do líquido testado $\left(\sigma_{\rho_{L}} / \rho_{L}\right)$, assim:

$$
\frac{\sigma_{\eta_{d}}}{\eta_{d}}=\sqrt{\left(\frac{\partial \eta_{d}}{\partial r}\right)^{2}\left(\frac{\sigma_{r}}{r}\right)^{2}+\left(\frac{\partial \eta_{d}}{\partial \theta}\right)^{2}\left(\frac{\sigma_{\theta}}{\theta}\right)^{2}+4\left(\frac{\sigma_{v_{s}}}{v_{s}}\right)^{2}+4\left(\frac{\sigma_{\rho_{s}}}{\rho_{s}}\right)^{2}+\left(\frac{\sigma_{\rho_{L}}}{\rho_{L}}\right)^{2}},
$$

onde:

$$
\frac{\partial \eta_{d}}{\partial r}=1+\frac{-2 r^{2}}{1-r^{2}}-\frac{4 r(r+\cos \theta)}{1+r^{2}+2 r \cos \theta}
$$

$\mathrm{e}$

$$
\frac{\partial \eta_{\theta}}{\partial \theta}=\frac{\theta}{\tan \theta}+\frac{4 \theta r \sin \theta}{1+r^{2}+2 \mathrm{r} \cos \theta} .
$$

Com relação às grandezas mostradas acima, nota-se que o desvio relativo é a razão entre o desvio padrão e o valor médio para cada uma delas.

No próximo capítulo (resultados), são mostrados os valores da magnitude e da fase do coeficiente de reflexão para vários óleos de diferente viscosidade. Nessa seção, são usados alguns desses resultados para analisar qual é a grandeza que mais influencia 
o desvio relativo da viscosidade. Para azeite de oliva a $15^{\circ} \mathrm{C}$ e freqüência de operação de $3,5 \mathrm{MHz}$, foram obtidos aproximadamente os seguintes valores: $r=0,95$ e $\theta=1,6^{\circ}$, e para óleo SAE 250 a $22^{\circ} \mathrm{C}$ e $5 \mathrm{MHz}: r=0,78$ e $\theta=8,5^{\circ}$. Usando esses valores na equação 6.1 , podem ser obtidas as expressões do desvio relativo da viscosidade em função somente dos desvios relativos das grandezas medidas. Assim, no caso do azeite de oliva tem-se:

$$
\frac{\sigma_{\eta_{d}}}{\eta_{d}}=\sqrt{378,8\left(\frac{\sigma_{r}}{r}\right)^{2}+1,001\left(\frac{\sigma_{\theta}}{\theta}\right)^{2}+4\left(\frac{\sigma_{v_{s}}}{v_{s}}\right)^{2}+4\left(\frac{\sigma_{\rho_{s}}}{\rho_{s}}\right)^{2}+\left(\frac{\sigma_{\rho_{L}}}{\rho_{L}}\right)^{2}},
$$

e para o SAE 250 resulta a seguinte expressão:

$$
\frac{\sigma_{\eta_{d}}}{\eta_{d}}=\sqrt{14,89\left(\frac{\sigma_{r}}{r}\right)^{2}+1,041\left(\frac{\sigma_{\theta}}{\theta}\right)^{2}+4\left(\frac{\sigma_{v_{s}}}{v_{s}}\right)^{2}+4\left(\frac{\sigma_{\rho_{s}}}{\rho_{s}}\right)^{2}+\left(\frac{\sigma_{\rho_{L}}}{\rho_{L}}\right)^{2}} .
$$

Supondo um desvio relativo igual para todas as grandezas, pode-se determinar quais delas geram a maior incerteza na determinação da viscosidade.

Nas medições foi observado que o desvio relativo no caso da fase foi sempre maior em pelo menos uma ordem de grandeza que o desvio da magnitude. Nesse caso, para o óleo menos viscoso (equação 6.2), a contribuição ao erro na viscosidade devido à incerteza na determinação da magnitude foi o dobro da contribuição devido à fase. Já no caso do óleo mais viscoso (equação 6.3), o erro contribuído pela incerteza na determinação da fase é muito maior.

No caso da velocidade de cisalhamento e as densidades do sólido e do líquido, o erro fornecido é independente da viscosidade do líquido e da frequiência de operação. Como a velocidade pode ser medida com boa precisão, seu desvio relativo é muito pequeno. No caso das densidades, seu valor também pode ser medido com boa precisão, além disso, sua variação com a temperatura é pequena. 
CAPÍTULO 7

\section{RESULTADOS}

Neste capítulo, são apresentados os resultados experimentais obtidos e suas respectivas discussões. Na primeira seção, são feitas algumas definições necessárias na interpretação das figuras e tabelas. Nas seguintes seções, são apresentados os resultados ordenados segundo o dispositivo usado nas as medições e o tipo de líquido testado.

\subsection{DEFINIÇÕES}

O erro percentual entre as medições de viscosidade é definido por:

$$
e=\frac{\left|\eta-\eta_{d}\right|}{\eta} .100 \%
$$

onde $\eta$ é a viscosidade de baixa freqüência medida com o viscosímetro rotacional e $\eta_{d}$ é a viscosidade a alta freqüência medida por ultra-som.

Nos gráficos, também é plotado o desvio padrão ocasionado pela dispersão dos resultados do coeficiente de reflexão nas sucessivas aquisições de um mesmo teste. Esse desvio representa a incerteza na determinação do coeficiente de reflexão devido à influência dos fatores externos.

Neste capítulo, a frequiência de operação refere-se à freqüência que vem especificada no transdutor. A freqüência central da onda recebida pelo transdutor é menor, isso devido à atenuação das ondas que é maior nas frequiências altas e ocasiona que o valor central (máxima amplitude do espectro de Fourier) se desloque para a esquerda. Por exemplo, com os transdutores de $1,2,25$ e 3,5MHz e o dispositivo de medição 2, os valores recebidos foram 0,972, 1,92 e 3,16 MHz, respectivamente.

Nas tabelas e gráficos de resultados apresentados neste capítulo, são usadas a nomenclatura e as unidades mostradas na seguinte tabela: 
Tabela 7.1 Nomenclatura e unidades usadas nas tabelas e gráficos de resultados.

\begin{tabular}{|l|c|c|}
\hline \multicolumn{1}{|c|}{ Grandeza } & Símbolo & Unidade \\
\hline Magnitude do coeficiente de reflexão & $r$ & Adimensional \\
\hline Fase do coeficiente de reflexão & $\theta$ & Grau $\left(^{\circ}\right)$ \\
\hline Temperatura & $T$ & Grau Célsius $\left({ }^{\circ} \mathrm{C}\right)$ \\
\hline Freqüência & $f$ & Megahertz $(\mathrm{MHz})$ \\
\hline Tempo & $t$ & Microsegundos $(\mu s)$ \\
\hline $\begin{array}{l}\text { Viscosidade a baixa freqüência medida com o } \\
\text { viscosímetro rotacional. }\end{array}$ & $\eta$ & Pascal segundo $(\mathrm{Pa.s})$ \\
\hline $\begin{array}{l}\text { Viscosidade a alta freqüência medida por ultra-som. } \\
\text { Viscosidade a alta freqüência medida por ultra-som } \\
\text { usando a simplificação para líquido Newtoniano } \\
\text { (equação 5.9). }\end{array}$ & $\eta_{n}$ & $($ Pa.s $)$ \\
\hline $\begin{array}{l}\text { Erro percentual } \\
\text { Desvio padrão }\end{array}$ & $\sigma$ & Porcentagem $(\%)$ \\
\hline
\end{tabular}

\subsection{DISPOSITIVO 1}

Tabela 7.2 Medições feitas com o dispositivo 1 para diferentes líquidos: cálculo do coeficiente de reflexão feito no domínio da frequiência.

\begin{tabular}{|c|c|c|c|c|}
\cline { 2 - 5 } \multicolumn{1}{l|}{} & Óleo de milho & SAE 40 & SAE 90 & SAE 140 \\
\hline$T$ & 30,0 & 20,3 & 22,4 & 21,3 \\
\hline$r$ & - & $0,995 \pm 8.10^{-4}$ & $0,981 \pm 3.10^{-4}$ & $0,971 \pm 0,002$ \\
\hline$\theta$ & $1,503 \pm 0,032$ & $1,403 \pm 0,030$ & $1,738 \pm 0,031$ & $2,1438 \pm 0,146$ \\
\hline$\eta_{d}$ & - & $0,055 \pm 0,010$ & $0,267 \pm 0,007$ & $0,507 \pm 0,070$ \\
\hline$\eta$ & 0,046 & 0,351 & 0,597 & 1,333 \\
\hline$e$ & - & 84,33 & 55,28 & 61,97 \\
\hline$G^{\prime}$ & - & $-0,428 \pm 0018$ & $-0,408 \pm 0,023$ & $-0,404 \pm 0,050$ \\
\hline
\end{tabular}


Com o dispositivo 1 foram testados um óleo alimentício (óleo de milho) e três óleos automotivos (SAE 40, SAE 90 e SAE 140) na frequiência de 0,5 MHz. As tabelas 7.2 e 7.3 apresentam os resultados obtidos, quando o coeficiente de reflexão é calculado no domínio da freqüência e no domínio do tempo, respectivamente. É mostrada a temperatura na qual foi realizado cada teste. São apresentadas a viscosidade medida por ultra-som e a viscosidade medida com o viscosímetro rotacional, sendo calculado o erro percentual (e) entre elas. Além disso, é calculado o módulo elástico (equação 3.24).

Tabela 7.3 Medições feitas com o dispositivo 1 para diferentes líquidos: cálculo do coeficiente de reflexão feito no domínio do tempo.

\begin{tabular}{|c|c|c|c|c|}
\cline { 2 - 5 } \multicolumn{1}{c|}{} & Óleo de milho & SAE 40 & SAE 90 & SAE 140 \\
\hline$T$ & 30,0 & 20,3 & 22,4 & 21,3 \\
\hline$r$ & $0,995 \pm 3.10^{-4}$ & $0,973 \pm 0,001$ & $0,964 \pm 0,002$ & $0,956 \pm 0,003$ \\
\hline$\theta$ & $0,692 \pm 0,052$ & $1,327 \pm 0,044$ & $1,723 \pm 0,031$ & $2,039 \pm 0,138$ \\
\hline$\eta_{d}$ & $0,027 \pm 0,003$ & $0,301 \pm 0,013$ & $0,516 \pm 0,020$ & $0,746 \pm 0,104$ \\
\hline$\eta$ & 0,046 & 0,351 & 0,597 & 1,333 \\
\hline$e$ & 41,30 & 14,25 & 13,57 & 44,04 \\
\hline$G^{\prime}$ & $-0,082 \pm 0,014$ & $0,151 \pm 0,057$ & $0,329 \pm 0,096$ & $0,542 \pm 0,092$ \\
\hline
\end{tabular}

A figura 7.1 mostra as curvas de magnitude e fase do coeficiente de reflexão em função do tempo para os casos do óleo de milho a $30^{\circ} \mathrm{C}$ e SAE 90 a $22,4^{\circ} \mathrm{C}$. No caso do óleo de milho, o valor mostrado na figura 7.1(a) foi calculado no domínio do tempo. O cálculo do coeficiente de reflexão no domínio da frequiência resultou num valor absurdo $(r>1)$ que foi descartado. A figura 7.1(b) mostra o melhor resultado obtido com o dispositivo 1, calculado no domínio da frequiência. Os resultados restantes mostraram maior dependência temporal, similares ao caso da figura 7.1(a). Nesses gráficos é plotado o valor negativo da fase $(-\theta)$ por razões de visualização, mas nas equações sempre é substituído seu valor absoluto. 

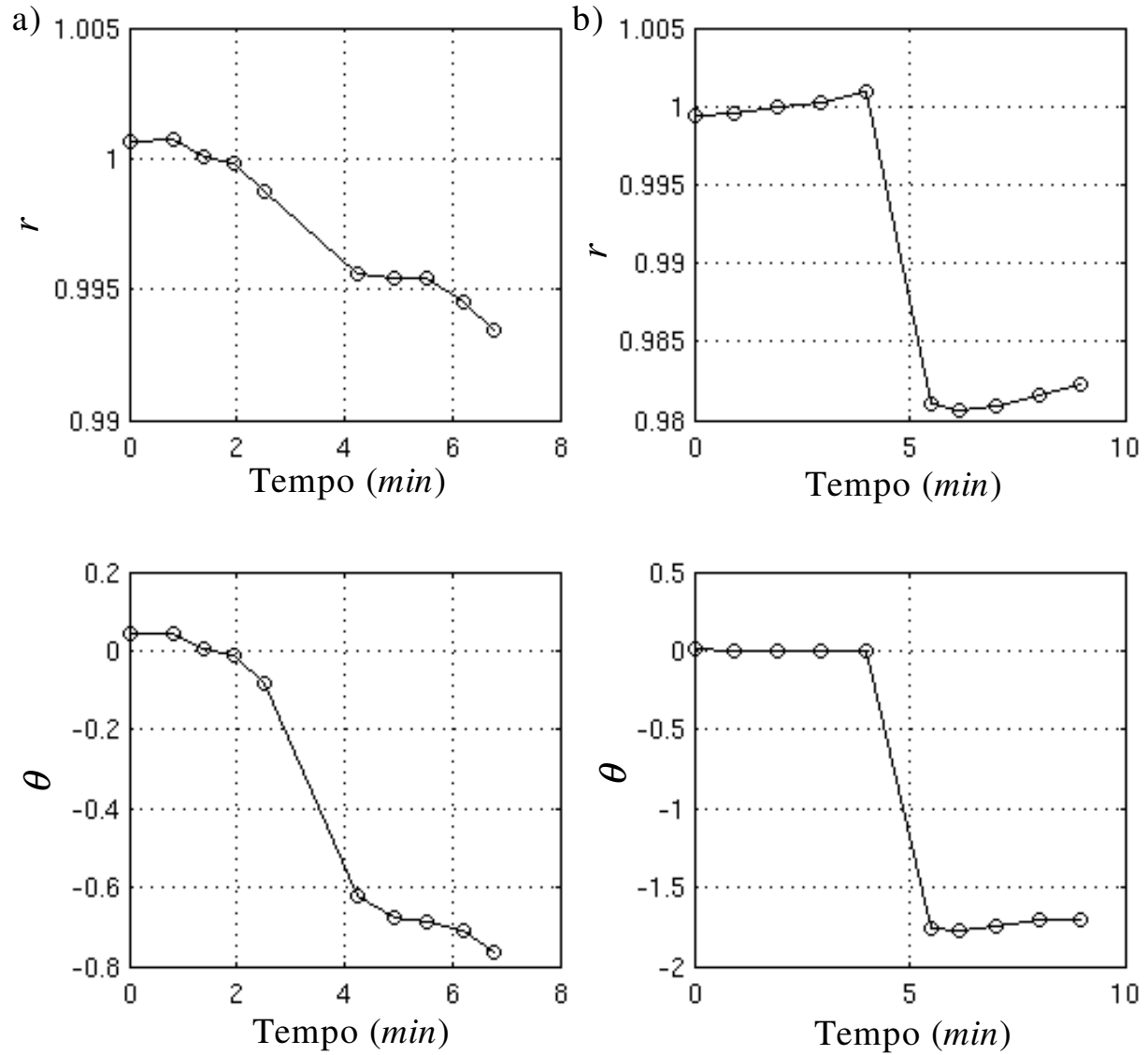

Figura 7.1. Gráficos do coeficiente de reflexão em função do tempo para a) óleo de milho a $30^{\circ}$ $C$ no domínio do tempo e b) SAE 90 a $22,4^{\circ} C$ no domínio da freqüência.

Com base nos dados plotados na figura 7.1, verifica-se que o coeficiente de reflexão apresenta forte variação temporal, levando a grandes desvios na determinação da viscosidade. Esses desvios influenciam principalmente os resultados dos líquidos de baixa viscosidade, cujos valores de magnitude e fase do coeficiente de reflexão são menores.

Os resultados apresentados nesta seção mostram que o dispositivo 1 é muito sensível à influência dos fatores externos: temperatura e instabilidade da eletrônica. $\mathrm{O}$ fato de estar a superfície de medição fora do banho, impossibilita um bom controle da temperatura da amostra. Além disso, são induzidos gradientes no sólido devido à diferença de temperatura entre o banho e o ambiente que, como foi dito no capítulo 6, afeta fortemente a medição da fase. O maior problema dessa montagem é a presença indesejável da onda longitudinal gerada pelo transdutor de cisalhamento. A onda longitudinal, ao contrário da onda de cisalhamento, propaga-se facilmente no líquido, 
mas também é refletida completamente no caso da medição com ar. Então, como as duas ondas se somam de forma diferente em cada caso, apresentam-se grandes erros na comparação dos sinais.

Nas especificações do transdutor, acha-se que a razão entre a amplitude da onda de cisalhamento e da onda longitudinal, gerada simultaneamente no transdutor de cisalhamento, é superior a $30 \mathrm{~dB}$. Entretanto, como a atenuação das ondas de cisalhamento é muito maior, essa razão vai ficando menor quanto maior for a distância percorrida. Uma outra desvantagem dos transdutores de cisalhamento consiste em que precisam estar colados às linhas de retardo ou acoplado com alguma resina de altíssima viscosidade, ficando difícil sua troca, necessária quando se deseja mudar a frequiência de operação.

\subsection{DISPOSITIVO 2}

O dispositivo 2 usa conversão de modo para gerar as ondas de cisalhamento a partir de ondas longitudinais, método inicialmente proposto por Buiochi et al. (1995). Sua principal vantagem consiste no fato de gerar ondas de cisalhamento mais puras, sem a onda longitudinal presente no caso dos transdutores de cisalhamento. Uma outra vantagem, consiste na maior gama de freqüências com que são fabricados os transdutores de ondas longitudinais, possibilitando a análise numa gama maior de freqüências.

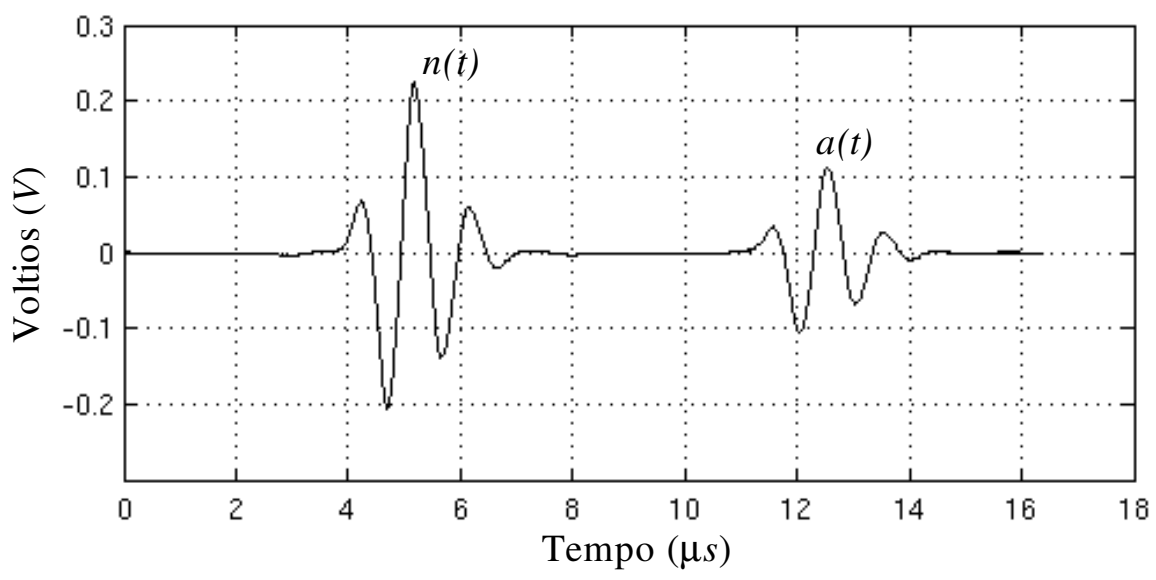

Figura 7.2. Sinal obtido com o dispositivo 2 a $1 \mathrm{MHz}$.

Na figura 7.2, são mostrados dois sinais obtidos com o dispositivo 2: o eco refletido pela interface de referência $n(t)$ e o eco refletido pela interface de medição $a(t)$. 
A amplitude dos sinais de referência e medição são aproximadamente de 400 e $200 \mathrm{mV}$ pico a pico, respectivamente, com ganho de $0 d B$. Essa amplitude fornece uma boa relação sinal-ruído, a principal vantagem ao se usar um transdutor convencional para emitir e receber as ondas, em comparação aos receptores de PVDF testados (ver seção 6.1.3).

\subsubsection{Produtos alimentícios}

\subsubsection{Azeite de oliva}
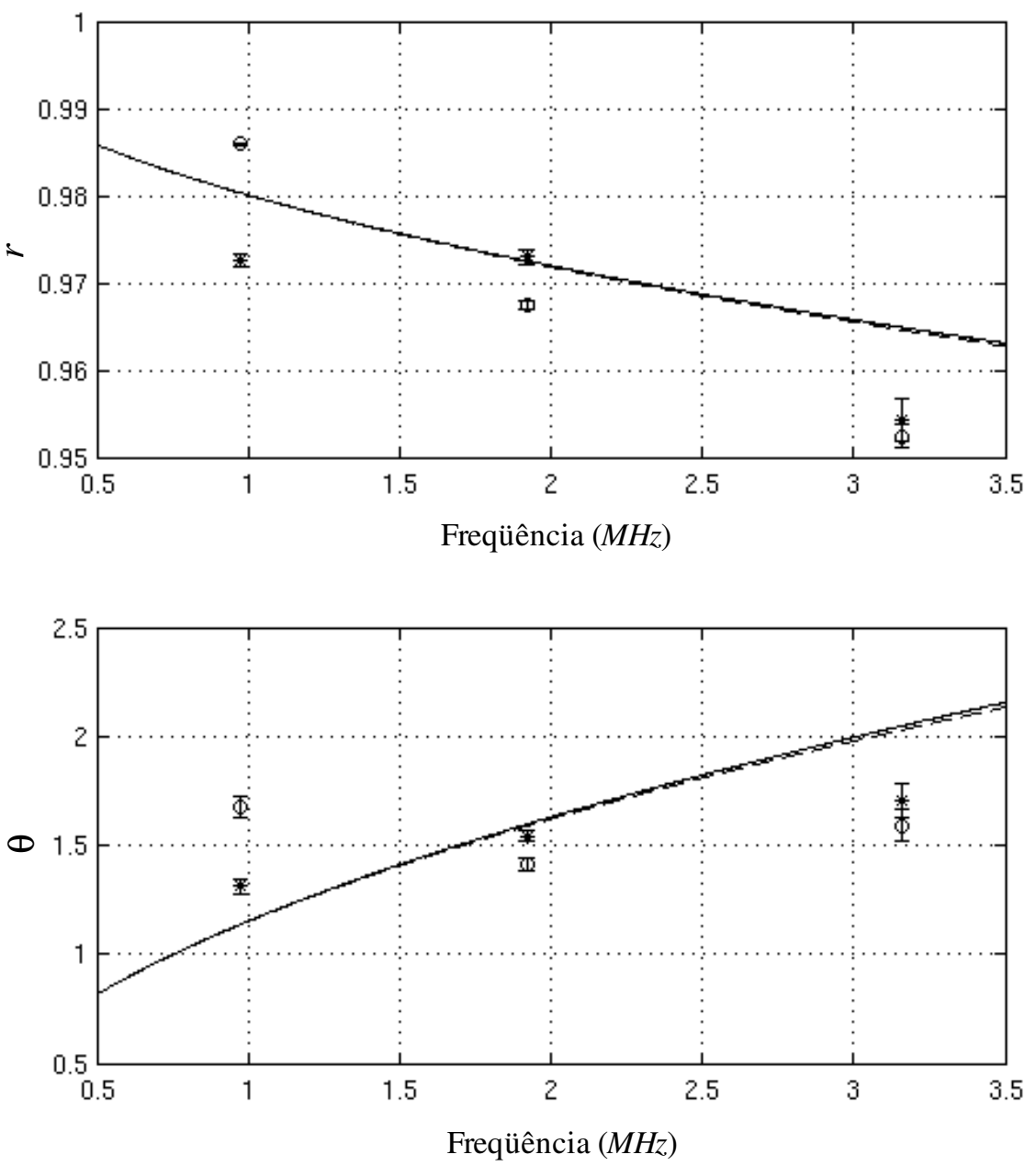

Figura 7.3. Coeficiente de reflexão em função da freqüência do azeite de oliva a $15^{\circ} \mathrm{C}$, calculado no domínio da frequiência (círculos) e no domínio do tempo (estrelas).

A figura 7.3, mostra a magnitude e a fase do coeficiente de reflexão do azeite de oliva a $15^{\circ} \mathrm{C}$, nas frequiências de $1,2,25$ e 3,5MHz . Nessa figura, os círculos (o) e as estrelas (*) representam os valores médios do coeficiente de reflexão quando calculado 
no domínio da frequiência e quando calculado no domínio do tempo, respectivamente. Também é mostrado o desvio padrão de cada medição, ocasionado pela dispersão das grandezas medidas entre cada uma das aquisições (mudança no tempo do coeficiente de reflexão). A linha sólida representa a predição do coeficiente de reflexão feita com o modelo de líquido Newtoniano. Observou-se diferenças entre os valores da magnitude e da fase quando calculados no domínio do tempo e da freqüência. Embora os resultados mostrem a mesma tendência que a predição feita pelo modelo Newtoniano, principalmente no caso da magnitude, os valores numéricos são diferentes.

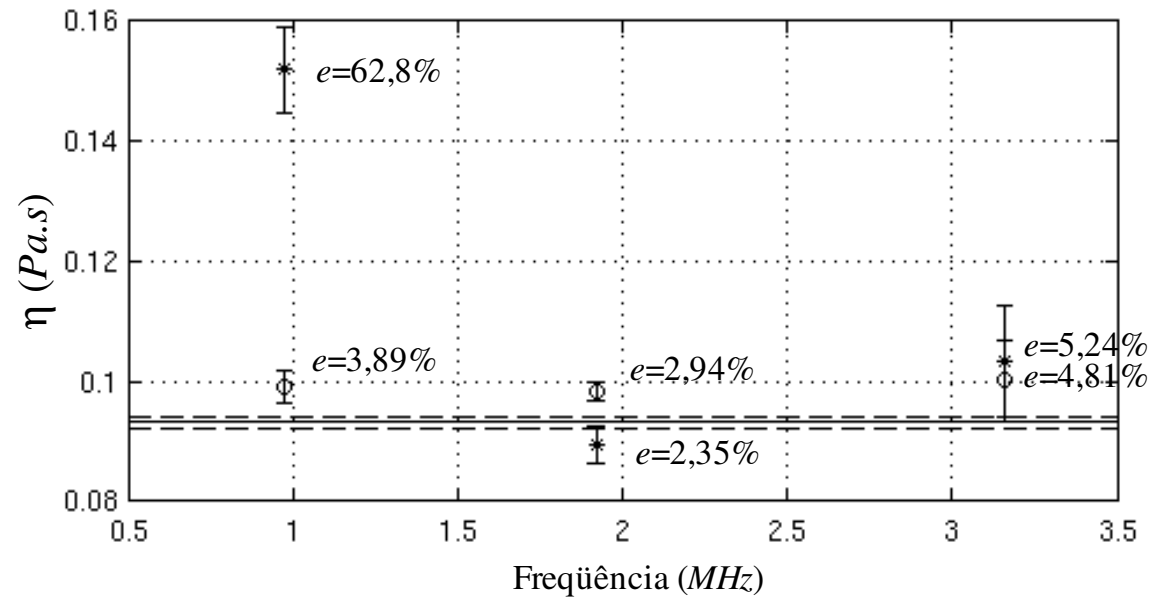

Figura 7.4. Viscosidade em função da frequiência do azeite de oliva a $15^{\circ} \mathrm{C}$, valores calculados no domínio da frequiência (círculos) e domínio do tempo (estrelas).

A figura 7.4 mostra a viscosidade calculada a partir dos valores do coeficiente de reflexão mostrados na figura 7.3. Nessa figura, os círculos e as estrelas representam a viscosidade calculada, respectivamente, no domínio da freqüência e no domínio do tempo. A linha sólida representa a média da viscosidade a baixa frequiência (independente da freqüência segundo o modelo de líquido Newtoniano) e as linhas tracejadas representam a faixa de viscosidade definida pela precisão no controle da temperatura do banho, neste caso $\pm 0,2^{\circ} \mathrm{C}$. Os valores obtidos no domínio da frequiência ficam muito perto daqueles medidos com o viscosímetro rotacional. No caso dos valores obtidos no domínio do tempo o erro foi maior, principalmente a $1 \mathrm{MHz}$, Além disso, os desvios, ocasionados pela incerteza na determinação do coeficiente de reflexão, também são maiores. Na figura, são mostrados os valores do erro percentual que, no caso do cálculo feito na freqüência, são significativamente menores ( $e \leq 4,81 \%)$. Além disso, os resultados mostram independência da frequiência, o que é esperado quando o 
comportamento do líquido é puramente viscoso (Newtoniano).

A figura 7.5 compara os valores de viscosidade obtidos usando a equação 5.7 (círculos), que leva em conta tanto a magnitude como a fase do coeficiente de reflexão, com os valores obtidos mediante a simplificação para líquido Newtoniano (estrelas) usando a equação 5.9, que considera para o cálculo da viscosidade somente a magnitude do coeficiente de reflexão. O erro percentual é muito maior no segundo caso que, além disso, varia com a freqüência.

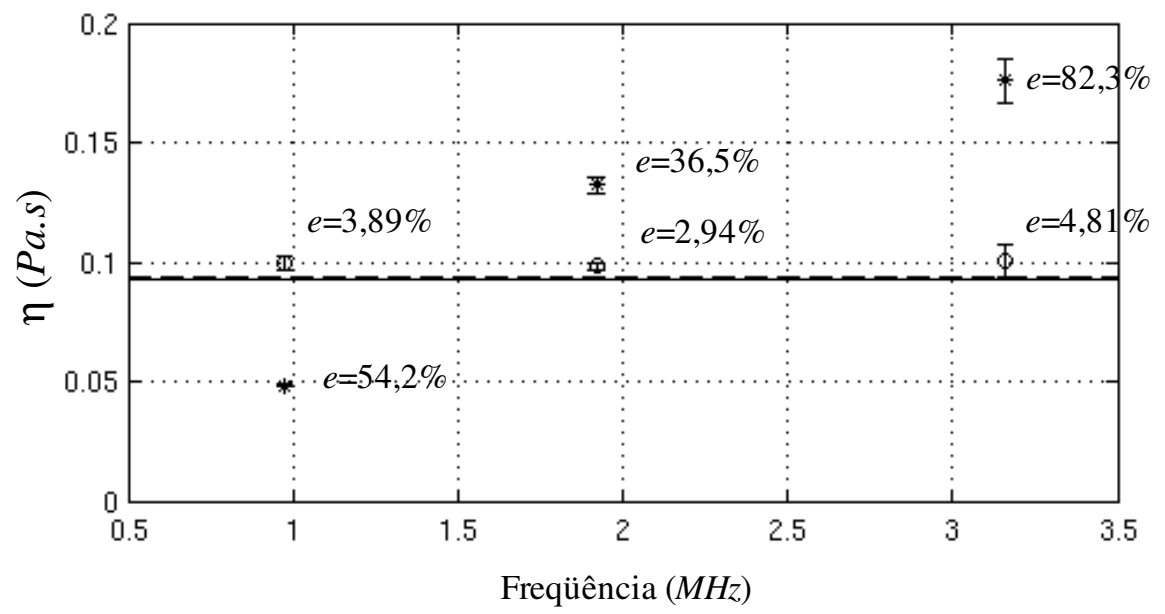

Figura 7.5. Viscosidade em função da freqüência do azeite de oliva a $15^{\circ} \mathrm{C}$. Valores obtidos usando a magnitude e a fase do coeficiente de reflexão (círculos) e simplificação para líquido Newtoniano (estrelas).

A figura 7.6 mostra o módulo elástico $\left(G^{\prime}\right)$ que, como era esperado, aumenta com a freqüência. O módulo elástico representa o nível de elasticidade apresentado pelo líquido nessa frequiência, sendo próximo de zero quando o comportamento do líquido é Newtoniano e tendendo a um valor máximo $\left(G_{\infty}\right)$ quando a freqüência tende ao infinito. Os valores mostrados de $G^{\prime}$ para azeite de oliva a $15^{\circ} \mathrm{C}$ são pequenos quando comparados com o valor de $G_{\infty}=1000 \mathrm{MPa}$ achado na literatura para a maioria dos líquidos (Buiochi, 2000). Como visto na seção 7.2, também foram obtidos valores negativos do módulo de elasticidade. Teoricamente esses valores são absurdos, mas podem ser interpretados como uma elasticidade pequena (valor positivo perto de zero), que ficam dessa maneira como conseqüência da incerteza na determinação do coeficiente de reflexão. 
O módulo elástico pode ser usado para determinar se o comportamento do líquido é Newtoniano. Nesse tipo de experimento, o líquido apresenta um certo nível de elasticidade. O problema consiste em determinar até que valor do módulo elástico podese considerar o líquido como Newtoniano.

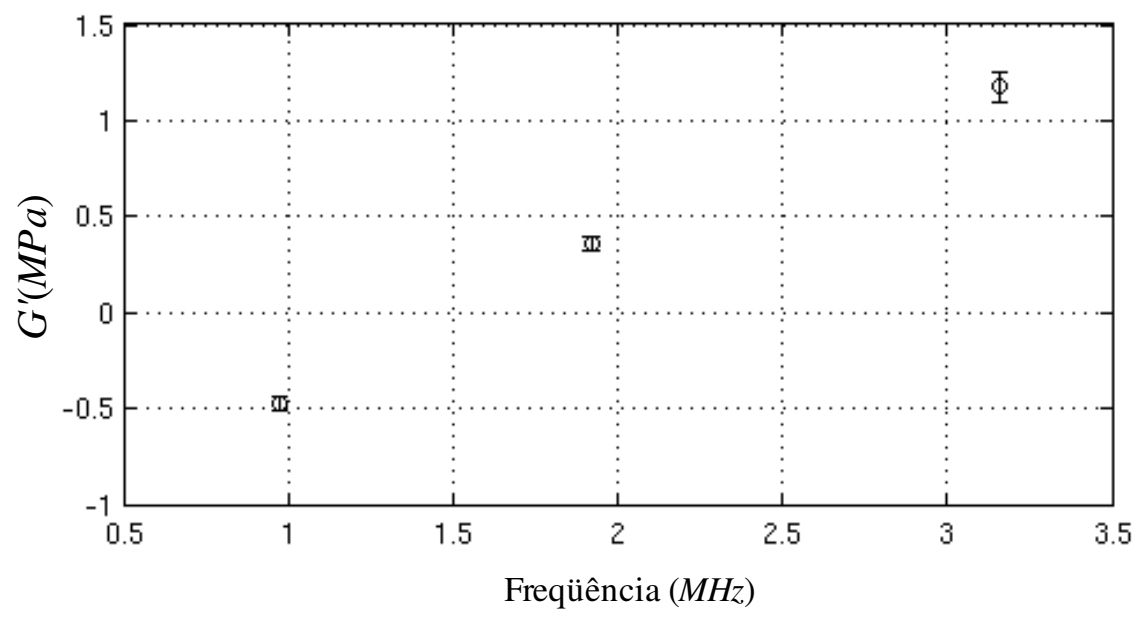

Figura 7.6. Módulo elástico em função da freqüência do azeite de oliva a $15^{\circ} \mathrm{C}$.

No capítulo 5 (seção 5.2), foi concluído que quando o líquido tem comportamento Newtoniano, as componentes real (resistência) e imaginária (reatância) da impedância acústica de cisalhamento devem ser iguais. A tabela 7.4 mostra as impedâncias acústicas calculadas no caso do azeite de oliva a $15^{\circ} \mathrm{C}$ para as três freqüências de operação usadas. Esses valores são comparados com a impedância acústica calculada a partir do modelo de líquido Newtoniano (equação 3.40). Observa-se que os valores medidos diferem muito dos calculados. Além disso, a parte real da impedância acústica é aproximadamente a metade da parte imaginária.

Tabela 7.4. Impedância acústica de cisalhamento em função da freqüência para azeite de oliva a $15^{\circ} \mathrm{C}$.

\begin{tabular}{|c|c|c|c|}
\hline $\begin{array}{c}\text { Freqüência } \\
(M H z)\end{array}$ & $Z_{L}$ - Medida $\left(\mathrm{kg} / \mathrm{m}^{2} s\right)$ & $X_{L^{-}} R_{L}$ & $\begin{array}{c}Z_{L^{-}} \text {Modelo de líquido } \\
\text { Newtoniano }\left(\mathrm{kg} / \mathrm{m}^{2} s\right)\end{array}$ \\
\hline 1 & $8992+19346 j$ & 10354 & $15800+15800 j$ \\
\hline 2,25 & $8506+17528 j$ & 9022 & $22206+22206 j$ \\
\hline 3,5 & $7898+16582 j$ & 8684 & $28488+28488 j$ \\
\hline
\end{tabular}


Nos resultados mostrados anteriormente, o desvio padrão plotado corresponde à variação das quantidades mensuráveis (magnitude e fase do coeficiente de reflexão) entre as diferentes aquisições de um mesmo experimento. Esse desvio fornece informação sobre como foi afetada a medição pelos fatores externos nesse experimento em particular, e não sobre como é a dispersão dos resultados em experimentos sucessivos. Para testar a repetibilidade da medição, foram feitos quatro testes com azeite de oliva a $15^{\circ} \mathrm{C}$ e freqüência de operação de $1 \mathrm{MHz}$. A viscosidade em baixa freqüência é 0,0927Pa.s. Foram calculados a média e o desvio padrão do coeficiente de reflexão e a média e o desvio padrão da viscosidade, utilizando os valores dos quatro experimentos. Finalmente, foi determinado o erro percentual (e) para todas as medições. Também foi calculado o módulo de elasticidade $\left(\mathrm{G}^{\prime}\right)$. A tabela 7.5 mostra os resultados obtidos.

Tabela 7.5. Teste de repetibilidade da medição com azeite de oliva a $15^{\circ} \mathrm{C}$ e frequiência de operação de $3,5 \mathrm{MHz}$.

\begin{tabular}{|c|c|c|c|c|c|}
\hline Experimento & & $R^{*}$ & $\eta_{d}($ Pa.s $)$ & $e(\%)$ & $G^{\prime}(M p a)$ \\
\hline \multirow{2}{*}{1} & $r$ & 0,9851 & \multirow{2}{*}{0,1158} & \multirow{2}{*}{24,9} & \multirow{2}{*}{$-0,5913$} \\
\hline & $\theta$ & 1,8508 & & & \\
\hline \multirow{2}{*}{2} & $r$ & 0,9859 & \multirow{2}{*}{0,0993} & \multirow{2}{*}{7,12} & \multirow{2}{*}{$-0,4734$} \\
\hline & $\theta$ & 1,6769 & & & \\
\hline \multirow{2}{*}{3} & $r$ & 0,9869 & \multirow{2}{*}{0,0870} & \multirow{2}{*}{6,15} & \multirow{2}{*}{$-0,4287$} \\
\hline & $\theta$ & 1,5864 & & & \\
\hline \multirow{2}{*}{4} & $r$ & 0,9875 & \multirow{2}{*}{0,0968} & \multirow{2}{*}{4,42} & \multirow{2}{*}{$-0,4739$} \\
\hline & $\theta$ & 1,8475 & & & \\
\hline \multirow{2}{*}{ Resultados } & $r$ & $0,9864 \pm 0,0011$ & \multirow{2}{*}{$0,0997 \pm 0,0120$} & \multirow{2}{*}{7,55} & \multirow{2}{*}{$-0,4918 \pm 0,0696$} \\
\hline & $\theta$ & $1,7404 \pm 0,1309$ & & & \\
\hline
\end{tabular}

Nesse teste, foi verificado que a magnitude do coeficiente de reflexão apresenta uma excelente repetibilidade, sendo isso mostrado pelo pequeno desvio padrão de $0,11 \%$ do valor médio (desvio relativo percentual). No caso da fase, o desvio padrão foi maior, sendo $7,52 \%$ do valor médio. Já no caso da viscosidade, o valor obtido teve um desvio padrão considerável, igual a 7,55\% do valor médio. Esse desvio é conseqüência 
principalmente da incerteza no cálculo da fase e pode ser obtido a partir dos valores do coeficiente de reflexão, aplicando os resultados da seção 6.7 sobre a propagação do erro na medição.

No caso do módulo elástico, era esperado que seu valor oscilaria em torno de zero, com um valor médio muito próximo de zero. Entretanto, como se pode ver na tabela 7.5 , foi obtido um valor negativo com um desvio padrão pequeno. Nota-se que entre as quatro medições, três ficaram acima do valor de viscosidade medido com o viscosímetro. Isso pode ser devido a algum tipo de erro sistemático na medição.

A tabela 7.6 mostra os resultados da impedância acústica de cisalhamento das mesmas medições da tabela 7.5. Embora tenha sido obtida uma boa repetibilidade da impedância medida, o valor da parte real continuou sendo aproximadamente a metade da parte imaginária.

Tabela 7.6. Impedância acústica de cisalhamento para azeite de oliva a $15^{\circ} \mathrm{C}$ e $1 \mathrm{MHz}$.

\begin{tabular}{|c|c|c|}
\hline Experimento & $\begin{array}{c}Z_{L} \text { - Medida } \\
\left(\mathrm{kg} / \mathrm{m}^{2} \mathrm{~s}\right)\end{array}$ & $\begin{array}{c}Z_{L} \text { - Modelo de líquido Newtoniano } \\
\left(\mathrm{kg} / \mathrm{m}^{2} \mathrm{~s}\right)\end{array}$ \\
\hline 1 & $8992+19346 j$ & $15800+15800 j$ \\
\hline 2 & $8506+17528 j$ & \\
\hline 3 & $7898+16582 j$ & $15800+15800 j$ \\
\hline 4 & $7535+19311 j$ & $15192 j$ \\
\hline
\end{tabular}

Com azeite de oliva foi realizado outro teste medindo a viscosidade em função da temperatura entre 15 e $30^{\circ} \mathrm{C}$. Os dados foram comparados com o polinômio ajustado a partir das medições feitas com o viscosímetro (seção 6.5.2). Foi usada a frequiência de operação de $3,5 \mathrm{MHz}$, devido à maior sensibilidade obtida na medição das baixas viscosidades do óleo de oliva nessas temperaturas. Na figura 7.7 são apresentados os resultados obtidos, onde os círculos (o) representam a medição considerando a magnitude e a fase do coeficiente de reflexão, as estrelas (*) indicam o cálculo feito usando a simplificação para líquido Newtoniano e a linha sólida é o polinômio de viscosidade ajustado. São mostrados os desvios padrões devidos à incerteza na 
determinação do coeficiente de reflexão, além do erro percentual entre as viscosidades a alta e a baixa freqüência medidas com ultra-som e com o viscosímetro, respectivamente.

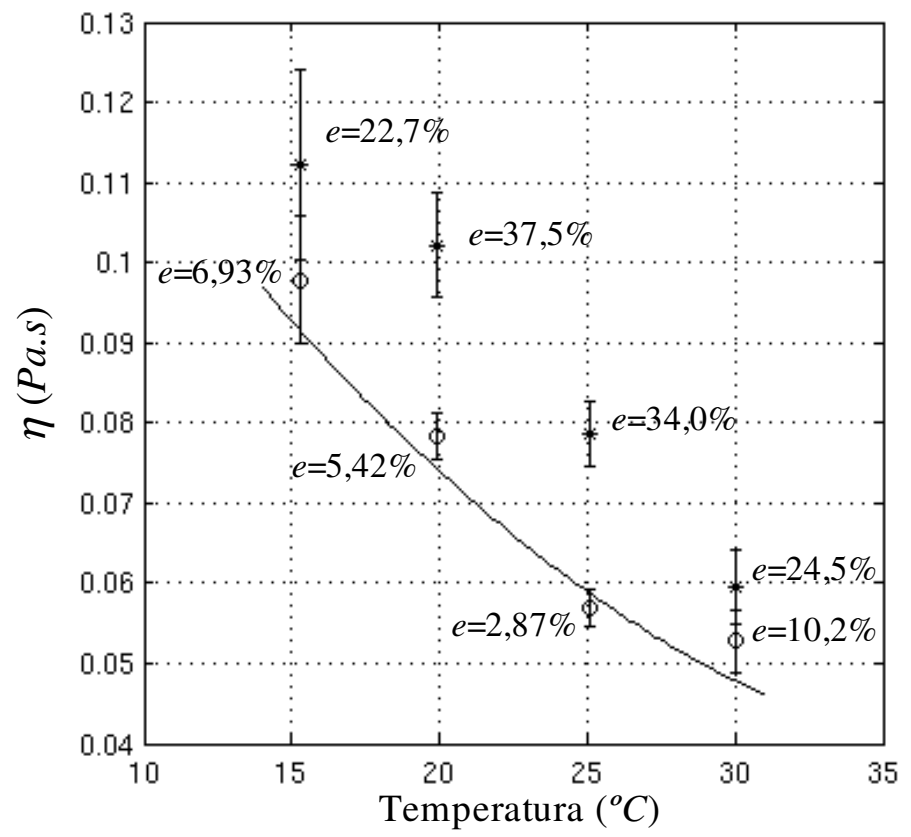

Figura 7.7. Viscosidade em função da temperatura do azeite de oliva, na freqüência de operação de $3,5 \mathrm{MHz}$. Valores obtidos usando a magnitude e a fase do coeficiente de reflexão (círculos) e simplificação para líquido Newtoniano (estrelas).

Foi obtida uma boa concordância entre as viscosidades medidas com o viscosímetro rotacional e a medida com ultra-som, usando a magnitude e a fase do coeficiente de reflexão, com erros percentuais pequenos $(e<10,2 \%)$. Já no caso da simplificação para líquido Newtoniano, os erros percentuais foram consideravelmente maiores $(e>22 \%)$, mas a viscosidade mostrou a mesma tendência que no caso sem simplificação. Esse é um resultado interessante, porque permitiria obter o valor da viscosidade multiplicando o valor obtido com a simplificação para líquido Newtoniano por um fator de escala, ou seja:

$$
\eta_{d}(r, \theta)=k_{e} \eta_{n}(r)
$$

onde $k_{e}$ é uma constante obtida experimentalmente. 


\subsubsection{2 Óleo de milho}

O óleo de milho foi testado na freqüência de operação de 1 e $2,25 \mathrm{MHz}$ e na faixa de temperatura entre 15 e $30^{\circ} \mathrm{C}$. Na figura 7.8 são comparados os coeficientes de reflexão medidos com os valores previstos pelo modelo de líquido Newtoniano e os polinômios de viscosidade obtidos. Nota-se que os valores medidos têm pouca concordância numérica com os valores estimados, e que somente no caso da magnitude na freqüência de $2,25 \mathrm{MHz}$ a concordância foi boa. Os resultados com ajuste pior foram os resultados da medição da fase.
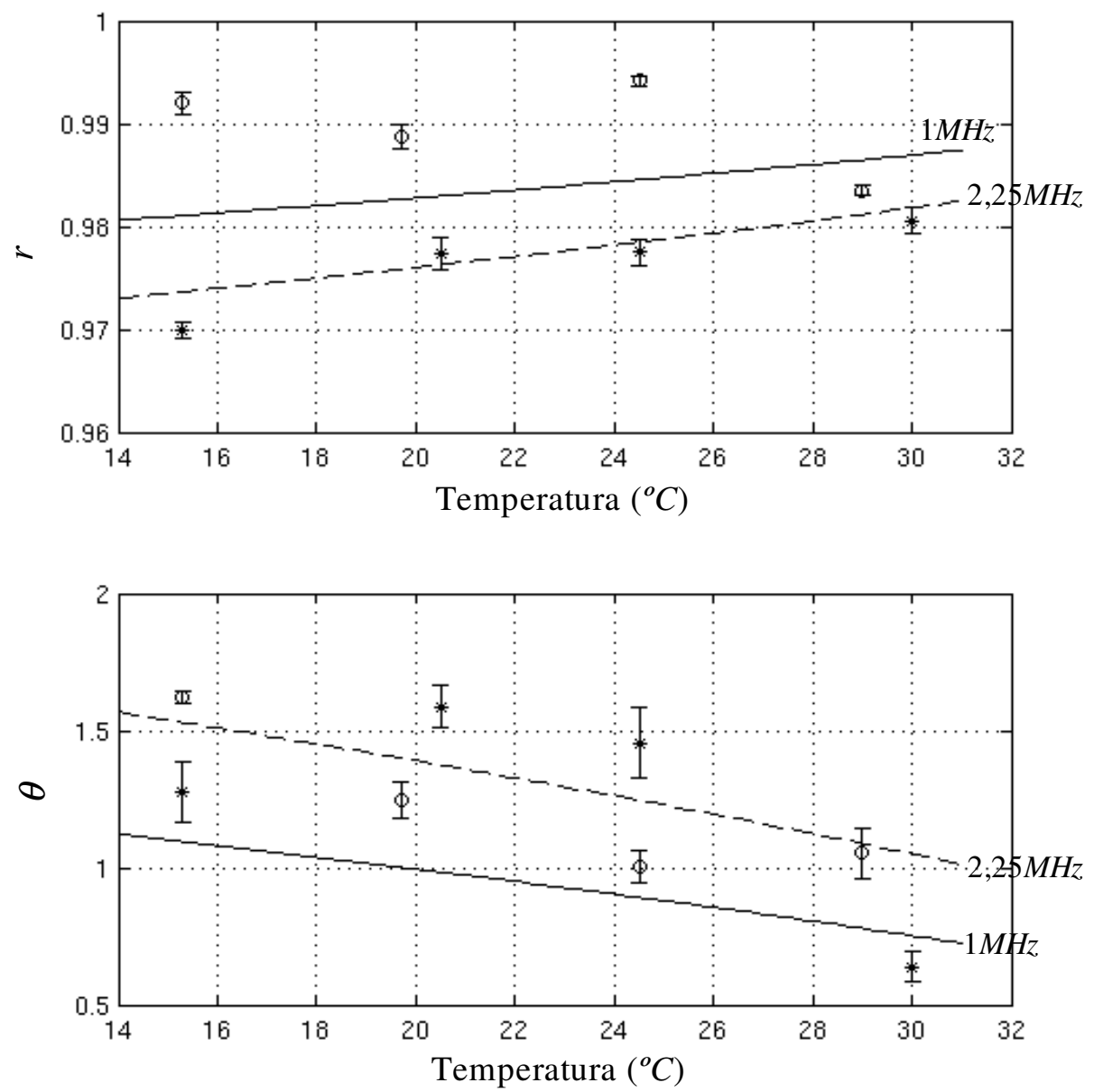

Figura 7.8. Coeficiente de reflexão em função da temperatura para óleo de milho nas freqüências de $1 \mathrm{MHz}$ (círculos) e 2,25 MHz (estrelas). Linha sólida: modelo Newtoniano a $1 \mathrm{MHz}$ e linha tracejada: modelo Newtoniano a $2,25 \mathrm{MHz}$.

Na figura 7.9 são mostrados os resultados de viscosidade obtidos no caso de $1 \mathrm{MHz}$, a linha sólida representa o polinômio da viscosidade em função da temperatura obtido com o viscosímetro rotacional, os círculos representam as medições feitas com 
ultra-som com viscosidade calculada a partir da magnitude e da fase do coeficiente de reflexão (equação 5.7) e as estrelas representam a simplificação para líquido Newtoniano (equação 5.9). Verificou-se que para a viscosidade calculada em ambos os casos, tanto a tendência como a concordância numérica é muito pobre e os erros percentuais são grandes. Isso é devido à baixa sensibilidade na medição do coeficiente de reflexão nessa freqüência, principalmente na medição da magnitude, como mostrado na figura 7.8 .

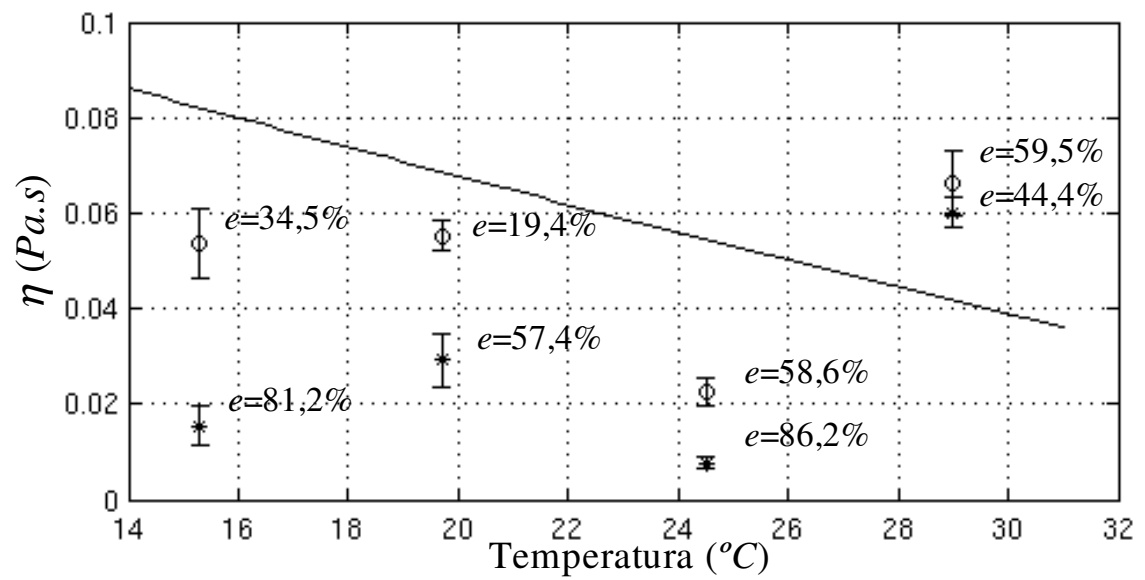

Figura 7.9. Viscosidade dinâmica em função da temperatura para óleo de milho, na freqüência de operação de $1 \mathrm{MHz}$. Valores obtidos usando a magnitude e a fase do coeficiente de reflexão (círculos) e simplificação para líquido Newtoniano (estrelas).

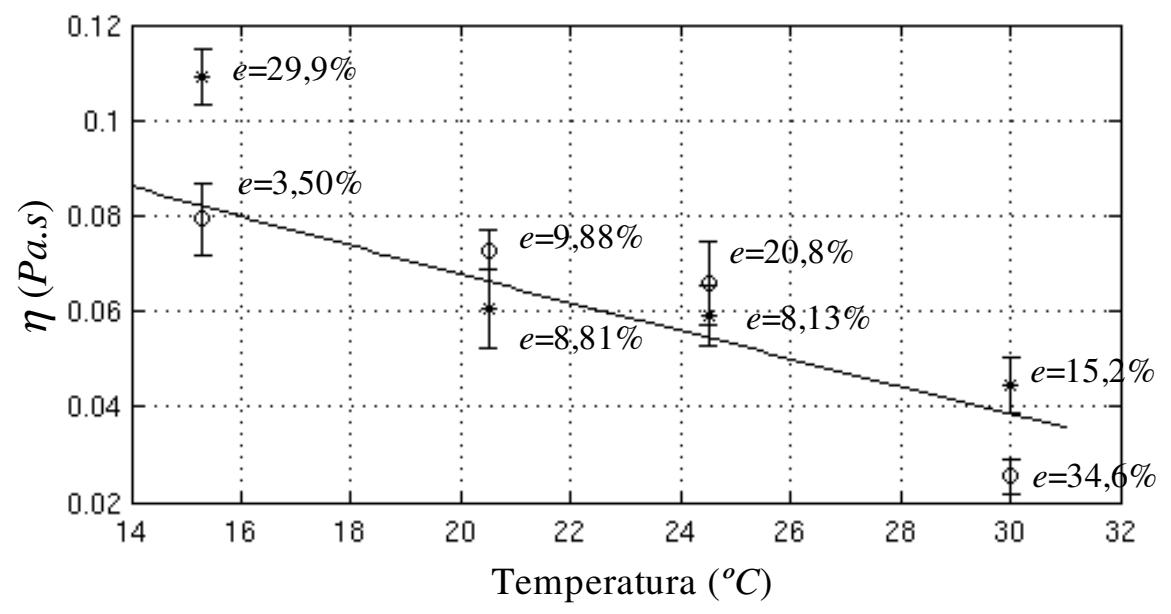

Figura 7.10. Viscosidade dinâmica em função da temperatura para óleo de milho, na frequiência de operação de 2,25MHz. Valores obtidos usando a magnitude e a fase do coeficiente de reflexão (círculos) e simplificação para líquido Newtoniano (estrelas). 
A figura 7.10 mostra os mesmos resultados de viscosidade da figura 7.9, mas no caso de 2,25MHz. Os valores de viscosidade calculados sem simplificação mostram boa concordância numérica, principalmente nas temperaturas mais baixas, onde a viscosidade é maior. Já no caso com simplificação, os resultados não mostraram o comportamento da figura 7.9

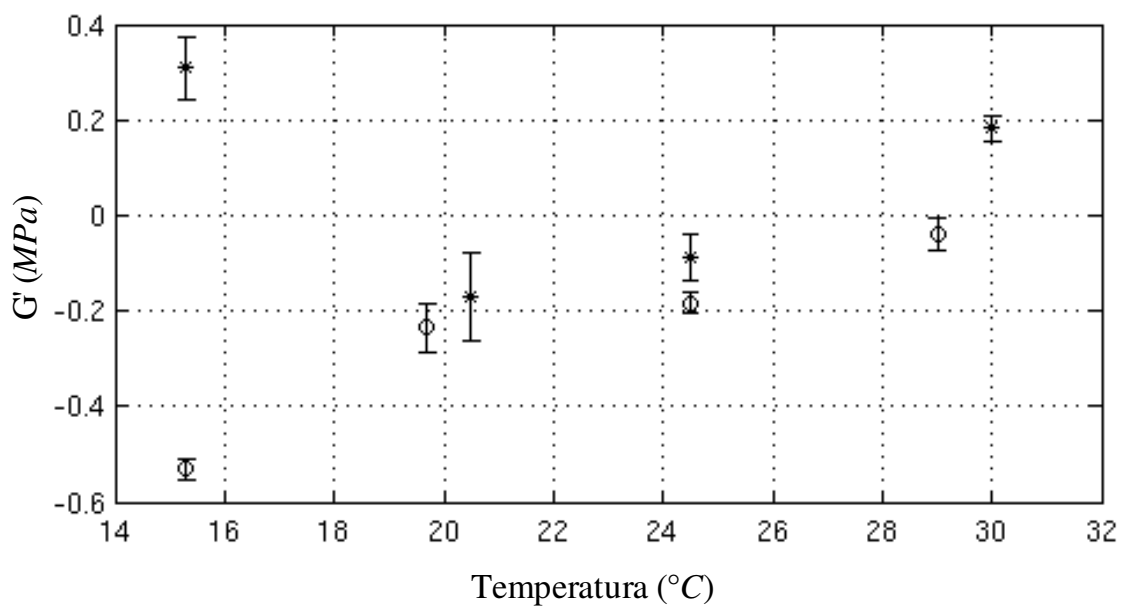

Figura 7.11. Módulo elástico em função da temperatura para óleo de milho a $1 \mathrm{MHz}$ (círculos) e $2,25 \mathrm{MHz}$ (estrelas).

A figura 7.11 apresenta os resultados do cálculo do módulo de elasticidade do óleo de milho em função da temperatura para $1 \mathrm{MHz}$ (círculos) e 2,25MHz (estrelas). Como era esperado, foram obtidos valores pequenos (quando comparados com $G_{\infty}$ ), a maioria deles negativos.

\subsection{2 Óleos automotivos}

Foram testados os óleos automotivos SAE 40, 90, 140 e 250 (ver seção 6.4), cuja viscosidade varia entre 0,3 e 6 Pa.s à temperatura ambiente $\left(22^{\circ} \mathrm{C}\right)$.

\subsubsection{1 Óleos SAE 40 e SAE 90}

Na figura 7.12, são apresentados os coeficiente de reflexão medidos com SAE 40 e SAE 90, à temperatura ambiente $22,5 \pm 0,5^{\circ} \mathrm{C}$. Os resultados são comparados com os valores previstos pelo modelo de líquido Newtoniano (linha sólida) e pelo modelo de Maxwell com $G_{\infty}=1.10^{8}$ e $G_{\infty}=1.10^{9} \mathrm{~Pa}$. Nota-se que a linha do modelo de Maxwell para $G_{\infty}=1.10^{9} \mathrm{~Pa}$ fica praticamente sobreposta à linha para líquido Newtoniano. Para os dois 
casos (SAE 40 e SAE 90) a variação da magnitude do coeficiente de reflexão com a freqüência apresenta a mesma tendência que os valores estimados pelos modelos, embora os resultados numéricos sejam diferentes. Já no caso da fase, a diferença entre os valores estimado e medido foi muito grande, observando-se somente a tendência de aumentar com a freqüência. Sempre foram obtidos valores da mudança da amplitude e a fase menores que aqueles previstos pelos modelos teóricos.
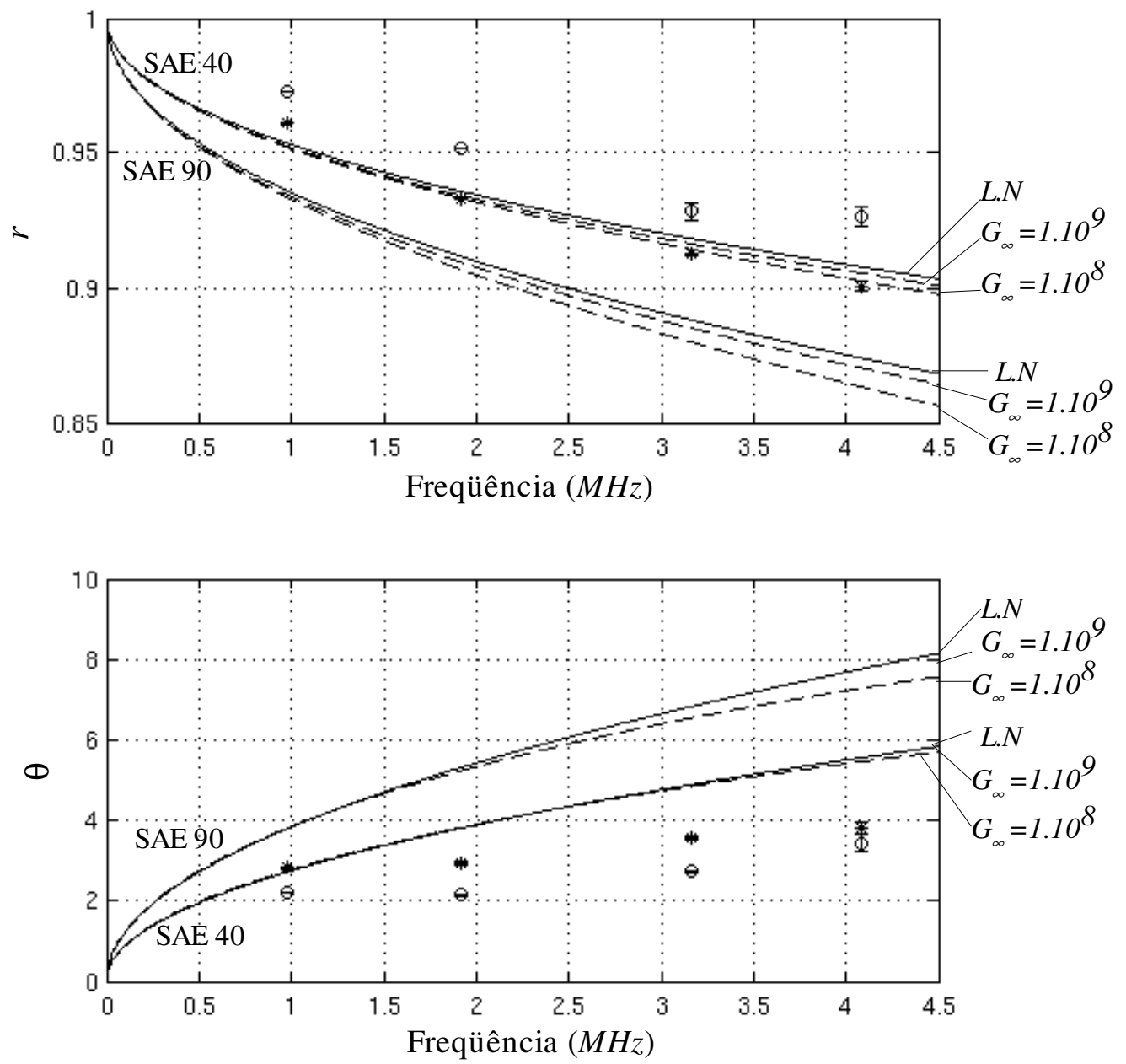

Figura 7.12. Coeficiente de reflexão em função da freqüência para SAE 40 (círculos) e SAE 90 (estrelas) a $22,5 \pm 0,5^{\circ} \mathrm{C}$. Linha sólida: modelo Newtoniano e linha tracejada: modelo de Maxwell $\left(G_{\infty}=1.10^{8}\right.$ e $\left.1.10^{9} \mathrm{~Pa}\right)$.

A figura 7.13 compara os resultados de viscosidade calculados sem a simplificação para líquido Newtoniano (círculos) e com a simplificação (estrelas) com os valores de viscosidade medidos com o viscosímetro à temperatura de $22,5 \pm 0,5^{\circ} \mathrm{C}$. A linha sólida representa a viscosidade na temperatura média e as linhas tracejadas o desvio padrão. $\mathrm{O}$ erro percentual foi pequeno para as duas freqüências maiores $(3,5 \mathrm{e}$ 
$5 \mathrm{MHz}$ ), mas o desvio padrão ocasionado pela incerteza na determinação do coeficiente de reflexão foi maior que nas outras duas freqüências. Isso pode ser devido à perda de resolução na medição da fase que acontece quando aumenta a freqüência da onda.

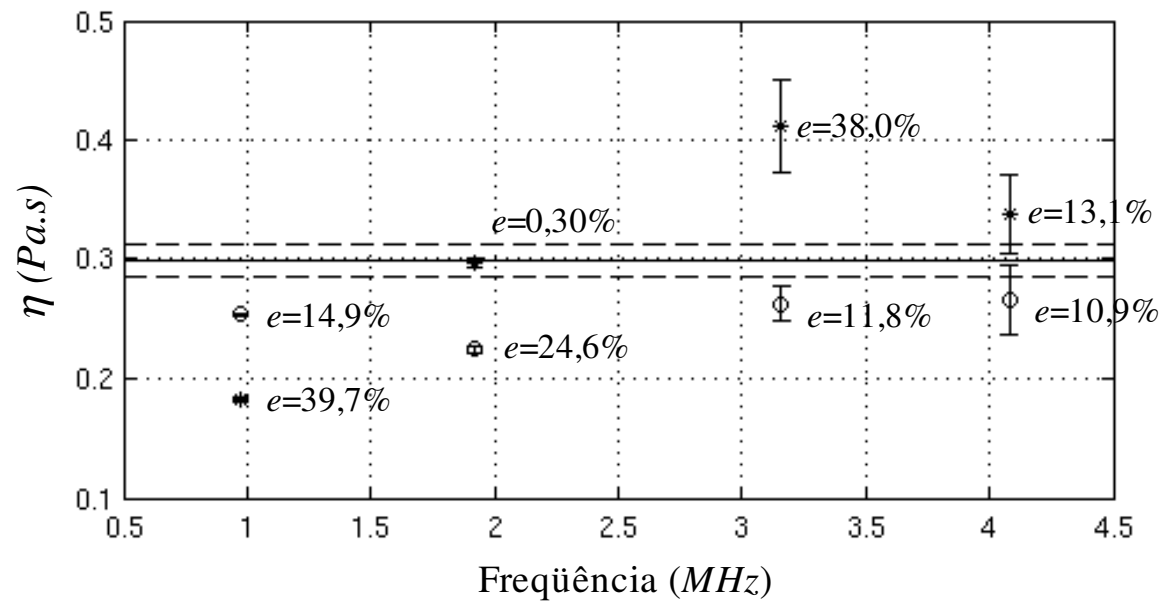

Figura 7.13. Viscosidade em função da freqüência para SAE 40 à temperatura ambiente $\left(22,5 \pm 0,5^{\circ} \mathrm{C}\right)$ : Valores obtidos usando a magnitude e a fase do coeficiente de reflexão (círculos) e simplificação para líquido Newtoniano (estrelas).

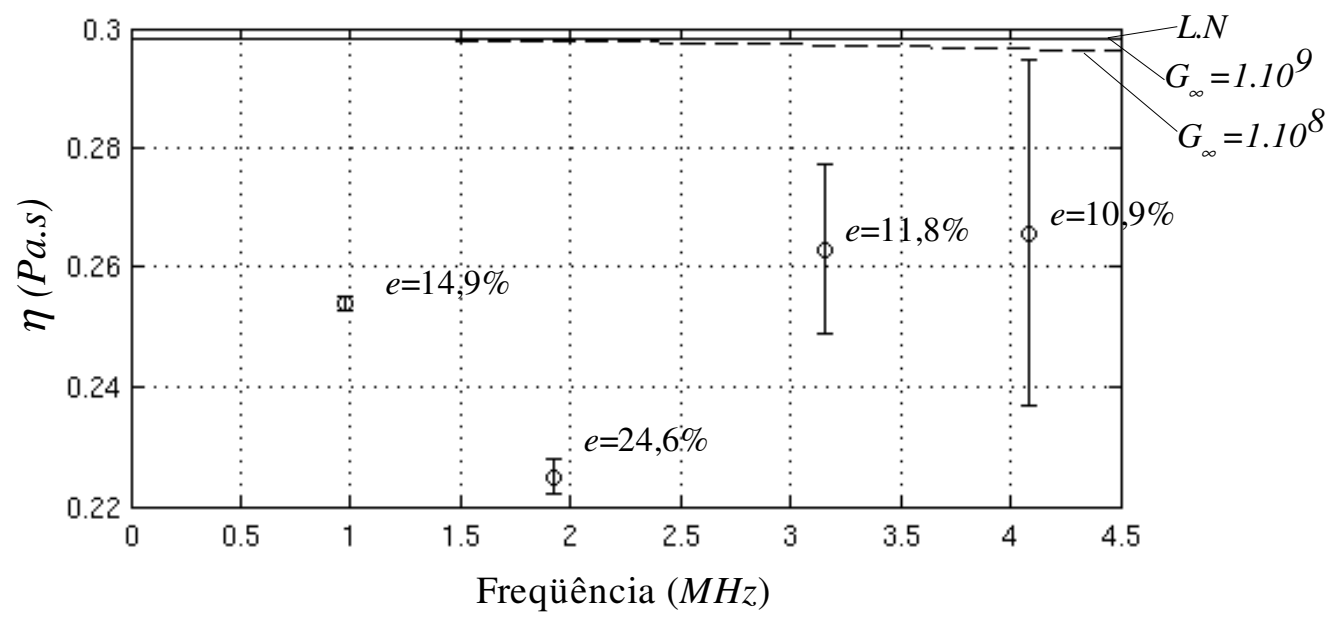

Figura 7.14. Viscosidade em função da freqüência para SAE 40 à temperatura ambiente $\left(22,5 \pm 0,5^{\circ} \mathrm{C}\right)$. Comparação entre os valores medidos por ultra-som e os calculados usando os modelos teóricos.

A figura 7.14 compara a viscosidade medida por ultra-som com os resultados obtidos mediante os modelos teóricos. Nota-se que nesta faixa de frequiência, os modelos teóricos predizem pouca variação da viscosidade. Isso parece ser corroborado pelos resultados de viscosidade obtidos por ultra-som, que mostram certa independência da freqüência, Assim, nessa faixa de freqüência, o SAE 40 comporta-se, ainda, como 
líquido Newtoniano.

Na figura 7.15, são mostrados os resultados para o caso do óleo SAE 90 utilizado a mesma analise da figura 7.13. No cálculo feito sem a simplificação, a viscosidade mostrou tendência decrescente com a freqüência e os erros percentuais se incrementaram levemente. Já no caso com a simplificação, o valor da viscosidade incrementou-se com a freqüência.

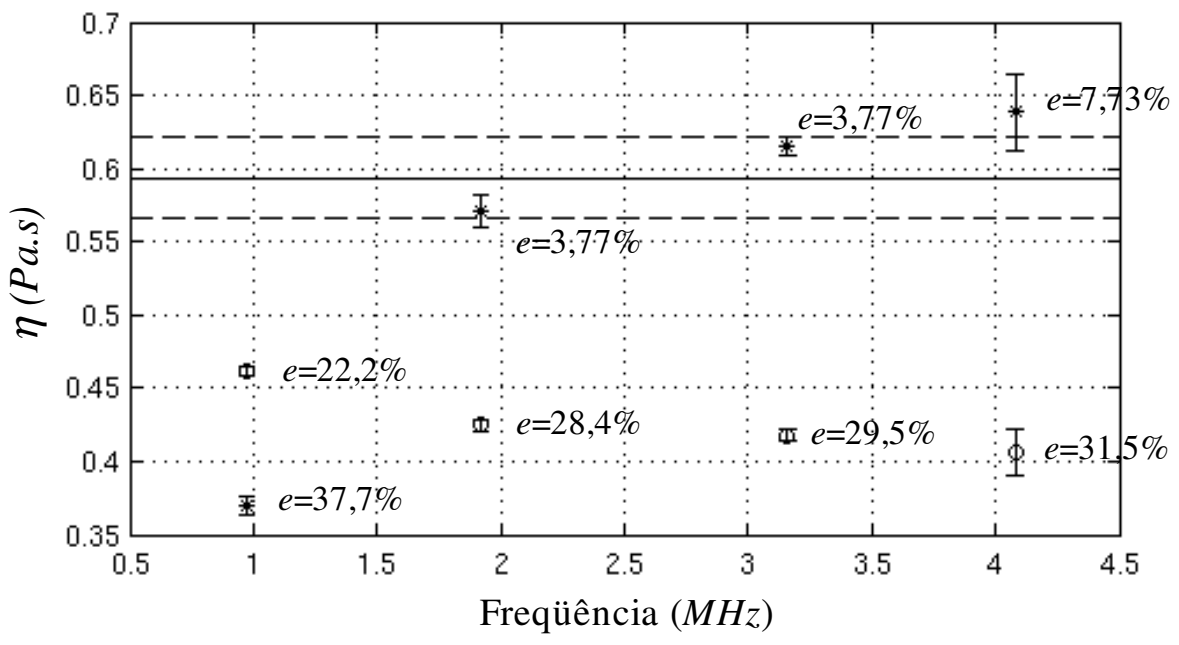

Figura 7.15. Viscosidade em função da freqüência para SAE 90 a temperatura ambiente $\left(22,5 \pm 0,5^{\circ} \mathrm{C}\right)$. Valores obtidos usando a magnitude e a fase do coeficiente de reflexão (círculos) e simplificação para líquido Newtoniano (estrelas).

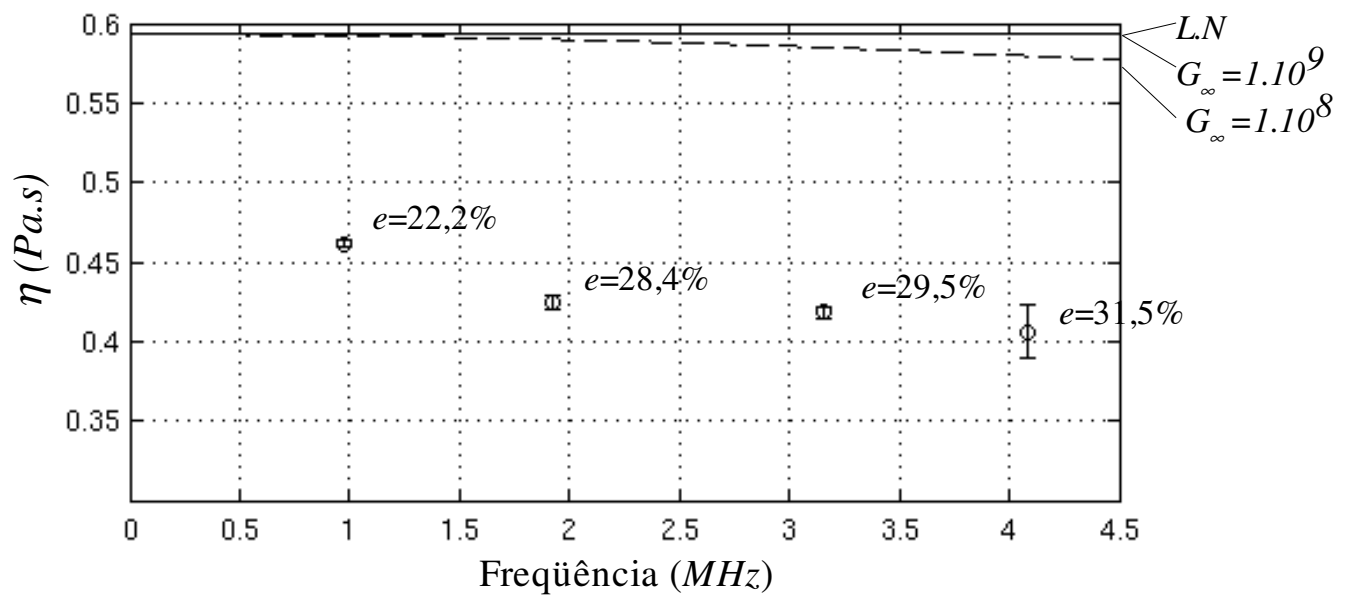

Figura 7.16. Viscosidade em função da freqüência para SAE 90 à temperatura ambiente $\left(22,5 \pm 0,5^{\circ} \mathrm{C}\right)$. Comparação entre os valores medidos por ultra-som e os calculados usando os modelos teóricos. 
Na figura 7.16, os resultados no caso do óleo SAE 90 são comparados com os modelos Newtoniano e de Maxwell. Os valores teóricos de viscosidade variam pouco nesta faixa de freqüência e, embora os resultados não tenham apresentado concordância numérica, a leve tendência decrescente da viscosidade é similar à prevista pelo modelo de Maxwell.

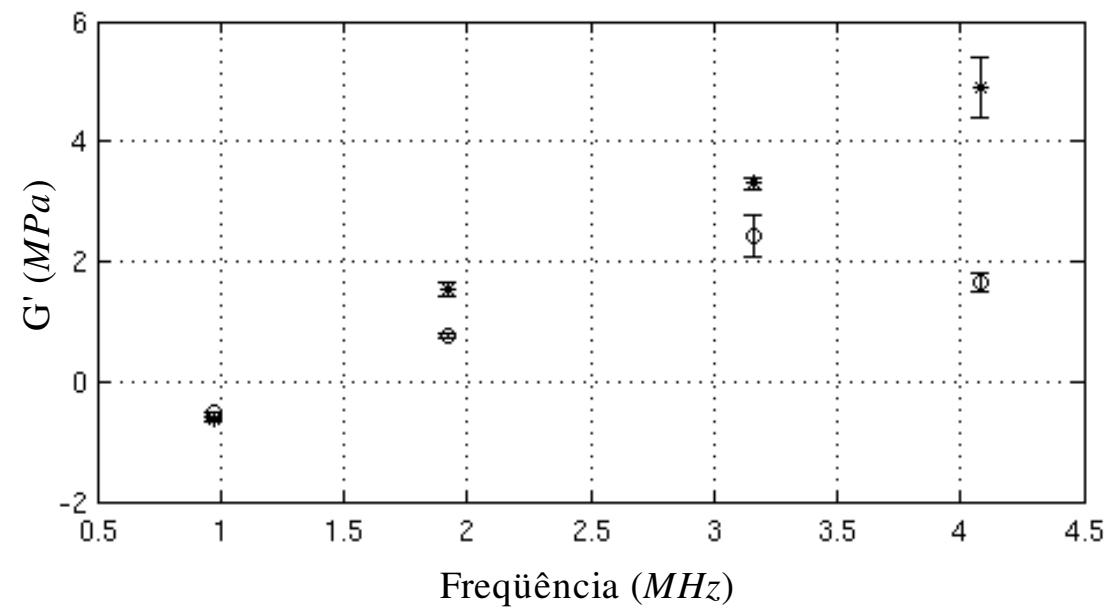

Figura 7.17. Módulo elástico em função da freqüência para SAE 40 (círculos) e SAE 90 (estrelas) à temperatura ambiente $\left(22,5 \pm 0,5^{\circ} \mathrm{C}\right)$.

A figura 7.17 mostra os resultados do módulo elástico. O valor incrementa-se com a freqüência, como era esperado, já que o líquido afasta-se do comportamento Newtoniano. Devido aos pequenos valores de elasticidade obtidos a $1 \mathrm{MHz}$, acredita-se que nessa freqüência ambos os líquidos têm comportamento Newtoniano.

\subsubsection{2 Óleos SAE 140 e SAE 250}

Nesta seção são mostrados os resultados obtidos para os óleos automotivos SAE 140 e SAE 250. Na figura 7.18 é mostrado o coeficiente de reflexão medido, sendo comparado com os valores obtidos mediante os modelos teóricos. Como no caso dos óleos SAE 40 e SAE 90, a magnitude medida mostrou ter o mesmo comportamento que a prevista pelos modelos teóricos, principalmente o modelo Newtoniano e o de Maxwell com $G_{\infty}=1 \cdot 10^{9} \mathrm{~Pa}$. A fase também mostrou um comportamento similar ao previsto nesses modelos. No caso dos valores numéricos, a magnitude do SAE 140 foi o resultado melhor ajustado. Igualmente, os valores da fase medidos ficaram muito abaixo dos 
valores previstos pelos modelos. Pode-se ver que os desvios padrões dos coeficientes de reflexão são muito pequenos quando comparados aos resultados obtidos com os óleos alimentícios. Isso ocorre devido aos grandes valores da variação de magnitude e de fase obtidos, que melhoram a sensibilidade da medição.

Com esses resultados, observa-se que foram obtidas grandes mudanças de amplitude e de fase nas frequiências maiores, quando comparados aos casos anteriores. Por exemplo, para SAE 250 a $5 \mathrm{MHz}$, foi obtida uma magnitude e uma fase de 0,78 e $8^{\circ}$, respectivamente. As variações para esses valores são grandes, levando em conta que para os óleos alimentícios os valores de magnitude e fase sempre foram menores que 0,95 e $2^{\circ}$, respectivamente. No caso dos óleos alimentícios o comportamento é praticamente Newtoniano, o que não acontece com o óleo SAE 250, onde é evidente um comportamento viscoelástico, dependente da freqüência.

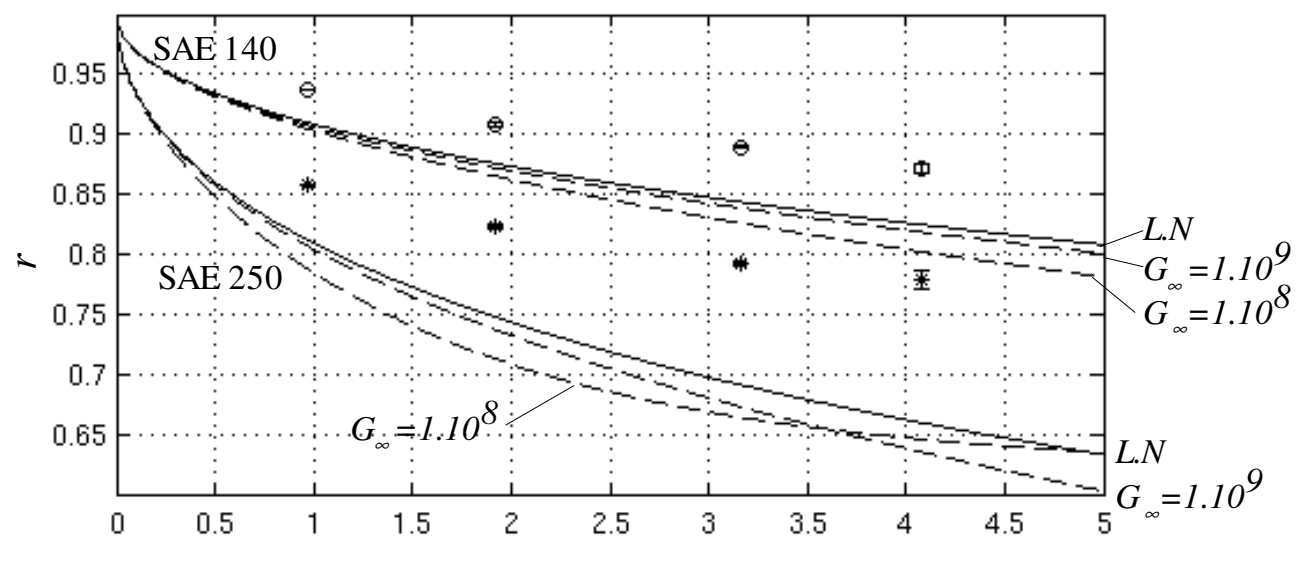

Freqüência $(\mathrm{MHz})$

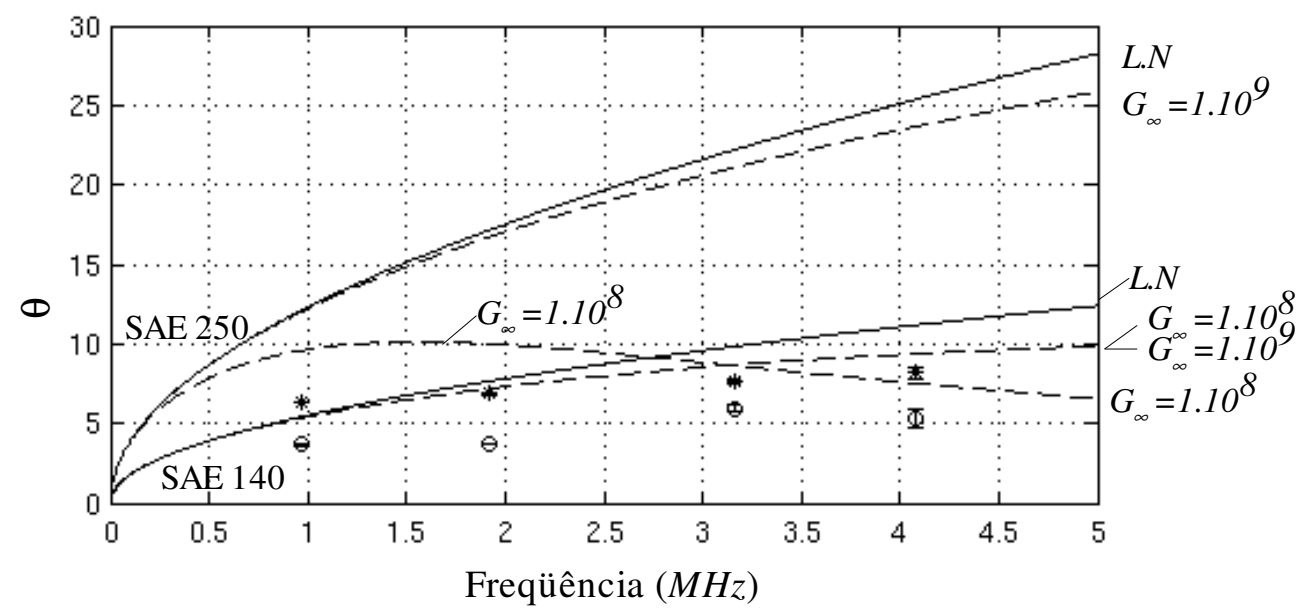

Figura 7.18. Coeficiente de reflexão em função da freqüência para SAE 140 (círculos) e SAE 250 (estrelas) à temperatura ambiente $\left(22,5 \pm 0,5^{\circ} \mathrm{C}\right)$. 
Uma das limitações do método quando se pretende determinar a viscosidade é o compromisso entre a escolha de uma freqüência suficientemente alta para se obter uma boa resolução na medição do coeficiente de reflexão, mas baixa o suficiente para que o comportamento do líquido seja Newtoniano. Isso reduz consideravelmente a faixa de viscosidade abrangida para determinada freqüência de trabalho.

As figuras 7.19 e 7.20 mostram os resultados da viscosidade do óleo SAE 140. Na figura 7.19, são comparadas as viscosidades medidas por ultra-som, com (estrelas) e sem (círculos) a simplificação para líquido Newtoniano, com a viscosidade medida com o viscosímetro. Novamente, as linhas tracejadas mostram a faixa de viscosidade definida pelas mudanças na temperatura ambiente na qual foram feitos os testes. Nota-se que a viscosidade medida por ultra-som sempre esteve abaixo da medida com o viscosímetro rotacional, sendo os valores calculados com a simplificação para líquido Newtoniano os que ficaram, numericamente, mais próximos.

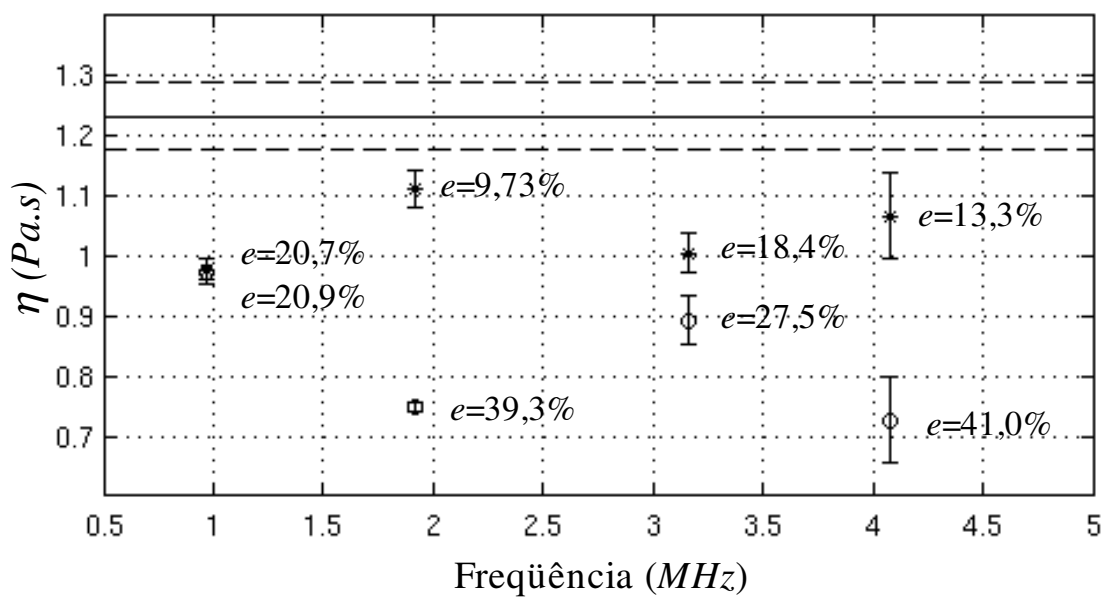

Figura 7.19. Viscosidade em função da frequiência para SAE 140 à temperatura ambiente $\left(22,5 \pm 0,5^{\circ} \mathrm{C}\right)$. Valores obtidos usando a magnitude e a fase do coeficiente de reflexão (círculos) e simplificação para líquido Newtoniano (estrelas).

A figura 7.20 compara os valores medidos com ultra-som, usando a magnitude e fase do coeficiente de reflexão, com os modelos teóricos. Percebe-se que a tendência da viscosidade é decrescente com a freqüência, como é previsto pelo modelo de Maxwell, principalmente no caso com $G_{\infty}=1.10^{8} \mathrm{~Pa}$. Novamente, a incerteza na determinação do coeficiente de reflexão foi maior nas frequiências de 3,5 e $5 \mathrm{MHz}$ que, como já foi dito, deve-se à perda de resolução na medição da fase quando aumenta a freqüência da onda. 


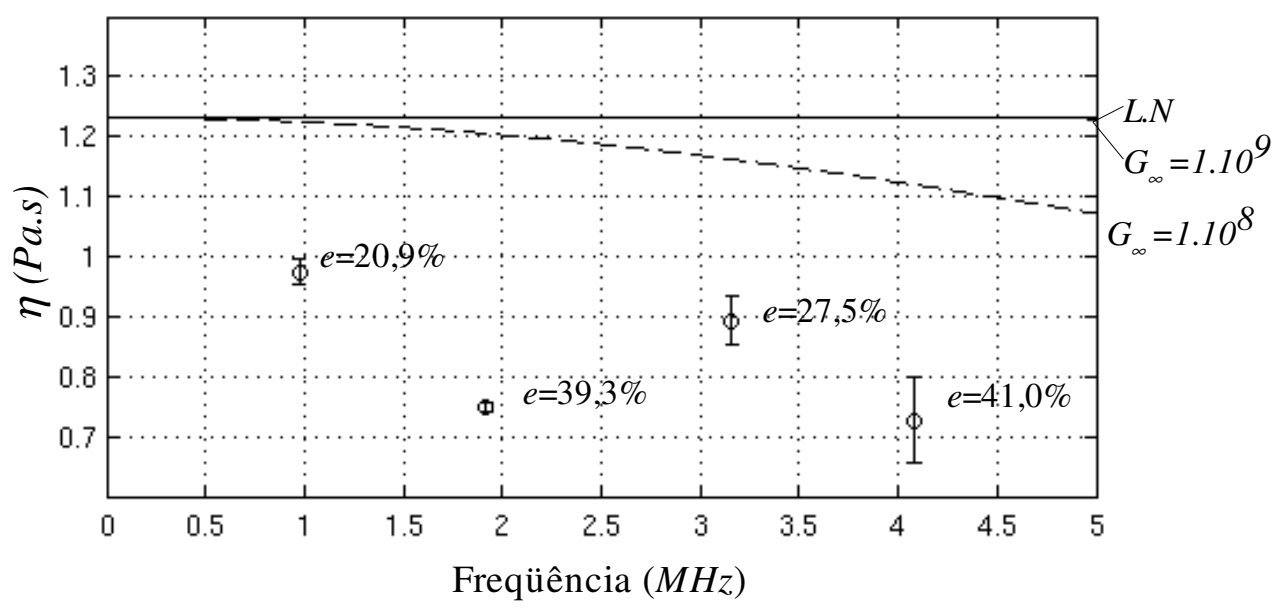

Figura 7.20. Viscosidade em função da frequiência para SAE 140 à temperatura ambiente $\left(22,5 \pm 0,5^{\circ} \mathrm{C}\right)$. Comparação entre os valores medidos por ultra-som e os calculados usando os modelos teóricos.

As figuras 7.21 e 7.22 mostram os mesmos resultados das figuras 7.19 e 7.20 no caso do óleo SAE 250. Na figura 7.21, verifica-se que os valores de viscosidade, nos casos com (estrelas) e sem (círculos) a simplificação para líquido Newtoniano, são continuamente decrescentes. Os valores com a simplificação sempre foram maiores que no caso sem simplificação. Além disso, a sua diferença foi aproximadamente da mesma quantia em todas as freqüências.

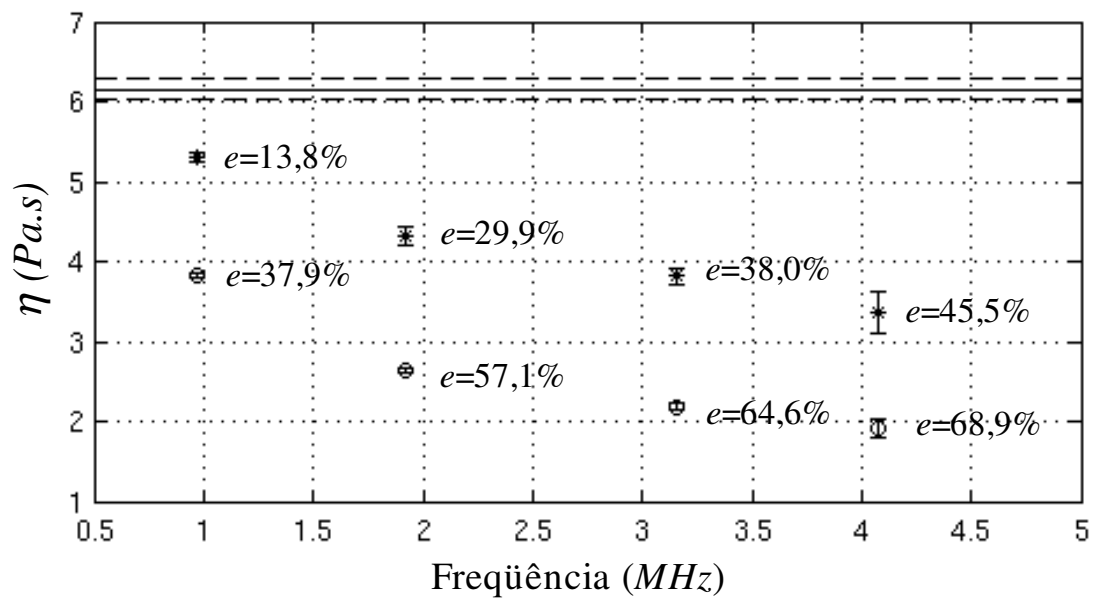

Figura 7.21. Viscosidade em função da freqüência para SAE 250 à temperatura ambiente $\left(22,5 \pm 0,5^{\circ} \mathrm{C}\right)$. Valores obtidos usando a magnitude e a fase do coeficiente de reflexão (círculos) e simplificação para líquido Newtoniano (estrelas).

Na figura 7.22 é feita a comparação entre os valores de viscosidade obtidos por ultra-som e aqueles obtidos com os modelos teóricos. No caso do modelo de Maxwell 
com $G_{\infty}=1.10^{8} \mathrm{~Pa}$, os valores medidos se ajustam razoavelmente bem ao modelo.

A figura 7.23 mostra os resultados do módulo elástico para SAE 140 e SAE 250. O valor do módulo elástico é consideravelmente maior para o SAE 250, estando em concordâncias com a teoria. No caso do óleo SAE 140 a $1 \mathrm{MHz}$, foi obtido um valor de elasticidade muito perto de zero, podendo-se concluir que nessa frequiência $o$ comportamento desse óleo é ainda Newtoniano.

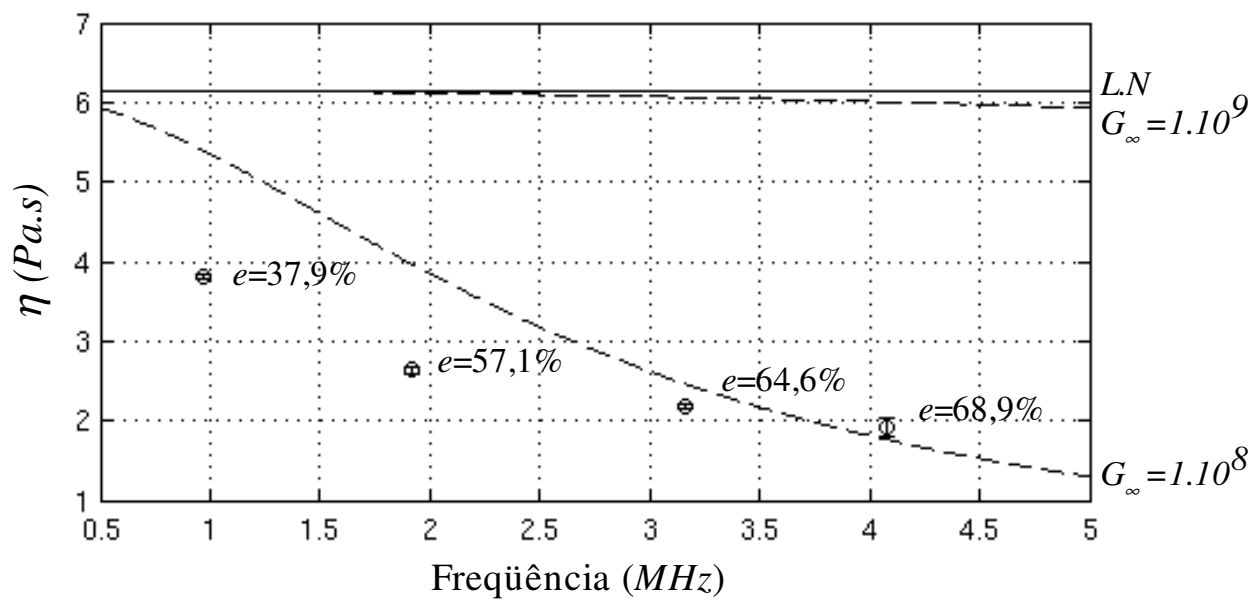

Figura 7.22. Viscosidade em função da freqüência para SAE 250 à temperatura ambiente $\left(22,5 \pm 0,5^{\circ} \mathrm{C}\right)$. Comparação entre os valores medidos por ultra-som e os calculados usando os modelos teóricos.

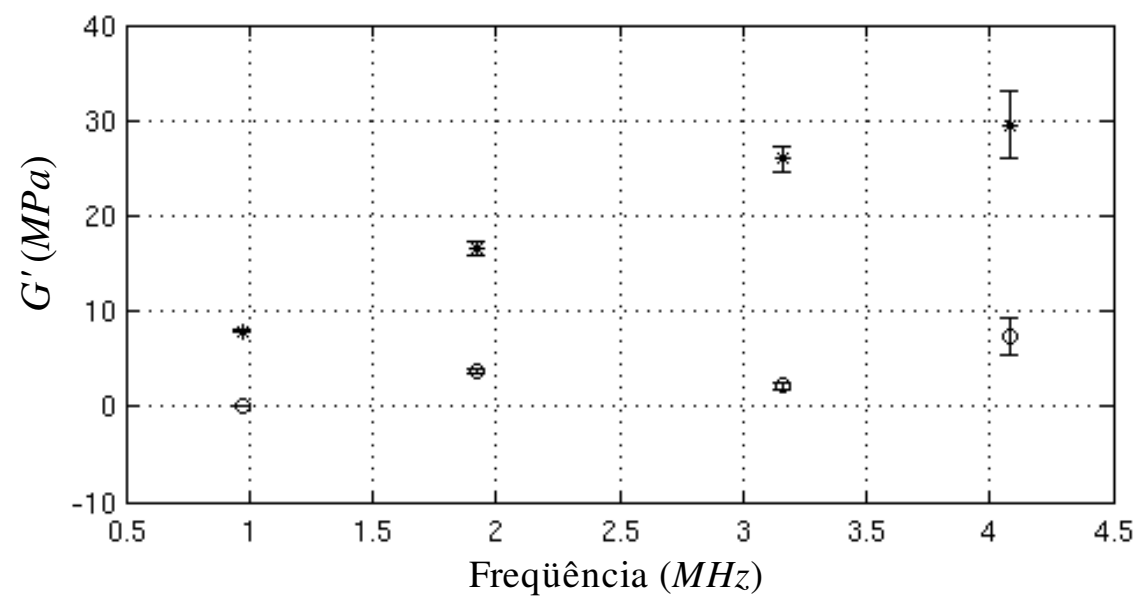

Figura 7.23. Módulo elástico em função da freqüência para SAE 140 (círculos) e SAE 250 (estrelas) à temperatura ambiente $\left(22,5 \pm 0,5^{\circ} \mathrm{C}\right)$. 


\subsection{DISPOSITIVO COM TRANSDUTOR DUPLO-ELEMENTO}

Nesta seção, são apresentados os resultados obtidos com o transdutor duploelemento descrito no capítulo 6 (seção 6.1.3). Foram testados os óleos automotivos SAE 40, 90 e 140 à temperatura ambiente $\left(20,3 \pm 0,2^{\circ} \mathrm{C}\right)$ na freqüência de operação de $0,5 \mathrm{MHz}$. Na tabela 7.7 são mostrados os resultados obtidos. A incerteza na determinação do coeficiente de reflexão é pequena, menor que no caso do dispositivo 2, embora os erros percentuais da viscosidade sejam grandes. Isso se deve à pequena espessura da camada de acrílico, não projetada para trabalhar a $0,5 \mathrm{MHz}$, que não permite uma adequada separação no tempo dos ecos refletidos pelas interfaces de referência e de medição. A maior precisão na medição da fase, deve-se à maior resolução obtida nessa freqüência de operação.

Tabela 7.7. Resultados do teste feito com o transdutor duplo-elemento com conversão de modo, para os óleos automotivos SAE 40, 90 e 140 a $20,3 \pm 0,2^{\circ} \mathrm{C}$ e freqüência de operação de $0,5 \mathrm{MHz}$.

\begin{tabular}{|c|c|c|c|c|c|c|c|c|}
\hline Líquido & \multicolumn{2}{|r|}{$R^{*}$} & $\eta(\mathrm{Pa} . \mathrm{s})$ & $\eta_{\mathrm{d}}($ Pa.s $)$ & $e(\%)$ & $\eta_{\mathrm{n}}($ Pa.s $)$ & $e(\%)$ & $G^{\prime}(\mathrm{Mpa})$ \\
\hline \multirow{2}{*}{ SAE 40} & $r$ & $0,9683 \pm 0,0008$ & \multirow{2}{*}{0,3506} & \multirow{2}{*}{0,5229} & \multirow{2}{*}{52,0} & \multirow{2}{*}{0,5867} & \multirow{2}{*}{67,3} & \multirow{2}{*}{0,1511} \\
\hline & $\theta$ & $1,6489 \pm 0,0422$ & & & & & & \\
\hline \multirow{2}{*}{ SAE 90} & $r$ & $0,9592 \pm 0,0021$ & \multirow{2}{*}{0,7020} & \multirow{2}{*}{0,8261} & \multirow{2}{*}{17,7} & \multirow{2}{*}{0,9660} & \multirow{2}{*}{37,6} & \multirow{2}{*}{0,3248} \\
\hline & $\theta$ & $2,0486 \pm 0,0220$ & & & & & & \\
\hline \multirow{2}{*}{ SAE 140} & $r$ & $0,9537 \pm 0,0020$ & \multirow{2}{*}{1,4473} & \multirow{2}{*}{0,6931} & \multirow{2}{*}{52,1} & \multirow{2}{*}{1,2383} & \multirow{2}{*}{14.4} & \multirow{2}{*}{1,0705} \\
\hline & $\theta$ & $1,5192 \pm 0,0766$ & & & & & & \\
\hline
\end{tabular}




\section{CAPÍTULO 8}

\section{CONCLUSÕES}

Foi verificado experimentalmente que um líquido comporta-se como Newtoniano para freqüências de excitação muito menores que o inverso do tempo de relaxação de Maxwell $\left(\omega<<1 / \tau_{m}\right)$. Isso foi concluído a partir dos valores de viscosidade e elasticidade obtidos. No caso dos óleos alimentícios, os valores de viscosidade ficaram muito próximos daqueles medidos com o viscosímetro rotacional e os módulos elásticos tiveram valores próximos de zero. Os óleos automotivos menos viscosos mostraram um comportamento similar ao comportamento dos óleos alimentícios. Outro resultado importante que verifica essa afirmação foi a independência da frequiência mostrada pelas medições com os óleos menos viscosos.

Os resultados experimentais mostraram que a simplificação para líquido Newtoniano usada por vários autores, a qual permite calcular a viscosidade a partir somente da magnitude do coeficiente de reflexão, não fornece os valores corretos de viscosidade. Neste trabalho, para líquidos com comportamento puramente viscoso, os valores que reproduzem a viscosidade medida com o viscosímetro foram obtidos a partir da magnitude e da fase do coeficiente, contrário aos valores obtidos através da simplificação para líquido Newtoniano. Foi observado em alguns casos, que os resultados sem a simplificação para líquido Newtoniano podiam ser obtidos multiplicando os valores com a simplificação por uma constante de proporcionalidade.

No caso dos óleos mais viscosos, foi verificada a dependência da freqüência da viscosidade e elasticidade. No caso da viscosidade, o valor é decrescente, como é previsto pelo modelo de Maxwell. No caso da elasticidade, seu valor incrementa-se.

Os resultados apresentados da impedância acústica de cisalhamento não mostraram concordância com os previstos pelo modelo de líquido Newtoniano. 
Os modelos teóricos apresentaram uma descrição mais qualitativa que quantitativa do comportamento do coeficiente de reflexão e da viscosidade com a freqüência. Somente no caso do modelo de líquido Newtoniano para os óleos menos viscosos, foi verificado que quando o valor da viscosidade estava perto do valor medido com o viscosímetro rotacional, os valores do coeficiente de reflexão medidos também estavam mais próximos daqueles previstos pelo modelo. Dessa forma, o modelo de líquido Newtoniano descreve aceitavelmente o comportamento desses líquidos.

Foi mostrado que o melhor método na determinação do coeficiente de reflexão é realizar seu cálculo no domínio da frequiência. O método no domínio do tempo tem a desvantagem de que os valores obtidos, principalmente na magnitude do coeficiente, são dependentes da largura de banda da onda usada.

Foi verificado que a conversão de modo é um meio efetivo para gerar ondas de cisalhamento mais puras, sem os modos de vibração indesejados presentes nos transdutores que geram diretamente essas ondas.

O controle da temperatura é fundamental na medição de viscosidade por ultrasom. Além da viscosidade ser dependente da temperatura, a propagação das ondas, principalmente a fase, é fortemente afetada por este fator, que durante o experimento deve ser mantido dentro de uma faixa de variação pequena. Além disso, mesmo garantindo uma pequena variação da temperatura, a fase pode mudar vários graus, mas essas mudanças são geralmente lentas o suficiente para não influir nas medições feitas num pequeno espaço de tempo.

A normalização mostrou ser um excelente método na determinação do coeficiente de reflexão. Essa técnica reduz consideravelmente os erros induzidos na medição pela variação de parâmetros acústicos durante a propagação das ondas entre o transdutor e a interface de referência. Uma grande parte dos erros induzidos são devidos aos gradientes de temperatura, à difração das ondas e à instabilidade na eletrônica.

Os gráficos do coeficiente de reflexão em função do tempo, no qual foram feitas as sucessivas aquisições, mostraram ser valiosos na análise dos efeitos que os fatores externos têm sobre a medição.

O uso de transdutores convencionais para gerar e receber as ondas forneceu uma melhor relação sinal-ruído, quando comparados com os receptores de membrana de PVDF testados. 
O modelo matricial para a modelagem de transdutores estudado é uma ferramenta poderosa no projeto das células de medição, permitindo um estudo detalhado dos efeitos dos materiais e das geometrias inerentes à célula, assim como o efeito de fatores externos na medição.

\subsection{TRABALHOS PROPOSTOS}

Um trabalho importante a ser desenvolvido é a aplicação de modelos viscoelásticos mais complexos que possibilitem a determinação da viscosidade de líquidos a baixa frequiência a partir da viscosidade obtida a alta freqüência.

Além disso, devem-se desenvolver novas células de medição que permitam a obtenção simultânea dos sinais de referência (refletido no ar) e de medição (refletido no líquido), possibilitando a realização de medições à mesma temperatura. Outro passo importante é a substituição da linha de retardo de água por uma sólida, permitindo um dispositivo mais robusto que pode ser usado fora do banho termostático. 


\section{REFERÊNCIAS BIBLIOGRÁFICAS}

Adamowski, J. C., Buiochi, F., Simon, C., Silva, E. C. N., Sigelmann, R. A., Ultrasonic Measurement of Density of Liquids, J. Acoust. Soc. Am., vol. 97, n. 1, p. 354-361, 1995.

Alig, I., Lellinger, D., Sulimma, J., Tadjbakhsch, S., Ultrasonic shear wave reflection method for measurements of the viscoelastic properties of polymer films, Rev. Sci. Instrum., vol. 63, no. 3, p. 1536-1542, 1997.

Auld, B. A., Acoustic Fields and Waves in Solids, New York, John Wiley \& sons, 1990, Vol 1, second edition.

Balasubramaniam, K., Shah, V. V., Costley, R., D., Boudreaux, G., Singh, J., High temperature ultrasonic sensor for the simultaneous measurement of viscosity and temperature of melts, Review of Scientific Instruments, vol. 70, n. 12, p. 4618-4623, 1999.

Balasubramaniam, K., Sankaran, S., Rajwade, A. V., Ultrasonic NDE rheological measurement tools for industrial process control, 16th WCNDT 2004 - World Conference on NDT, Montreal, Canada, CD-ROM Proceedings, Aug 30 - Sep 3, 2004.

Barlow, A. J., Subramaniam, S., Experimental technique for the determination of the viscoelastic properties of liquids in the frequency range 5-75Mc/s, Brit. J. Appl. Phys., vol. 17, p. 1201-1214, 1966.

Buiochi, F., Adamowski, J. C., Furukawa, C. M., Measurement of Viscosity Using Wave Mode Conversion, IEEE Ultrasonic Symposium, p. 1193-1196, 1998.

Buiochi, F., Adamowski, J. C., Tavares, R. M., Pimienta, M. M., Alvim, L. A. P., Estudo do comportamento da viscosidade de resina por ultra-som, VII ENCIT, Rio de Janeiro, RJ, Brazil, p. 1141-1145, november 1998.

Buiochi, F., Medição de viscosidade de líquidos por ultra-som. 2000, 142p, São Paulo, tese de doutorado, Escola Politécnica da Universidade de São Paulo, 2000. 
Buiochi, F., Higuti, R. T., Furukawa, C. M., Silva, E. C., Adamowski, J. C., Medição de viscosidade de líquidos pelo método de múltiplas reflexões acústicas com conversão de modo, Revista Controle \& Automação, vol. 14, no. 3, julho, p. 330-337, agosto e setembro de 2003.

Cohen-Tenoudji, F., Pardee, W. J., Tittmann, B. R., Ahlberg, L., Elsley, R. K., A Shear Wave Rheology Sensor, IEEE Trans. Ultrasound, Ferroelectric and Frequency Control, vol. UFFC-34, n. 2, p. 263-269, march 1987.

Dealy, J. M., Broadhead, T., Rheometry for process control, Techniques of Rheological Measurements, ed. A. A. Collyer, Chapman \& Hall, New York, p. 285-264, 1993.

Dixon, S., Lanyon, B., Phase change measurement of ultrasonic shear waves on reflection from a curing epoxy system, J phys D: Appl phys, vol. 38, p. 4115-4125, 2005.

Eiras, J. A., Capítulo 2: Materiais Piezelétricos, em Sensores: Tecnologia e Aplicações - Vol 1, livro publicado em CD-ROM, Escola Politécnica da Universidade de São Paulo.

Franco, E. E., Andrade, M. A. B., Higuti, R. T., Adamowski, J. C., Buiochi, F., Acoustic Transmission with Mode Conversion Phenomenon, Proceedings of COBEM 2005, Ouro Preto - MG, Brazil, november 6-11 2005.

Greenwood, M. S., Bamberger, J. A., Measurement of viscosity and shear wave velocity of a liquid or slurry for on-line process control, Ultrasonics, vol. 39, p. 623-630, 2002.

Harrison, G., Barlow, A. J., Dynamic Viscosity Measurement, Method of Experimental Physics, Academic Press, Inc., vol. 19, p. 137-178, 1981.

Higuti, R. T., Caracterização de líquidos por ultra-som, São Paulo, tese de doutorado, Escola Politécnica da Universidade de São Paulo, 2001.

Higuti, R. T., Buiochi F., Adamowski, J. C., Montero Espinosa, F., Ultrasonic density measurement cell design and simulation of non-ideal effects, Ultrasonics, vol. 44, p. 302-309, 2006.

Kino, G. S., Acoustic Waves: Devices, Imaging and Analog Signal Processing, Prentice-Hall Inc, New Jersey, 1987.

Kirk, F., Martinoty, P., Ultrasonic investigation of anisotropic viscosties in a nematic liquid-crystal, Le Journal de Physique, vol. 38, p. 153, 1976.

Kulmyrzaev, A, McClements, D. J., High frequency dynamic shear rheology of honey, Journal of Food Engineering, vol. 45, p. 219-224, 1999. 
Lamberti, N., Giua, P. E., Pappalardo, M., Modello matriciale e suo impiego nell'ottimizzazione della risposta impulsiva del transduttore multielemento, Salerno: Universitá di Salerno, 1987 (Tech. Rep. RS61).

Longin, P. Y., Verdier, C., Piau, M., Dynamic shear rheology of high molecular weight polidimethylsiloxanes: comparison of rheometry and ultrasound, J. Non-Newtonian Fluid Mech., vol. 76, p. 213-232, 1998.

Martinoty, P., Flexible polimers in a nematic medium: ultrasonic measurements, $\mathbf{J}$. Physique, vol. 44, p. L935-L945, dezembro 1983.

Mason, W. P., Measurement of the Viscosity and Shear Elasticity of liquids by means of a Torsionally Vibrating Crystal, Proc. A.S.M.E, may 1947.

Mason, W. P., Baker, W. O, McSkimin, H. J., Heiss, J. H., Measurement of shear elasticity and viscosity of liquids at ultrasonic frequencies, Physical Review, vol. 75, n. 6, p. 936-946, 1949.

Mason, W. P., McSkimin, H. J., Attenuation and Scattering of Hihg Frequency Sound Waves in Metals and Glasses, J. Acoust. Soc. Amer., vol. 19, n. 3, p. 464-473, 1947.

Massey, B. S., Mechanics of Fluids, Princeton N. J., London 1968.

McSkimin, H. J., Andreatch, Jr. P., Measurement of dynamic shear impedance of low viscosity liquids at ultrasonic frequencies, J. Acoust. Soc. Amer., vol. 42, n. 1, p.248252, 1967.

Moore, R. S., McSkimin, H. J., Gieniewski, C., Andreatch, P. Jr., Dynamic Mechanical Properties of Concentrated Polyestyrene Solutions at $40 \mathrm{MHz}$, The Journal of Chemical Physics, vol. 47, no. 1, p. 3-9, july 1967.

Mukai, K., Makino, N., Usui, H., Amari, T., Measurement of rheological properties for Smectic-A liquid crystal by using ultrasound rheometer and rotational viscometer, Progress in Organic Coating, vol. 31, p. 179-184, 1997.

Oliner, A., Microwave network method for guided elastic waves, IEEE Transactions of Microwave Theory and Techniques, vol. MTT-17, no. 11, p. 812-826, 1969.

O'Neil, H. T., Reflection and refraction of plane shear waves in viscoelastic media, Physical Review, vol. 75, n. 6, p. 928-935, 1949.

Race, S. W., Improved product quality through viscosity measurement, Food Technology's Special Reports, ed. J. D. Dziezak, Institute of Food Technologists Chicago, p. 86-88, july 1991. 
Saggin ,R., Coupland, J. N., Oli Viscosity Measurement by Ultrasonic Reflectance, JAOCS, vol. 78, no. 5, p. 509-511, may 2001.

Saggin ,R., Coupland, J. N., Rheology of xanthan/sucrose mixtures at ultrasonic frequencies, Journal of Food Engineering, vol. 65, p. 49-53, 2004.

Shah, V. V., Balasubramaniam, K., Costley, R. D., Singh, J., Measurement of viscosity in liquids using reflection coefficient: phase difference method, Review of progress in Quantitative Nondestructive Evaluation, vol. 15B, p. 2067-2073, 1996.

Shah, V. V., Balasubramaniam, K., Effect of viscosity on ultrasound wave reflection from solid/liquid interface, Ultrasonics, vol. 34, p. 817-824, 1996.

Shah, V. V., Balasubramaniam, K., Measuring Newtonian viscosity from the phase of reflected ultrasonic shear wave, Ultrasonics, vol. 38, p. 921-927, 2000.

Sheen, S., Chien, H., Raptis, A. C., An in-line ultrasonic viscometer, Review of progress in Quantitative Nondestructive Evaluation, vol., 14, p. 1151-1158, 1995.

Sheen, S., Chien, H., Raptis, A. C., Measurement of Shear Impedances of Viscoelastic Fluids, IEEE Ultrasonic Symposium, 1996.

Sherrit, S., Mukherjee, B. K., The Use of Complex Material Constants to Model the Dynamic Response of Piezoelectric Materials, IEEE Ultrasonic Symposium, p. 633640, 1998.

Whorlow, R. W., Rheological Techniques, second edition, Ellis Horwood, 1992.

Wu, J., Determination of velocity and attenuation of shear waves using ultrasonic spectroscopy, J. Acoust. Soc. Amer., vol. 99, n. 5, p. 2871-2875, 1996. 